\title{
Epipathogenesis of caries: Analyses of family structure, fear, and fatalism upon World Health Organization decayed, missing, and filled teeth severity in Appalachia West Virginia and Pennsylvania
}

\author{
R. Constance Wiener \\ West Virginia University
}

Follow this and additional works at: https://researchrepository.wvu.edu/etd

\footnotetext{
Recommended Citation

Wiener, R. Constance, "Epipathogenesis of caries: Analyses of family structure, fear, and fatalism upon World Health Organization decayed, missing, and filled teeth severity in Appalachia West Virginia and Pennsylvania" (2012). Graduate Theses, Dissertations, and Problem Reports. 509.

https://researchrepository.wvu.edu/etd/509

This Dissertation is protected by copyright and/or related rights. It has been brought to you by the The Research Repository @ WVU with permission from the rights-holder(s). You are free to use this Dissertation in any way that is permitted by the copyright and related rights legislation that applies to your use. For other uses you must obtain permission from the rights-holder(s) directly, unless additional rights are indicated by a Creative Commons license in the record and/ or on the work itself. This Dissertation has been accepted for inclusion in WVU Graduate Theses, Dissertations, and Problem Reports collection by an authorized administrator of The Research Repository @ WVU. For more information, please contact researchrepository@mail.wvu.edu.
} 
Epipathogenesis of caries: Analyses of family structure, fear, and fatalism upon World Health Organization decayed, missing, and filled teeth severity in Appalachia West Virginia and Pennsylvania

R. Constance Wiener, DMD, MA

Dissertation submitted to the

School of Public Health at West Virginia University in partial fulfillment of the requirements

for the degree of

Doctor of Philosophy

in

Public Health Sciences

Richard J. Crout, DMD, PhD, Chairperson

Daniel W. McNeil, PhD, Chairperson

Matthew Gurka, PhD

Michael Hendryx, PhD

Anoop Shankar, MD, PhD

Department of Epidemiology

Morgantown, WV

2012

Keywords: fear, fatalism, family, oral health, Appalachia

Copyright 2012 R. Constance Wiener, DMD, MA 


\section{ABSTRACT \\ Epipathogenesis of caries: Analyses of family structure, fear, and fatalism upon World Health Organization decayed, missing, and filled teeth severity in Appalachia West Virginia and Pennsylvania}

\section{R. Constance Wiener, DMD, MA}

Appalachian has many social, economic, and biologic factors impacting dental health over the life-course.

Purpose: This study examined dental caries experience and family structure, dental fear, and fatalism in West Virginia and Pennsylvania.

Method: Using a cross-sectional study design, 2002-2009 Center for Oral Health Research in Appalachia data were analyzed utilizing the World Health Organization definitions for caries experience, dichotomized into low and high. Three groups were studied: 1) children, 11-13 years ( $\mathrm{N}=237)$; 2) adolescents, 14-17 years $(\mathrm{N}=191)$; and 3) adults, 18 years and above $(\mathrm{N}=1125)$. For multivariable model development, generalized estimating equations with exchangeable working structures accounted for family clusters.

Results. For children, family (second biological child vs. first biological child and niece/nephew/step-/grandchild/other vs. first biological child) Fatalism Scale, Dental Fear Survey, and Short Form Fear of Pain Questionnaire failed to reach a significant difference with caries experience. There were 38.0\% reporting fear on the Dental Fear Survey, and $80.2 \%$ on the Short Form Fear of Pain Survey. There were $62.0 \%$ reporting fatalism. There were $44.7 \%$ first biological children, $32.1 \%$ second biological children, and $23.2 \%$ with other family relationships.

Overall, for adolescents, family (single parent vs. both parents, same home; and second biological child vs. first biological child and niece/nephew/step-/grandchild/other vs. first biological child) failed to reach a significant difference with caries experience. However, in gender sub-group analysis, living with a single parent was protective for males, with an adjusted odds ratio (AOR) of 0.08 (95\% Confidence Interval [CI]: 0.01, 0.42; $p=0.0249$ ). The Fatalism Scale failed to reach a significant difference with caries experience in the overall model. For females, there was an AOR of 6.60 (95\% CI: 1.89, 9.64; p = 0.0076). Although the Short Form Fear of Pain Questionnaire failed to reach a significant difference with caries experience in the overall model, for males, the AOR was 12.86 (95\% CI: 1.71, 96.59; $\mathrm{p}=0.0130$ ) and for females, the AOR was $0.08(95 \% \mathrm{CI}: 0.01,0.55 ; \mathrm{p}=0.100)$. There were $36.1 \%$ reporting fear on the Dental Fear Survey; 63.9\% on the Short Form Fear of Pain Survey; and 43.5\% reporting fatalism on the Fatalism Scale. There were 54.6\% first biological children; 20.6\% second biological children, and $24.8 \%$ with other family relationships; $53.5 \%$ lived in single parent homes.

For adults, a high Dental Fear Survey score was associated with a high caries experience. The AOR was 1.76 (95\% CI: 1.29, 2.40; $\mathrm{p}=.0003)$. It remained significant for females (AOR= 2.11[95\% CI: 1.41, 3.14; $\mathrm{p}=0.0003]$ ). For males, those never married, divorced, widowed, separated, or had other living arrangements vs. married/domestic partnering had an AOR of 0.12 (95\% CI: 0.04, 0.36; $\mathrm{p}=.0002$ ).

Conclusion: Caries is a complex disease with many influences. Gender differences exist in age categories in terms of family relationships, fear, and fatalism. Further exploration of these factors is needed to aid in the development of successful interventions to decrease caries severity. 


\section{DEDICATION}

It is my honor and privilege to dedicate this dissertation to my husband, Michael A. Wiener, DMD, MBA, the love of my life, and the most ethical, brilliant, courageous, gracious, fun, kind, Christian humanitarian I could ever know. It has been pure joy to have shared a life with him.

\section{ACKNOWLEDGEMENTS}

I would like to extend my heartfelt thanks to my family and friends for their love and support. My parents, Paul and Josephine Midler always believed in me and encouraged my efforts. My children and their spouses, Michael and Judy Wiener, Regina and Pedro Pla Davila, Diane and Troy Lionberger and my grandchildren, Michael August and Grace Elizabeth, encouraged me along the journey. My siblings and their spouses and children were always helpful and incredible: Cecile and Carl Canales, Christine; Paulette and Brian Thomas, Jerry and Lauren; Paul and Donna Midler, Evan, Chase and Marisa; Katheryn Lepczyk, Kyle, Jenna and Spencer. I would also like to thank my extended family, especially my Aunt Mary Midler.

My gratitude is extended to my fellow graduate students in the $\mathrm{PhD}$ program, in particular my classmates, Omayma Alshaarawy, and Adam Baus.

I am in deep gratitude to the gracious generosity of my co-advisors, Dr. Richard J. Crout, and Dr. Daniel W. McNeil, who shared the role of my dissertation committee chairperson. They provided time, talent, and wisdom in helping me with my research. Their own research is an inspiration and has helped untold thousands of people. My entire committee was very wonderful and I extend my thanks to them: Drs. Richard Crout, Daniel W. McNeil, Matthew Gurka, Michael Hendryx, Anoop Shankar.

I am happy to thank the faculty and staff in the Department of Epidemiology with whom I studied: Dr. Rachel Abraham, Dr. Geri Dino, Dr. Kelley Gurka, Dr. Matthew Gurka, Dr. George Kelley, Dr. Harshbarger, Dr. Michael Hendryx, Dr. Kim Horn, Dr. Karen Innes, Dr. Nancy Lan, Dr. William Reger-Nash, Dr. Anoop Shakar, and Dr. Keith Zullig.

I would also like to thank the COHRA executive committee who permitted this project to proceed: Drs. Daniel W. McNeil, Richard Crout, Mary Marazita, Robert Weyant.

My thanks is also extended to the researchers and those who worked with the COHRA etiology study whom I know: Stella Chapman, and Linda Brown, Debbie Anderson, Kathy Neiswanger as well as to the many whom I do not know. And I also thank the staff in the School of Public Health: Tara Mullins, Leah Atkins, Crystal Toth, Kathy Hess, and Helen Burns.

Thank you all. "God bless Us, Every One!"1 


\section{TABLE OF CONTENTS}

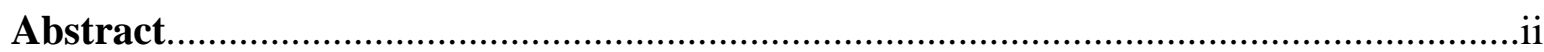

Chapter 1 Overview of the Research

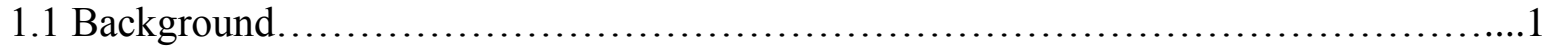

1.2 Current Gap in the Literature......................................................

1.3 Purpose of the Current Research.............................................6

Chapter 2

Cross-sectional analyses of family structure, fear and fatalism upon caries experience in West Virginia and Pennsylvania children, ages 11-13 years

2.1 Introduction.................................................................... 11

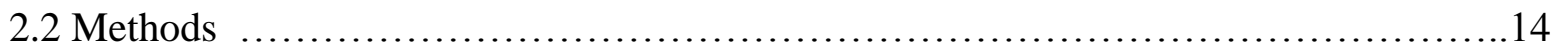

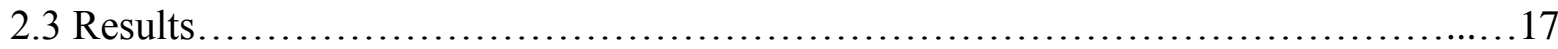

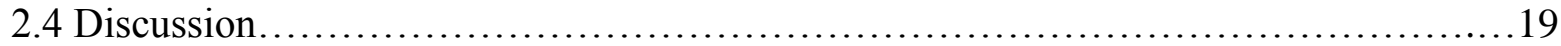

Chapter 3

Cross-sectional analyses of family structure, fear and fatalism upon caries experience in West Virginia and Pennsylvania adolescents, ages 14-17 years

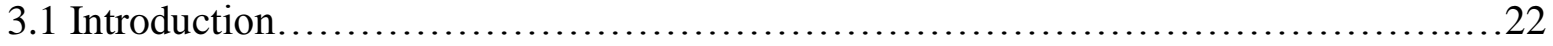

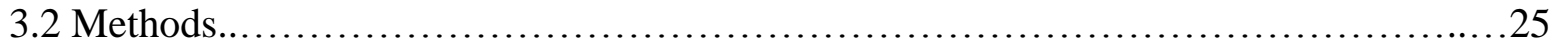

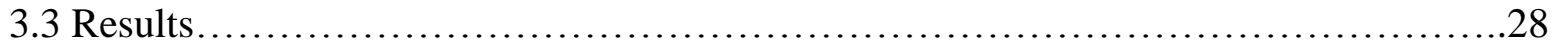

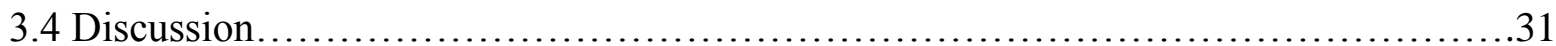

Chapter 4

Cross-sectional analyses of family structure, fear and fatalism upon caries experience in West Virginia and Pennsylvania adults, ages 18 years and above

4.1 Introduction..................................................................... 34

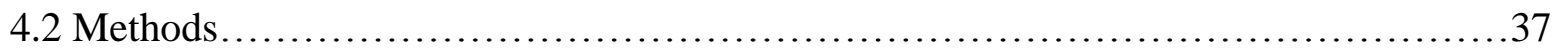

4.3 Results......................................................................... 40

4.4 Discussion...................................................................

Chapter 5 Summary of the Research

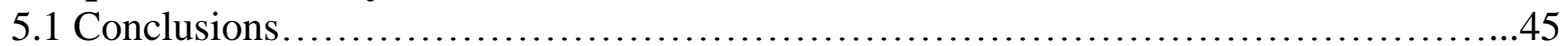

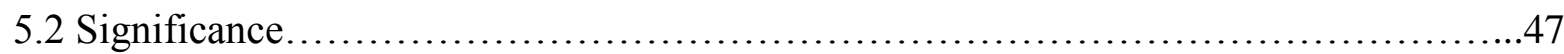

5.3 Strengths and Limitations.................................................. 49

5.4 Future Research..........................................................49

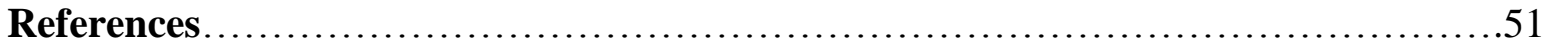

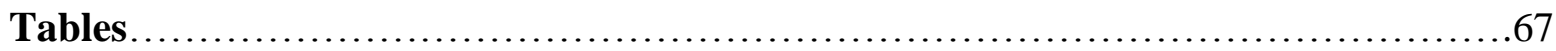




\section{Chapter 1 Overview of the Research}

\subsection{Background}

\section{Public Health and families - definitions and the historical antecedent ecosystem conditions}

The preamble to the U.S. Constitution explains why American societal laws and rules exist: "...to form a more perfect Union, establish Justice, Insure domestic Tranquility, provide for the common defence, promote the general Welfare, and secure the Blessings of Liberty to ourselves and our Posterity." 2 The framers of the Constitution were concerned about public health (general welfare) and family (posterity) from the inception of the United States. Living during the period known as the Enlightenment, a time in which empiricism was valued and authority was questioned, they considered the welfare of citizens as a collective concern, a social contract. Theirs was the first constitution which mandated a census to learn about the citizens as a public collective, ${ }^{3}$ while concurrently establishing individual freedoms and rights to life, liberty, and the pursuit of happiness as expressed in the Declaration of Independence. Just as the U.S. government is a tenuous balance of disparate views of the legislative, executive, and judicial branches, there exists a tenuous balance of disparate views of individual rights/freedoms and general welfare. Additionally, we lack much empirical knowledge about what is needed for the blessings to ourselves and our posterity--the family determinants that would benefit us to secure such blessings.

Though general welfare of the citizens was important enough to be in the Constitution, it was not until 1911 that general welfare as Public Health, per se, was defined by CEA Winslow. He defined Public Health as the "science and art of preventing disease, prolonging life, and promoting health and efficiency through organized community"... ${ }^{4}$ Lay meaning of selfperceived health is defined many ways, depending upon one's social and cultural context. ${ }^{5}$ In 1949, the World Health Organization (WHO) defined health as being in a state of complete physical, mental, and social well-being; not merely the absence of disease or infirmity. ${ }^{6}$

Public health is a community or societal concern. In 1988, the U.S. Institute of Medicine defined a public health mission as ensuring "the conditions in which people can be healthy."7 Public health is a concern for humanitarian/caring reasons, such as decreasing suffering, helping humanity, and providing support. It is a responsibility of society to promote the general welfare, but additionally, there are self-serving, pragmatic, fiduciary benefits of preventing disease or injury, preventing the spread of disease or incidence of injury, or minimizing diseases or injuries, and improving health rather than caring for sick or injured individuals after the contraction of a disease or the incurrence of an injury. As such, the roles of public health professionals can vary from: 1) conducting descriptive research with the provision of surveillance and assessments of community health needs; 2) the identification of health problems, risks assessment and their prioritization; 3) analytic research with the formulation of interventions and policy proposals; 4) the assurance and assessment of access to cost-effective appropriate care; and 5) the provision of 
health promotion and disease prevention education and interventions so that all people can be as healthy as possible. ${ }^{8}$

Public health recommendations which have become laws or policies have been successful in many areas. Epidemiology is the study of "population distributions of disease, disability, death, health, and their determinants and deterrents across time and space. . to create knowledge relevant to improving population health and preventing suffering, including eliminating health inequities." 3 Or, more simply, the study of the distribution and determinants of states of health in populations. ${ }^{9}$ Utilizing the knowledge generated through epidemiological research, public health measures have resulted in widespread use of vaccinations. The vaccinations have led to the eradication of the pervasive disease, small pox, and the control of measles, rubella, tetanus, diphtheria, and haemophilus influenza. ${ }^{7}$ Injury prevention epidemiology has resulted in motor vehicle related safety improvements in the vehicles themselves (front and side airbags, seat belts, safer braking systems, cage safety designs, etc.), safer roads (designs with fewer sharp curves, divided highways, signals of approaching light changes, etc.), and policies (no drinking and driving laws, seat belt laws, car child safety-seat laws and helmet laws, etc.). Workplace safety has improved workers' lives through laws and public health policies. ${ }^{7}$ Through clean water and improved sanitation, some infectious disease prevalences have plummeted or have been limited. ${ }^{7}$ Monitoring blood pressure, blood assays, and new treatments have lowered risks for heart attacks and strokes. ${ }^{7}$ Foods are safer and more healthful. ${ }^{7}$ Tobacco has been recognized as a health hazard and prevention/cessation programs have been implemented. ${ }^{7}$ And water fluoridation has resulted in the reduction of dental caries. ${ }^{7}$

Public health policies in the United States are often contentious, and challenging, as well they should be. They require a knowledgeable citizenry to formulate appropriate courses of action and appropriately budget limited resources. Much of the public health debate focuses upon an individual's needs of freedom to make personal choices without a paternalistic, intrusive government versus societal needs to provide a safe and healthful environment to limit needless pain and suffering. When public health policies and directives become laws, certain personal choices are abrogated. Some examples are: helmet use requirements for motorcyclists and bicyclists; speed limits on roads; limitations on smoking; not serving alcohol to minors; seatbelt use and child safety-seat requirements; child endangerment laws, etc.

Public health interventions have economic costs that cannot be negated and are subject to debate also - subsidized flu vaccination programs, mammography screening programs, blood pressure screenings, clinics, etc. all have costs, and cost-benefit analysis is appropriate.

Research in public health is also beginning to focus upon an ecosocial theory of disease distribution. The theory captures many features determining health. It integrates societal and biophysical determinants of disease distribution and health inequities over the life-course, across generations, in geographical and historic context within and across levels and over different scales of time and space. ${ }^{3}$ The theory emphasizes many factors which result in a person embodying (developing or assimilating) a disease state-including where a person lives (both physical location, and within local, state, regional, national and world-wide government structures and within other structures of rules), when a person lives, family structure and beliefs, his or her age of exposure, length of exposure, access to care (including the education to seek 
care, the financial ability to receive care, and the social status to leave work or other duties to be able to report to care), any discriminatory features, genetic make-up, culture, susceptibility, resistance, etc.

Historically, such complex systems could not be modeled, and large databases with large sample sizes either did not exist or were not easily accessible. Now, data collection, data storage, and data analyses methods exist for large, complex data sets. National surveys, electronic patient records, as well as hospital discharge, and insurance information may be used to make determinations of health outcomes based on multiple layers of stratification. It is now possible to determine health outcomes for different levels of education, age, economic status, race, ethnicity, and place of residence, among other ecosocial and economic factors. Health disparities (differences in health), health inequalities (descriptive, numerical comparisons intended to be value neutral), and health inequities (judgments of social justice and fairness) can be assessed utilizing many, differing statistical models and producing varying results. ${ }^{10}$ The manner in which social inequity in health should be handled will require a continuation of serious debate, as well as the need to identify and develop new theories and methodologies to better understand and explain health inequities. ${ }^{11}$

There are many oral diseases which impact public health and quality of life. Dental caries is a microbially-induced biofilm disease of endogenous bacteria involving the teeth. ${ }^{12}$ It is defined as: "a complex disease caused by an imbalance in physiologic equilibrium between tooth mineral and biofilm fluid." "12 Tooth surfaces develop biofilms of bacterial colonies within hours of being cleaned, and each bacterial species has its own ecological niche, with significant adaptive abilities, within the microenvironment. ${ }^{12}$ The microbiological caries process requires: time; vulnerable or susceptible tooth surfaces and subsurfaces; and a bacteriological biofilm to interact in a manner in which the metabolically active bacteria change the plaque $\mathrm{pH} .{ }^{12}$ When the plaque $\mathrm{pH}$ is less than or equal to 5.5, the tooth will lose mineral. When the plaque $\mathrm{pH}$ is above 5.5, the tooth will remineralize-within limitations. ${ }^{12}$ Demineralization may result in cavitation. The biofilm paradigm of dental caries indicates that caries may occur where a biofilm bacterial community matures and remains in close proximity to a tooth surface over time. ${ }^{12}$ Clinicians diagnose caries from the appearance of active and inactive white spots to the presence or absence of frank cavitation. Treatment decisions are based on the determination of caries activity which may be: rapidly active; slowly active; or arrested.

Caries exists in the context of a complex person with an epigenetic landscape and changing interactions of the person, his or her biological processes, and multiple levels of environment, policies, and opportunities at individual, family household, area, regional, national and global levels for various gradients from caries to good oral health to occur. The disease is complex and has no simple causation pathway and no good predictor model, and as such requires research into determining the contributing factors in a multidisciplinary approach to develop effective caries control methodologies. ${ }^{12}$

Surgeon General, Dr. David Satcher, prepared Oral Health in America: A Report of the Surgeon General, in 2000. He identified oral health as a critical concern. He reiterated that associations exist between oral health and general health, with the hope of eliciting more empirical research into the associations. ${ }^{13}$ Caries and other oral diseases are not innocuous. 
Caries is the most common chronic disease of childhood, with a frequency 5-8 times the next most common chronic disease of childhood, asthma. ${ }^{13}$ Caries has many determinants, and many psychosocial associations. One survey indicated poverty status is a predictor of caries in primary teeth, with the lowest income groups having 2-5 times the prevalence of caries as compared with the high income groups. ${ }^{14}$ Children who have early childhood caries, ECC, have one or more lesions in primary dentition (cavitated or not), or one or more primary teeth missing due to caries, or one or more filled primary teeth at ages 0-71 months. ${ }^{15}$ Nationwide, ECC increased in children, ages 2-5 years, from $24 \%$ during 1988-1994 to $28 \%$ during $1999-2004$. $^{16}$

Also on a national level, children, ages 6-11 years, had a decrease in caries in permanent teeth from $25 \%$ to $22 \%$; and children, ages 6-11 years, had dental sealants placements increase from $22 \%$ to $30 \%$ from $1988-1994$ and $1999-2004$. $^{16}$ The caries burden is not equally shared. A national study showed that $80 \%$ of the caries in children, ages $5-17$ years, was in $25 \%$ of children. $^{17}$

In terms of other oral diseases in the United States, $47.2 \%$ or 64.7 million people aged 30 years or older have mild, moderate, or severe periodontal disease, a disease of the supporting tissues of teeth. ${ }^{18}$ The prevalence among current smokers is $64.2 \%$; for adults 65 years and older, it is $70.1 \%$, and for those living below the federal poverty level it is $65.4 \%{ }^{18}$ Each year 35,000 incident cases of oral and pharyngeal cancer develop and 7,600 people die from oral and pharyngeal cancer. ${ }^{19}$ Oral and pharyngeal cancer is the $17^{\text {th }}$ cause of person-years lost due to cancer, and for those who have oral and pharyngeal cancer, there is only a 50\% 5-year survival rate. $^{19}$

Additionally, tooth loss has been associated with a variety of conditions and diseases. In men with fewer than 24 teeth, the incidence of ischemic stroke has been associated with periodontal disease and tooth loss with a hazard ratio of 1.57 and a $95 \%$ confidence interval (CI) of $1.24,1.98 .^{20}$ Older adults have an increased risk of chronic disease with tooth loss due to dietary change (fewer fruits, vegetables, fiber and vitamins), ${ }^{21}$ even though total calories may be maintained. $^{22}$ An Asian population had an increased risk of total death of $18 \%$ (95\% CI: $9 \%, 18 \%$ ); death from upper gastrointestinal cancer of 35\% (95\% CI: 14\%,59\%); heart disease of $28 \%$ (95\% CI: $17 \%, 40 \%)$; and stroke of $12 \%$ (95\% CI 2\%,23\%) with greater than age-specific median number of teeth lost. ${ }^{23}$ Poorer quality of life has been associated with individuals who have fewer than 24 teeth. ${ }^{24}$ Fortunately, most oral disease is preventable. ${ }^{18}$ Population research has identified many causal factors of poor oral health as well as many preventive factors for good oral health.

In addition to the pain and suffering associated with the pathology of dental diseases, the financial impact of dental care is considerable. In 2009, the cost of dental care was $\$ 102$ billion dollars. ${ }^{18}$ There were 500 million dental visits. ${ }^{18}$ It is difficult to assess the other impacts, such as emergency room visits, loss of time and/or productivity to individuals and family members, social and psychological impacts to the individual and/or family, and quality of life for the individual and/or family. And, as previously stated, the burden is not equally shared. 


\subsection{Current Gap in the Literature}

Although the health of rural residents has improved over the last decade, rural residents fare worse than residents of other areas on many health determinates. ${ }^{14}$ Healthy People 2020, (an initiative with goals for 2020 set by the U.S. Department of Health and Human Services, $\mathrm{HHH}$ ), defines health disparity as "a particular type of health difference that is closely linked with social, economic and/or environmental disadvantage. $" 25$ HHH recognizes that health disparities exist in many contexts. In its Healthy People 2020 program, the HHH identifies health disparities on the basis of race or ethnicity, sex, sexual identity, age, disability, socioeconomic status, and geographical location, with a goal of improving the health of all disparate groups. ${ }^{25}$ Eliminating health disparities and creating health equity, which is the attainment of the highest level of health for all, had been the agency's goal for the past 20 years. ${ }^{25}$ As the determinants of health (variables which influence health) are not fully understood, Healthy People 2020 will work to provide epidemiological research and demographics, including rural/urban geographic data. ${ }^{25}$ Though progress is being made, there is a lack of epidemiological research and literature for rural areas, a situation described as a data disparity. $^{26}$

One rural area of interest is the rural area of Appalachia. Appalachia is a region with several definitions. It is defined by the Appalachian Regional Commission as 420 specific counties along the Appalachian Mountains. ${ }^{27}$ It is alternatively geographically defined as the thirteen states which contain the Appalachian Mountains: New York, Pennsylvania, West Virginia, Maryland, Ohio, Virginia, Maryland, Ohio, Virginia, Kentucky, Tennessee, North Carolina, South Carolina, Alabama, Georgia, and Mississippi. And, Appalachia is culturally defined as the central and southern states on the list. Forty-two percent of Appalachia is rural. ${ }^{27}$ All of the state of West Virginia is in the Appalachian Region, and much of it geographically isolated.

In terms of dental health, the mid-Appalachia region of West Virginia and Pennsylvania are of particular interest. Of the available data, the indicators show that these Appalachian areas have not fared well. For example, the 2010 nationwide edentulous prevalence of individuals over age 65 years is $17.0 \%$. In Pennsylvania the edentulism prevalence was $18.0 \%$; and in West Virginia it was $36.0 \% .^{28}$ West Virginia is the state that has the greatest number of its residents over age 65 years being edentulous. However, in 1999, West Virginia had an edentulism prevalence of $44.3 \%$. The prevalence decreased to $41.3 \%$ in 2002, rose to $42.9 \%$ in 2004 , and declined again to $40.5 \%$ in 2006 and $37.8 \%$ in 2008, so progress is being made. ${ }^{28}$ The prevalence for adults with any permanent teeth extracted in Pennsylvania was $51.5 \%$, and $27.7 \%$ did not visit a dentist/dental clinic within the past year in 2010. Oral health in Appalachia West Virginia and Pennsylvania is a concern. Many determinants may impact the reception of essential dental care: ecosocial determinants, access, cost, lack of providers, fear, limited oral health literacy and understanding, socioeconomic status, and education, among others. ${ }^{29,30}$

Globally, dental caries has been shown to be associated with socioeconomic (SES) inequities and rural geographic status in children in some countries, such as Brazil, ${ }^{31}$ no differences in geography in some countries, such as Saudi Arabia, ${ }^{32}$ and increased caries in urban rather than rural areas in some countries, such as Sweden. ${ }^{33}$ Previous studies in the United States 
found that rural residency influences oral health in that rural dwellers were more likely to be edentulous, less likely to have had a dental visit in the past 12 months, ${ }^{34}$ and more likely to have had dental caries. ${ }^{35}$ Rural U.S. children from homes with lower household incomes were less likely to receive preventive dental care, even when insurance status was considered, and they were also less likely to have dental insurance than urban children. ${ }^{35}$ But, as with the countries of the world, rural areas within the United States are also heterogenous. ${ }^{36}$ For example, one study of a non-metro community, Beaver Dam, Wisconsin, had an edentulous prevalence of $15.3 \%,{ }^{37}$ much lower than nationally, or in rural West Virginia or Pennsylvania.

\subsection{The purpose of the current research}

Patterns and correlates of poor oral health have been postulated for people living in Appalachia. ${ }^{38}$ It is important to understand the determinants of oral health and how they impact the distribution of oral disease, which was the intent of the Center for Oral Health Research in Appalachia (COHRA), Genetic Factors Contributing to Oral Health Disparities in Appalachia study. ${ }^{38}$ COHRA researchers conducted a study of 1818 participants. There were 813 volunteer families in West Virginia and 542 volunteer families in Pennsylvania (280 children, ages 11-13 years; 219 adolescents, ages 14-17 years; and 1319 adults, ages 18 years and above). The study sought to characterize contributions of individual, family, and community factors to oral diseases in children and their relatives. ${ }^{30}$ Since it is unrealistic to include all diverse pathways in a study, ${ }^{3}$ the aim of the current research was to examine oral health in terms of family structure, dental fear and fatalism. Data for the study were collected between 2002 and 2009.

Oral health outcomes were identified using the World Health Organization's (WHO) severity designations based upon the decayed, missing, and filled teeth index (DMFT) in child, adolescent, and adult caries analyses. Family structure, living arrangements, dental fear, and fatalism were variables of interest, and the other social environmental determinants considered were: education level; income; race; and gender. Population health research is concerned with exploring the determinants of social and cultural, genetic, environmental, behavioral, spiritual, and personal qualities. ${ }^{38}$ For example, in overall health, rural residents have poorer lifestyle characteristics (smoking more, exercising less and more obesity) than suburban residents - all of which are related to low income and low education status, and all of which are more resistant to intervention to change in populations with low income and low education status. ${ }^{37,39}$ Identifying specific regional characteristics of people in Appalachia is important to develop successful interventions.

As previously mentioned, Appalachia may be defined at a state level as one of the thirteen states including the Appalachian Mountains. In this series of studies, the definition of Appalachia Pennsylvania and West Virginia are at the state level. This research sought to address the current gap in the literature by assessing the impact of Appalachian culture (as family structure, dental fear, and fatalism) on dental health. The cardinal, long-term goal of this project is to increase understanding of the public health effects of dental health inequities. The impact of the study may be to provide information to help improve dental health throughout the Appalachian region. 
Three studies are presented, each using secondary analysis of quantitative data from the COHRA research data. The theoretical basis for the research is the Krieger ecosocial epidemiological theory of disease distribution which integrates societal and biophysical determinants of disease distribution and health inequities over the life-course, across generations, in geographical and historic context within and across levels and over different scales of time and space. ${ }^{3}$ The holistic approach is needed to understand the effects of ecosocial inequities on health, and the need to consider broad population-level effects. ${ }^{40}$ There is a need to understand how family structures, education, and socioeconomics impact oral health to better develop policies and programs to address oral health needs. Specifically, there is a mounting call to improve oral health in West Virginia and Pennsylvania.

The Precede-Proceed Model of Health Program Planning and Evaluation utilizes surveillance data and epidemiological constructs as the basis to develop intervention plans, then proceeds with evaluating policies, regulations, and resource allocations for health education and advocacy and could be applied to the West Virginia and Pennsylvania situation with information generated in this research. ${ }^{41}$ The initial step, though, begins with obtaining and understanding the surveillance data. ${ }^{39}$

The study in Chapter 2 included cross-sectional analyses of family structure, fear and fatalism upon caries experience in West Virginia and Pennsylvania children, ages 11-13 years.

There is a need to understand the effects of ecosocial determinants of caries, particularly the effects of the role of the family, dental fear, and fatalism in caries development. The research hypotheses were that West Virginia and Pennsylvania children, ages 11-13 years, 1) who were the first biological children were more likely to have lower WHO DMFT severity than a second biological child or niece/nephew/step-/grandchild in the home; 2) who were fearful were more likely to have increased WHO DMFT severity than those reporting little or no fear; and 3) who were fatalistic were more likely to have severe WHO DMFT than those who were not fatalistic.

Children, ages 11-13 years, have many of the teeth of their permanent dentition.

Nevertheless, many primary teeth are still present and many permanent teeth are in the process of erupting during this time period. A child may have had a high dmft (the lower case letters indicate primary teeth's decayed, missing, and filled index), but he or she has the potential to have a DMFT $=0$ in the permanent dentition. The timing of the eruption sequence usually follows the pattern of: first molars and mandibular central incisors erupting at 6-7 years; maxillary central incisors and mandibular lateral incisors erupting at 7-8 years; maxillary laterals erupting at 8-9 years; mandibular canines erupting at 9-10 years; maxillary first premolars erupting at 10-11 years; maxillary second premolars and mandibular first premolars erupting at 10-12 years; maxillary canines and mandibular second premolars erupting at 11-12 years; mandibular second molars erupting at 11-13 years; maxillary second molars erupting at 12-13 years; and third molars erupting at 17-21 years. ${ }^{42}$

Although children have the second opportunity for a DMFT of 0 , dental caries is the most common chronic childhood disease in the United States; it is 5 times more common than asthma and 7 times more common than hay fever. ${ }^{13,43}$ Additionally, dental caries can cause difficulty chewing, which may lead to: loss of weight, and failure to thrive; difficulty speaking, especially 
enunciating "f" and "th"; missed school or difficulty during school; malocclusion (inefficient alignment of teeth or facial bones); caries in permanent teeth; and lowered self-esteem.

The purpose of the study in Chapter 2 was to discern the association of family structure, dental fear and fatalism upon dental status of West Virginia and Pennsylvania Appalachia children, ages 11-13 years. The analysis was planned to include significant relationships of WHO DMFT with the univaribles of gender, race/ethnicity, household income, age, BMI, highest grade attained in the household, and site. Additionally, analysis for confounding of those factors with the variables of interest, was also planned. The final multivariable model would consider the clustering effect of families in a generalized estimating equation of regression. It is significant to have this knowledge in that the appropriate intervention strategies and policies can be developed to address the specific dental needs of the families with children, ages 11-13 years, with high WHO DMFT.

The study in Chapter 3 included cross-sectional analyses of family structure, fear and fatalism upon caries experience in West Virginia and Pennsylvania children, ages 14-17 years.

Adolescence, being a time of change from childhood to maturity, has many biological, psychological, and sociological transformations. Some of the transformations will influence lifestyle practices, attitudes, and beliefs related to health and well-being throughout life. ${ }^{44}$ Adolescence is also a time of self-identity, self-actualization, and responsibility. In terms of caries and adolescence, the Health Belief Model applied to caries describes dependence upon the perception of the severity of potential caries, the susceptibility to caries, the benefits of preventive dental care, and the barriers to dental care for that adolescent as being influential upon his or her oral health related behavior. ${ }^{45}$ Adolescents develop their own oral health beliefs which may or may not be similar to their family's beliefs. They also may be more vocal about expressing their desire for, or opposition to, professional dental care; they may request dental care products or, or purchase them on their own; and they may place more or less emphasis upon their smiles than when they were younger children. Family relationships, in terms of single parents and biological parents as well as birth categories were explored. Also to be examined are dental fear and fatalism in terms of WHO DMFT severity. Adolescent invulnerability (lack of fear, and fatalism) has been previously postulated as contributing to risk taking and lack of weight to future, potentially more severe, consequences of their decision-making. ${ }^{46}$ Despite the maturational changes in the adolescent and parent relationship, it is anticipated that family structure is a significant force in the lives of West Virginia and Pennsylvania adolescents in terms of caries experience.

The research hypotheses were that West Virginia and Pennsylvania children, ages 14-17 years, 1) who were the first biological children were more likely to have lower WHO DMFT severity than a second biological child or niece/nephew/step-/grandchild in the home; 2) who were living with 2 parents in the same home were more likely to have lower WHO DMFT than those living in single parent homes; 3 ) who were fearful were more likely to have increased WHO DMFT severity as compared with those who had little or no fear; and 4) who were fatalistic were more likely to have severe WHO DMFT as compared with those who were not fatalistic. The purpose of the study in Chapter 3 was to discern the association of family 
structure, dental fear and fatalism upon dental status of West Virginia and Pennsylvania adolescents (ages 14-17 years).

The analysis was planned to include significant relationships of WHO DMFT with the univaribles of gender, race/ethnicity, household income, age, BMI, highest grade attained in the household, and site. Additionally, analysis for confounding of those factors with the variables of interest, was also planned. The final multivariable model would consider the clustering effect of families in a generalized estimating equation of regression. It is significant to have this knowledge in that the appropriate intervention strategies and policies can be developed to address the specific dental needs of the families with adolescents with high WHO DMFT caries experience.

Chapter 4 addresses the association of family structure, fear and fatalism upon caries experience in adults, ages 18 years and above, in West Virginia and Pennsylvania.

Family structure for adults has a potential to impact oral health. This study explored the association of marriage with the embodiment of caries and periodontal disease in West Virginia and Pennsylvania adults. An important variable in the analysis was age. The resident population of older adults in the U.S. between 2000 and 2005 was 67.1 million, which increased $13 \%$ over the 5 years. ${ }^{47}$ The older adult segment is the fastest growing segment of the U.S. population, having a growth rate four times the rate of residents under age 55 years. ${ }^{47}$ Their oral health needs are significantly different from those of children, and potentially different from younger adults. As one ages, tissues change, and susceptibilities are altered. Nevertheless, many people maintain healthy periodontal tissue and dentition throughout the life-course.

It is it is important to learn what factors are influencing good oral health and poor oral health. Both periodontal disease and caries are significant factor in tooth loss, which is rampant in West Virginia and Pennsylvania. The research hypotheses were that West Virginia and Pennsylvania adults, ages 18 years and above, 1) who were married or had domestic partners were more likely to have lower WHO DMFT severity than other living arrangements; 2) who were fearful were more likely to have increased WHO DMFT severity than those who had little or no fear; and 3) who were fatalistic were more likely to have severe WHO DMFT than those who were not fatalistic.

The purpose of the study in Chapter 4 was to discern the association of family structure, dental fear and fatalism upon dental status of West Virginia and Pennsylvania adults. Understanding influences on oral health care may inform the appropriate intervention strategies and policies to improve oral health.

The analysis was planned to include significant relationships of WHO DMFT with the univaribles of gender, race/ethnicity, household income, age, BMI, highest grade attained in the household, and site. Additionally, analysis for confounding of those factors with the variables of interest, was also planned. The final multivariable model considered the clustering effect of families in a generalized estimating equation of regression. It is significant to have this knowledge in that the appropriate intervention strategies and policies can be developed to address the specific dental needs of adults with high WHO DMFT severity. 
Chapter 5 is a summary chapter of the research and opportunities for continued research to improve oral health.

Caries etiology is a complex study. And incremental knowledge helps in the understanding of the process. Translating the knowledge into interventions is the ultimate hope for continued research. Acceptable interventions need to be developed with ready access to the interventions, and acceptability of use (across the social, behavioral, biological, economic, and life course realms). ${ }^{48}$ Chapter 5 will look to the past and to the future of caries research in Appalachia. 


\title{
Chapter 2
}

\section{Cross-sectional analyses of family structure, fear and fatalism upon caries experience in West Virginia and Pennsylvania children, ages 11-13 years}

\begin{abstract}
Within the Appalachian Region there are many psychological, social, and economic factors which may impact dental health for children.

Purpose: The purpose of this study was to examine family structure, dental fear, and fatalism upon dental caries experience using the World Health Organization's criteria for very low, low, moderate, and high caries experience upon children, ages 11-13 years, (dichotomized to low and high), living in West Virginia and Pennsylvania.

Method: A cross-sectional study design of data (2002-2009 Genetic Factors Contributing to Oral Health Disparities in Appalachia) collected from the Center for Oral Health Research in Appalachia (COHRA) etiology study were used in this study.

Results: Family relationships (second biological child vs. first biological child and niece/nephew/step-/grandchild/other vs. first biological child), Fatalism Scale, Dental Fear Survey, and Short Form Fear of Pain Questionnaire failed to reach a significant difference with caries experience. There were 38.0\% reporting fear on the Dental Fear Survey, and $80.2 \%$ on the Short Form Fear of Pain Survey. There were 62.0\% reporting fatalism on the Fatalism Scale. There were $44.7 \%$ first biological children, $32.1 \%$ second biological children, and $23.2 \%$ with other family relationships.

Conclusion: Children in Appalachia West Virginia and Pennsylvania, ages 11-13 years, were resilient when it came to birth categories, fatalism, and fear as they relate to dental health. Future research is needed to explore the levels of fear and fatalism reported.
\end{abstract}

\subsection{Introduction}

Dental caries is the most common chronic childhood disease in the United States; it is 5 times more common than asthma and 7 times more common than hay fever. ${ }^{1}$ In children, dental caries often results in pain and serious infections. Additionally, dental caries can cause difficulty chewing, which may lead to: loss of weight, and failure to thrive $(80 \%$ or less of ideal weight ${ }^{2}$ ); difficulty speaking; missed school or difficulty during school; malocclusion (inefficient alignment of teeth or facial bones); caries in permanent teeth; and lowered self-esteem. ${ }^{1}$ There are 5.61 deaths per year attributed to dental caries. ${ }^{3}$ When treatment requires a hospital operating room setting, in addition to the risks of general anesthesia, the financial burden may range from $\$ 4000-\$ 7000$. Of the unmet health needs of children in America, child dental care is the most prevalent. ${ }^{4}$

Caries does not occur in a vacuum in children. Etiologic bacteria are involved in a complex biofilm community which, when mature and undisturbed, demineralizes tooth surfaces 
by lowering plaque $\mathrm{pH}$ to below 5.5. Additionally, primary teeth have thinner enamel than permanent teeth, and newly erupted permanent teeth may not be fully mineralized, increasing susceptibility. Genetic and epigenetic factors have modifying effects on teeth, supporting structures, and oral conditions. A recent study indicated that the primary dentition carious phenotypes were highly heritable, with $54-70 \%$ of caries score variation accounted by genes. ${ }^{5}$ And, specific genes (tuftelin, ${ }^{6}$ ameloblastin, ${ }^{7}$ and the taste genes, TAS2R38, TAS1R $2^{8}$ ) have been identified as being associated with the caries process.

Equally important, children are dependent upon the lifestyle choices of parents/guardians/household adults, and caregivers for sugar presentation, frequency of snacks and sugary beverages, overall nutrition, fluoride use, presentation for professional care, and providing, instructing, or supervising oral hygiene behaviors (quality and frequency of brushing and flossing), among other factors. ${ }^{9}$

The choices of parents/guardians/household adults or caregivers may be influenced by family structure, culture, socioeconomics, education, community, geography, marketing, laws, dental fear, fatalism, and policies. For example, the presentation of sugary beverages and cariogenic foods to a child may have a variety of such motivations - to provide a reward; to use as motivation or coercion; to provide as a result of family or community tradition or custom; to use by being influenced by advertisement; to use as compensation for a particular circumstance; to feel good by providing something that makes the child happy; etc. The primary factors need to be explored as, over the past decade, in all highly industrialized countries, there has been an increase in the amounts of cariogenic foods and beverages consumed by children. ${ }^{9,10}$ As a result, caries is a complex, multifactorial disease.

Family structure has been associated with health outcomes. With overall health, a study of the 2003 National Survey of Children's Health indicated that children in step, single-mother, or grandparent-only circumstances had poorer health than children living with both biological parents. ${ }^{11}$ A study in Greece of 187 children, age 12 years, indicated that children living in single parent/other type family structure were 3 times as likely to have had oral pain within the previous month and 2.8 times as likely to have brushed their teeth fewer than two times a day compared with nuclear families. ${ }^{12}$ In a study in Germany, children living in family structures, other than nuclear families consumed higher amounts of sugary foods and drinks, particularly juices, cookies, and chocolate. ${ }^{13}$

Low family socioeconomic status (SES) has been associated with health inequity. ${ }^{14}$ However, globally, the impact and trends of SES upon caries for early adolescents are unclear. In countries with high family income, middle family income, and low family income, children age 12 years had a mean decayed missing filled permanent teeth (DMFT) score of: 2.1; 3.3; and 1.9 , respectively. ${ }^{10}$ And although caries was associated with SES in a study set in Brazil, oral health, in terms of dental erosion, was not. ${ }^{15}$

Inadequate access, utilization and/or provision of dental health care are risk factors for poor oral health for some children. Remote areas or residential areas with occupational isolation or segregation may exist in areas without good supermarkets, limiting the availability of fruits 
and vegetables and increasing the possibility of purchasing inexpensive, unhealthful foods and beverages which may contribute to poor oral health. ${ }^{15,16}$

Certain geographic areas are associated with increased caries. A South Carolina study of rural dental health care indicated that in adjusted analyses, rural children were more likely to not have preventive dental care, fluoride varnishes, and dental homes when compared with urban children. ${ }^{17}$ Similar results occurred for rural children in some studies globally, ${ }^{18,19}$ but were not found to exist in other studies. ${ }^{20,21}$ In general, in the United States, there is a shortage of dentists in underserved areas, ${ }^{22}$ often as a result of the economic situation of a dentist encumbered with heavy debt load to repay, as well as no, or inadequate employment for the spouse/significant other in the underserved area. One geographic area of interest is the region of Appalachia. Appalachia is composed of 205,000 square miles of territory including sections of New York, Pennsylvania, West Virginia, Maryland, Ohio, Virginia, Maryland, Ohio, Virginia, Kentucky, Tennessee, North Carolina, South Carolina, Alabama, Georgia, and Mississippi. ${ }^{23}$ Forty-two percent of the region is rural. ${ }^{23}$ All of the state of West Virginia is in the Appalachian Region.

Appalachia, particularly mid-Appalachia (West Virginia and Pennsylvania), lacks epidemiological data concerning the oral health of pre-teen children. Much of West Virginia's pediatric research has cited the clinical West Virginia Office of Maternal and Child Health 1999 report on 5 poorer and 5 more affluent counties which indicated $65.6 \%$ of West Virginia children had caries by age 8 , (as compared with the national caries prevalence at the time of $22 \%$ ). ${ }^{24}$ Much of the other oral health research on children in Appalachia has been more general, and involved self/parent report of children in a wide range of ages. In one study of West Virginia parents of children aged 6 months-15 years (mean 5.4 years), 75\% of parents reported their child brushed or had their teeth brushed twice daily. ${ }^{25}$ In another study of children 3-18.7 years, 85\% of parents reported their child brushed or had their teeth brushed daily, $80 \%$ reported yearly dental visits and $2 / 3$ reported dental health was important. ${ }^{26}$

Reports to the National Oral Health Surveillance System for caries experience indicated that $42.1 \%$ of $3^{\text {rd }}$ graders in West Virginia had caries experience and $17.1 \%$ had untreated dental caries in 2010-2011. The National Oral Health Surveillance System also reported that, for Pennsylvania $3^{\text {rd }}$ graders, $52.6 \%$ had caries experience and $27.3 \%$ had untreated dental caries from 1998 to $2000 .^{27}$

The 2007 National Survey of Children Health (NSCH) data for children, ages 1-17 years, indicated that fewer West Virginia and Pennsylvania parents and guardians described the condition of their child's teeth as fair or poor than nationally. That data indicated $5.1 \%(95 \% \mathrm{CI}$ $3.8,6.5)$ of parents in West Virginia rated their child's teeth as fair or poor; for Pennsylvania, it was $7.4 \%$ (95\% CI 5.2, 9.6); and nationally 8.4\% (CI 7.8, 9.0) of parents rated their child's teeth as fair or poor. (Table 1) Also, more West Virginia and Pennsylvania parents and guardians described the condition of their child's teeth as excellent than nationally (75.4\% (95\% CI 72.9, 77.9) for West Virginia; 74.6\% (95\% CI 71.2, 78.0) for Pennsylvania and 70.7 (95\% CI 69.9, 71.5 nationally). ${ }^{28}$

These results indicate inconsistencies in the parent/guardian appraisal of oral health. There is also a lack of clinical oral health data concerning children, ages 11-13 years, who reside 
in Appalachia, in general and there is a lack of oral health data concerning children, ages 11-13 years, who reside in West Virginia and Pennsylvania, in particular.

The research hypotheses for this study were that West Virginia and Pennsylvania children, ages 11-13 years, 1) who were the first biological children were more likely to have low World Health Organization decayed, missing, and filled teeth (WHO DMFT) dichotomized categories than a second biological child or niece/nephew/step-/grandchild in the home; 2) who were fearful were more likely to have high WHO DMFT dichotomized categories than those who reported no or little fear; and 3) who were fatalistic were more likely to have high WHO DMFT dichotomized categories than those who were not fatalistic. As previously mentioned, Appalachia may be defined at a state level as one of the thirteen states including the Appalachian Mountains. In this study, the definition of Appalachia Pennsylvania and West Virginia are at the state level.

\subsection{Methods}

This study analyzed data from the Center for Oral Health Research in Appalachia etiology survey for years 2002-2009 entitled Genetic Factors Contributing to Oral Health Disparities in Appalachia (COHRA). WVU IRB approval was obtained (\#H-24094). The COHRA study was supported in part by grants from the National Institute of Dental and Craniofacial Research (R01-DE014899, R01-DE014899-03S1, R01-DE014899-04S1, and U01DE018903). Additional support was provided by the University of Pittsburgh, School of Dental Medicine, the West Virginia University School of Dentistry, and the West Virginia University Eberly College of Arts and Sciences. The COHRA protocols are presented elsewhere. ${ }^{29}$ Briefly, the study was a non-intervention, longitudinal project to determine risk factors for the disproportionate oral disease in Appalachia. The COHRA study had a unique dimension in that it was family based. This study is a cross-sectional study of the 11-13 year subgroup of the COHRA study population.

\section{Study Population}

Eligibility requirements for the COHRA study were that an individual (the primary informant or index person) had to have at least one biological child who was between the ages of 1 and 18 years. Additionally, all members of a household were eligible to be included into the study without regard to biological or legal relationship. The exclusion criteria for the study were neurological impairments, psychosis, severe physical or intellectual handicap and situations in which either the parent/child of the biological pair had impaired ability to clot or resist infection. There were 1,355 families recruited. From West Virginia, there were 813 families. From Pennsylvania, there were 542 families. There was a total of 1818 COHRA participants. The COHRA survey evaluated oral health, nutrition, and lifestyle behaviors in the families. The survey was conducted with questionnaires, clinical examinations, and laboratory tests of participating non-institutionalized, civilian adults and children.

The participants were recruited through newspaper, television, and radio advertisements as well as posted fliers, presentations, and distributed brochures. Each family member who participated in the study in Pennsylvania received \$25. Each family member who participated in the study in West Virginia received a \$25 gift card to a local merchant, and if everyone in the 
family participated, the family received an additional $\$ 100$ gift card. Written child assent, where appropriate, parental consent for the children and consent from the adult participants were obtained. This study is a cross-sectional study of the pre-teen subgroup of the original COHRA study population $(\mathrm{N}=280)$. This study's participants were the children, ages 11-13 years, with complete DMFT (7 had missing DMFT) and family relationship data and responses to at least $20 \%$ of the fear and fatalism items (36 had more than $20 \%$ of fear and fatalism items missing). The sample size was 237.

\section{Outcome of interest-caries experience}

COHRA clinical evaluations were conducted by calibrated dentists and dental hygienists. Inter-rater Cohen's Kappa was .83. ${ }^{29}$ World Health Organization (WHO) decayed, missing, and filled teeth (DMFT) dichotomized categories formed the outcome variable of interest. DMFT was a derived variable from the analysis of the buccal, lingual, mesial, distal, and occlusal tooth surfaces on all teeth present in the mouth (except wisdom teeth). It summarizes the presence of current caries, previous evidence of caries (restorations), and missing teeth due to caries (as reported by the participant). DMFT experience levels vary by age. A modified World Health Organization/University of Pittsburgh definition of caries experience, based on DMFT, was used. The tooth surfaces were evaluated after drying with air or gauze, as necessary. Artificial light and a dental mirror were used. Radiography and tactile examination were not employed (except where a dental explorer was used, as necessary, for suspected interproximal decay).

For children ages 11 and 12 years, the categories were: very low caries experience $(\mathrm{DMFT}=0,1)$; low caries experience $(\mathrm{DMFT}=2)$; moderate caries experience $(\mathrm{DMFT}=3,4)$ and high caries experience $(\mathrm{DMFT} \geq 5) .{ }^{30,31}$ For children 13 years, the categories were very low caries experience $(\mathrm{DMFT}=0-2)$; low caries experience $(\mathrm{DMFT}=3-5)$; moderate caries experience $(\mathrm{DMFT}=6-8)$ and high caries experience $(\mathrm{DMFT} \geq 9){ }^{30,31}$ In the generalized estimating equations, these categories were dichotomized to low (DMFT $=0-2)$ and high (DMFT $\geq 3$ ) for those 11 and 12 years. For those children age 13, low was DMFT = 0-5 and high was $\mathrm{DMFT} \geq 6$.

\section{Variables of interest}

The variables of interest to be evaluated for the children, ages 11-13 years, were 1) family structure, 2) dental fear, and 3) fatalism. For family structure, data were used that described the relationship of the child to the index person as being a first biological child, second biological child, and other (third biological child, fourth biological child, fifth biological child, seventh biological child, first step child, second step child, grandchild or niece/nephew). The data were provided by the adult index person.

Dental fear was measured with 2 self-reported questionnaires: the 20-question Dental Fear Survey; ${ }^{32-36}$ and the 9-question Short Form Fear of Pain Questionnaire ${ }^{37-42}$ For all inventories the potential Likert-type responses were: "Not afraid at all" (scored as "1" for each question with this response), "A little afraid," (scored as " 2 " for each question with this response), "Somewhat afraid,"(scored as "3" for each question with this response), "Pretty much afraid,"(scored as "4" for each question with this response) "Very afraid,"(scored as " 5 " for each question with this response) and "I don't know, because this never happened to me,"(scored as missing). A missing value was replaced with the variable's median value (there were 275 
imputations of 6873 potential values - 4.00\%--involving 51 participants). The Dental Fear Survey and Short Form Fear of Pain Questionnaire were presented either on paper or on a computer screen.

The Dental Fear Survey and Short Form Fear of Pain Questionnaire responses were added. The possible scores for the Dental Fear Survey were from 20 (no fear) to 100 (very much afraid) and for the Short Form Fear of Pain Questionnaire from 9 (no fear) to 45 (very much afraid). The Dental Fear Survey was dichotomized based upon previous research, ${ }^{40}$ as was the Short Form Fear of Pain Questionnaire.

The Dental Fear Survey is a scale with internal consistency, test-retest reliability, and usefulness both clinically and non-clinically. ${ }^{32-36}$ The Dental Fear Survey also is widely used in epidemiological research due to its validity. ${ }^{35-36}$ The Short Form Fear of Pain Questionnaire also has internal consistency, good test-retest reliability and usefulness both clinically and nonclinically. ${ }^{37}$

Fatalism was measured with a 12-item fatalism questionnaire (Fatalism Scale) $)^{41,42}$ presented either on paper or on a computer screen. It was based upon the Multiphasic Assessment of Cultural Constructs Short Form in which items 1-8 of the Fatalism Scale were the fatalism subscale of the cultural assessment. ${ }^{43}$ Items 9-12 of the Fatalism Scale are dentally related questions. The Fatalism Scale Likert-style responses were: "Definitely false," "Somewhat false," "Somewhat true," and "Definitely true." A missing value was replaced with the variable's mean value (there were 28 imputations of 2844 potential values - $0.98 \%$-involving 24 people). The fatalism response to question 7 was reverse scored. The items were added with potential scores with values of 12-48 and dichotomized into low and high. The Fatalism scale ${ }^{41}$ has been used previously in dental research. Dental specific items were significantly correlated with the Dental Neglect Scale $(\beta=-.385){ }^{42}$

\section{Other variables}

Gender, race/ethnicity, household income, highest educational level in the household, age, site (location of home), and body mass index were considered for the multivariable model. Due to the high, non-Hispanic White population in Appalachia, race/ethnicity was dichotomized into White and minority. Normal weight was a body mass index (BMI) less than 25, overweight was a BMI of 25 to 30 , and obese was a BMI of 30 and above. ${ }^{2}$ Highest education level in the household was a derived variable based upon relating index person with people living in the household. Education was dichotomized into less than high school and high school graduation vs. more than high school Household income was a derived variable based upon relating index person with people living in the household and was categorized as less than $\$ 15,000 ; \$ 15,000$ $\$ 49.999$; and \$50,000 and greater. Site was categorized as Pennsylvania (PA) or West Virginia (WV). Age was categorized as 11 years, 12 years, and 13 years.

\section{Statistical Analysis}

Statistical analysis was conducted using SAS (version 9.2, Cary, NC). Statistical significance was defined as $\mathrm{p}<0.05$. The descriptive characteristics of the study population were presented as frequencies and analyses comparing the characteristics and WHO DMFT 
levels. The calculations used Cochran-Mantel-Haenzel mean score test, Mantel-Haenzel Chi Square test with standardized midrank scores, or Mantel-Haenzel Exact Chi Square test.

Generalized estimating equation (GEE) regressions were planned to evaluate the associations between WHO DMFT and family structure, fatalism, fear. GEE was needed due to the families (clusters) under study which created units which were not independent. The exchangeable working correlation was used. For the overall full multivariable model, the potential confounding of race/ethnicity (minority vs. White), income (\$15,000 to $\$ 50,000$ and over $\$ 50,000$ vs. less than $\$ 15,000$ ), family education attainment (high school/less than high school vs. more than high school); age (13 years and 12 years vs. 11 years); body mass index (obese and overweight vs. normal weight); site (WV vs. PA), and gender (female vs. male), against the family, fatalism, or fear variables was considered.

\subsection{Results}

Table 2 presents the descriptive characteristics of the study's population. There was equal representation in gender (50.4\% females), and age (32.1\% aged 11 years, $31.7 \% 12$ years, and $36.3 \%$ aged 13 years). The majority of participants were white $(82.2 \%)$, lived in West Virginia (65.0\%), had families whose highest education was more than high school (56.6\%) and were either the first biological child $(47.7 \%)$ or the second biological child $(32.1 \%)$. There were $22.5 \%$ having an income of less than $\$ 10,000$. The mean body mass index was normal, $22.55( \pm$ standard deviation of 6.39). There were $38.0 \%$ reporting fear on the Dental Fear Survey. The majority of the children had some/pretty much/very much fear $(80.2 \%)$ on the Short Form Fear of Pain Questionnaire. Fatalism was reported by $38.0 \%$ on the Fatalism Scale. There were $33.8 \%$ who had a DMFT of 0. The mean DMFT was 2.17 (standard deviation 2.58).

Table 3 provides the relationships between/among WHO very low, low, moderate and high DMFT severity categories and gender, race/ethnicity, site, family income, highest education in the family, family relationship to the index person, age, and body mass index. There was one significant association, which was the association of increasing family educational level with a decreasing WHO DMFT severity level $(\mathrm{p}=0.0468)$. The family relationship with the index person was not significantly associated with WHO DMFT severity.

Table 4 relates the associations of the 12 fatalism questions and WHO DMFT severity categories. The Fatalism Scale (12 items) was not significantly related with WHO DMFT severity $(\mathrm{p}=.4592)$. Table 5 displays the Dental Fear Survey and the Short Form Fear of Pain Questionnaire results. There were no significant associations for WHO DMFT severity and fear $(\mathrm{p}=.3100$ for Dental Fear Survey, and $\mathrm{p}=.4491$ for Short Form Fear of Pain Questionnaire).

\section{Unadjusted odds ratios, single variables, overall}

Table 6 indicates the generalized estimating equation for the unadjusted single factors. There were 237 children, ages 11-13 years. The variables of interest failed to reach a significant association with the WHO DMFT dichotomized high vs. low categories. Second biological child vs. first biological child had an unadjusted odds ratio (OR) of 1.03 (95\% CI: 0.53, 1.97; $\mathrm{p}=$ .9405). For relationships in the household which were nieces, nephews, grandchildren or step children vs. first biological child, the OR was 1.61 (95\% CI: 0.78, 3.32; $\mathrm{p}=.1941)$. For Fatalism 
Scale, the OR was 1.23 (95\% CI: 0.66, 2.66; $\mathrm{p}=.6140)$. For the Dental Fear Survey, the OR was 0.74 (95\% CI: 0.39, 1.39; $\mathrm{p}=0.3501)$. For the Short Form Fear of Pain Questionnaire, the OR was 0.78 (95\% CI: $0.37,1.62 ; \mathrm{p}=0.5036)$.

\section{Overall multivariable models}

Included in the initial, full model were: gender (female vs. male), race/ethnicity (minority vs. White), birth categories (second biological child, other vs. first biological child); Fatalism Scale (high vs. low); Dental Fear Survey (high vs. low); Short Form Fear of Pain Questionnaire (high vs. low); income (less than $\$ 15,000, \$ 15,000$ to $\$ 50,000$ vs. $\$ 50,000$ and above), and family education attainment (high school/less than high school vs. more than high school); BMI (obese, overweight vs. normal weight); site (WV vs. PA), and age (13 years; 12 years vs. 11 years).

The model used an exchangeable working correlation structure (0.210276812). It had 187 clusters, and a Quasilikelihood under the Independence Model Criterion fit of 216.1571. The variables of interest failed to reach a significant association with the WHO DMFT dichotomized high vs. low categories. Second biological child vs. first biological child had an adjusted odds ratio (AOR) of 0.99 (95\% CI: 0.42, 2.32; $\mathrm{p}=.9726)$. For relationships in the household which were nieces, nephews, grandchildren or step children vs. first biological child, the AOR was 2.10 (95\% CI: 1.26, 5.54; $\mathrm{p}=.1359)$. For Fatalism Scale, the AOR was $1.01(95 \%$ CI: 0.48, 2.14; $\mathrm{p}=.9760)$. For the Dental Fear Survey, the AOR was 0.74 (95\% CI: 0.32, 1.71; $\mathrm{p}$ $=0.4867$ ). For the Short Form Fear of Pain Questionnaire, the AOR was 0.96 (95\% CI: 0.34, $2.77 ; \mathrm{p}=0.9468)$.

A reduced model was developed for more precision for the outcome variables of interest. The model adjusted for gender (female vs. male), age (13 years; 12 years vs. 11 years), and family education (less than/high school vs. more than high school) based upon the strong confounding of these variables and previous epidemiological research. ${ }^{14,44}$ The variables of interest failed to reach a significant association with the WHO DMFT dichotomized high vs. low categories. Second biological child vs. first biological child had an AOR of 1.22 (95\% CI: 0.56, 2.64; $\mathrm{p}=.6223$ ). For relationships in the household which were nieces, nephews, grandchildren or step children vs. first biological child, the AOR was 2.08 (95\% CI: 0.91, 4.74; p = .0817). For Fatalism Scale, the AOR was 1.05 (95\% CI: 0.53, 2.06; $\mathrm{p}=.8939)$. For the Dental Fear Survey, the AOR was 0.78 (95\% CI: 0.38, 1.61; $\mathrm{p}=.5036)$. For the Short Form Fear of Pain Questionnaire, the AOR was 1.20 (95\% CI: 0.46, 3.14; $\mathrm{p}=.7104)$.

\section{Male multivariable models}

Table 7 presents the multivariable models from the generalized estimating equation by gender, male. There were 117 males, ages 11-13 years. For the family, fear, and fatalism factors in the full model, there were no significant associations with WHO DMFT dichotomized high vs. low categories at the $\mathrm{p}=0.05$ level. The model included the same factors as the overall model. The model used an exchangeable working correlation structure (-0.56780622). It had 105 clusters, and a Quasilikelihood under the Independence Model Criterion fit of 102.5924. Second biological child vs. first biological child had an AOR of 0.37 (95\% CI: 0.06, 2.25; p = .2811). For relationships in the household which were nieces, nephews, grandchildren or step children vs. first biological child, the AOR was 2.72 (95\% CI: 0.62, 11.0; $\mathrm{p}=.1857)$. For Fatalism Scale, 
the AOR was 3.42 (95\% CI: 1.41, 16.44; $\mathrm{p}=.1250)$. For the Dental Fear Survey, the AOR was 1.08 (95\% CI: 0.29, 4.10; $\mathrm{p}=.9075)$. For the Short Form Fear of Pain Questionnaire, the OR was 0.58 (95\% CI: $0.12,15.73 ; \mathrm{p}=.4977)$.

The reduced model had the outcome variables of interest and adjusted for age (13 years; 12 years vs. 11 years), and family education (less than/high school vs. more than high school). The variables of interest failed to reach a significant association with the WHO DMFT dichotomized high vs. low categories. Second biological child vs. first biological child had an AOR of 0.62 (95\% CI: 0.20, 1.91; $\mathrm{p}=.4099)$. For relationships in the household which were nieces, nephews, grandchildren or step children vs. first biological child, the AOR was 2.88 (95\% CI: 0.90, 9.22; $\mathrm{p}=.0817)$. For Fatalism Scale, the AOR was 1.29 (95\% CI: 0.46, 3.63; $\mathrm{p}=$ $.6343)$. For the Dental Fear Survey, the AOR was 1.65 (95\% CI: 0.60, 4.60; $p=.3397)$. For the Short Form Fear of Pain Questionnaire, the AOR was 0.80 (95\% CI: 0.25, 2.62; $\mathrm{p}=.7188$ ).

\section{Female multivariable models}

Table 8 presents the multivariable models from the generalized estimating equation by gender, female. There were 119 females, ages 11-13 years. For the family, fear, and fatalism factors in the full model, there were no significant associations with WHO DMFT dichotomized high vs. low categories at the $\mathrm{p}=0.05$ level. The model included the same factors as the overall model. The model used an exchangeable working correlation structure (-0.127767533). It had 103 clusters, and a Quasilikelihood under the Independence Model Criterion fit of 119.6609. The variables of interest failed to reach a significant association with the WHO DMFT dichotomized high vs. low categories. Second biological child vs. first biological child had an AOR of 1.57 (95\% CI: 0.46, 5.29; $\mathrm{p}=.4685)$. For relationships in the household which were nieces, nephews, grandchildren or step children vs. first biological child, the AOR was 1.67 (95\% CI: 0.92, 6.29; $\mathrm{p}=.4516)$. For Fatalism Scale, the AOR was 0.74 (95\% CI: 0.25, 2.25; $\mathrm{p}=$ $.6009)$. For the Dental Fear Survey, the AOR was 0.54 (95\% CI: 0.16, 1.85; $\mathrm{p}=0.3289)$. For the Short Form Fear of Pain Questionnaire, the OR was 1.14 (95\% CI: 0.22, 5.76; $\mathrm{p}=0.8764$ ).

The reduced model had the outcome variables of interest and adjusted for age (13 years; 12 years vs. 11 years), and family education (less than/high school vs. more than high school). The variables of interest failed to reach a significant association with the WHO DMFT dichotomized high vs. low categories. Second biological child vs. first biological child had an AOR of 1.16 (95\% CI: 0.32, 4.19; $\mathrm{p}=.8235)$. For relationships in the household which were nieces, nephews, grandchildren or step children vs. first biological child, the AOR was 2.22(95\% CI: 0.76, 6.48; $\mathrm{p}=.1458)$. For Fatalism Scale, the AOR was 0.75 (95\% CI: 0.26, 2.14; $\mathrm{p}=$ $.5869)$. For the Dental Fear Survey, the AOR was 0.49 (95\% CI: 0.16, 1.51; $\mathrm{p}=.2138)$. For the Short Form Fear of Pain Questionnaire, the AOR was 2.14 (95\% CI: 0.42, 10.79; $\mathrm{p}=.3577$ ).

\subsection{Discussion}

The principle findings of this study of West Virginia and Pennsylvania children, ages 1113 years, were the failure to determine significant associations of WHO DMFT dichotomized categories and family relationships, fatalism, and fear. Similarly in male and female sub-group analyses, family relationships, fatalism, and fear were not significantly associated with WHO DMFT dichotomized categories. 
The Appalachian culture has often been described as more fatalistic than the remainder of the nation, a condition also described as a pejorative, cultural stereotype. ${ }^{45}$ There is little objective information describing variability in fatalism on a population level or among subgroups, ${ }^{40}$ particularly pre-teenage children. The overall fatalism to the Fatalism Scale by the children in this study was $62.0 \%$.

A literature search of PubMed for "dental fatalism children, adolescents, pre-teens" resulted in 1 article relating specifically to attitudes of dental fatalism, and it pertained to the development of 4 measures for beliefs/cognitions for mothers of children (ages 1-5 years). ${ }^{46}$ Beliefs such as fatalism, have been reported as barriers to preventive medical (specifically, cancer) services in West Virginian adults, ${ }^{47}$ and similar denial and fatalism may also function as barriers to preventive medical (cholesterol screenings) for pre-teens. ${ }^{48} \mathrm{~A}$ focus group study of cholesterol screening included 50 West Virginia adults and 92 West Virginia children aged 11 years. It found prevention was less of a concern to people who embraced the performance model of health in which health is equated to productivity, and fulfilling one's usual role. There were fatalistic themes for adults, with comments such as "I'm going to live the way I want to live. I'm going to die happy doing what I want to do. I think that's how a lot of people feel-you know, I'm going to die anyway. I might as well enjoy what I'm doing."48 Another parent remarked, "They just feel it's [heart disease] going to get them no matter what. It doesn't make any difference. That's pretty much the whole attitude. ${ }^{, 48}$ However, fatalism was not determined as a theme for the children aged 11 years in the focus group. Nevertheless, the results of the current study indicate fatalism exists in the area of oral health. Supportive of this outcome is a study of adolescents in Quebec which indicated similar attitudes in children, 13-14 years, who considered tooth loss to be a normal consequence of age. ${ }^{49}$

Limited global studies support the intergenerational differences in attitude between parents and children toward oral health. In a study of children, ages 11-14 years, in Canada, the children reported that their oral health impacted their quality of life to a greater extent than their mothers reported. ${ }^{50}$ In Brazil, a study of children, 11-14 years, indicated significant, although minor, differences between the children and mothers regarding oral health quality of life. ${ }^{51}$ As children mature, attitudes and appraisals differ, particularly on the domains that reflect social and emotional points of view, ${ }^{52}$ which would include self-assessment of quality of oral health, and dental fatalism.

There was a lack of literature citing family structure and dental health for pre-teens, particularly in the Appalachian culture. However, a study based in Germany, indicated that nonnuclear families were less likely to access dental care, and consumed $17 \mathrm{~g}$ of additional sugar than nuclear families, although the level of tooth care was the same in the non-nuclear as the nuclear families in terms of tooth brushing, and use of fluoridated toothpaste. ${ }^{13}$ While, a study in Brazil indicated that family structure, and number of siblings, were significantly related with poor oral health related quality of life, when placed into a multivariable model, these factors were no longer significant. ${ }^{53}$ Similarly, the results of this study were not significant for birth order (second biological child vs. first biological child, or for other family relationships such as a family including nieces, nephews, step-children, or grandchildren as compared with first biological child) and WHO DMFT severity. Previous research is limited and complex. This 
study adds an evaluation of birth order factors as they relate to dental health in Appalachia West Virginia and Pennsylvania to the literature.

In terms of fear, $38.0 \%$ reported some, pretty much or very much fear on the Dental Fear Survey and $80.2 \%$ on the Short Form Fear of Pain Questionnaire. A previous study testing the genetic dental fear component with twins (monogygotic and dizygotic) with probandwise concordance indicated that aspects of dental fear were heritable. ${ }^{54}$ Current research is in progress to determine the genetic and epigenetic components in the COHRA study and it is expected that fear may be explained, in part, with genetic antecedents. A study conducted in Spain with children, ages 7-14 years, indicated females were more likely to have a higher dental fear associated with a higher DMFT index, whereas male's dental fear did not influence DMFT index. ${ }^{55}$ Fear, in multivariable analysis of a study of children, ages 8-14 years, was not significant for oral health (using the Revised Children's Manifest Anxiety Scale for fear). ${ }^{56}$ A study in Sweden of children (full and pre-term) ages 12 to 14 years, indicated a low prevalence of fear (as measured with the Children's Fear Survey Schedule-Dental Subscale) as well as a satisfaction with dental care. ${ }^{57}$ Though the results were not significant, females with higher fear of pain had high caries experience, while males with higher fear of pain had low caries experience. The results reverse with the Dental Fear Survey in which the females with higher fear have a low caries experience and the males with higher fear have a higher caries experience. These results indicate the complexity in attitudinal and cultural factors occurring with this age group.

This study was cross-sectional in design, so causality is not possible to determine and inferential or temporal evaluations of WHO DMFT high vs. low categories and dental fear, fatalism and family relationships are also not possible. However, this was a moderately sized, recent study of children, ages 11-13 years, offering an insight to the changing nature of the Appalachian culture with this emerging age cohort. Nevertheless, a larger sample would have provided more precision in the analysis. Future research should attempt to develop and evaluate an intervention to reduce dental fatalism directed to these children and provide education concerning the value of preventive care.

\section{Acknowledgement}

This project was funded by National Institute of Dental and Craniofacial Research grants (R01DE014899, R01-DE014899-03S1, R01-DE014899-04S1, and U01-DE018903). Additional support was provided by the University of Pittsburgh, School of Dental Medicine; the West Virginia University School of Dentistry; and the West Virginia University Eberly College of Arts and Sciences. Gratitude is extended to the researchers and staff at the University of Pittsburgh and West Virginia University. 


\title{
Chapter 3 \\ Cross-sectional analyses of family structure, fear and fatalism upon caries experience in West Virginia and Pennsylvania adolescents, ages 14-17 years
}

\begin{abstract}
Globally, all adolescents are faced with many physical, fiscal, psychological, and social beliefs and challenges, many of which may impact their dental health.

Purpose: The purpose of this study was to explore the relationships of family structure, dental fear, and fatalism upon dental caries experience with the criteria established by the World Health Organization for very low, low, moderate, and high caries experience (dichotomized to high and low) upon West Virginia and Pennsylvania adolescents, ages 14-17 years.

Method: The 2002-2009 Genetic Factors Contributing to Oral Health Disparities in Appalachia data collected from the Center for Oral Health Research in Appalachia (COHRA) were used in a cross-sectional study.

Results: Overall, family (single parent vs.both parents, same home; and second biological child vs. first biological child and niece/nephew/step-/grandchild/other vs. first biological child) failed to reach a significant difference with caries experience. However, in gender sub-group analysis, living with a single parent was protective for males, with an adjusted odds ratio (AOR) of 0.08 (95\% Confidence Interval [CI]: 0.01, 0.42; $\mathrm{p}=0.0249$ ). The Fatalism Scale failed to reach a significant difference with caries experience in the overall model. For females, there was an AOR of 6.60 (95\% CI: 1.89, 9.64; p = 0.0076). Although the Short Form Fear of Pain Questionnaire failed to reach a significant difference with caries experience in the overall model, for males, the AOR was $12.86(95 \% \mathrm{CI}: 1.71,96.59 ; \mathrm{p}=0.0130)$ and for females, the AOR was 0.08 (95\% CI: 0.01, 0.55; $\mathrm{p}=0.100)$. There were 36.1\% reporting fear on the Dental Fear Survey; $63.9 \%$ on the Short Form Fear of Pain Survey; and $43.5 \%$ reporting fatalism on the Fatalism Scale. There were $54.6 \%$ first biological children; $20.6 \%$ second biological children, and $24.8 \%$ with other family relationships; $53.5 \%$ lived in single parent homes.

Conclusion: For adolescents, ages 14-17 years, in Appalachia West Virginia and Pennsylvania, caries experience was impacted in females by fatalism and in males by fear of pain therefore developing interventions addressing these issues may be helpful in lowering the caries burden.
\end{abstract}

\subsection{Introduction}

Adolescence is a time of significant change for children. There are shifts in biology, psychology, and cognition, as well as separation from parents/guardians/adult-household members. Some of the separation, rebellion, and harmful risk-taking behaviors are issues of concern. ${ }^{1-6}$ Smoking, illicit drug use, unprotected sexual activity, poor dietary choices, and poor driving skills are a few of the many public health challenges regarding adolescents. For example, there were $12.2 \%$ of high school seniors who smoked cigarettes within the last 30 days and $43 \%$ of students in ninth through twelfth grade who drank alcohol. ${ }^{2}$

Young children are dependent upon the parent/guardian/adult-household members for dietary choices, presentation for needed healthcare, and healthcare activities. Parental knowledge (education) greatly impacts young children. However, adolescents have less such 
dependence upon parent/guardian/adult-household members and begin to make their own dietary, and healthcare-seeking behavior lifestyle choices.

For example, there has been a significant increase in overweight and obesity in adolescents. From 1986-1998 the number of overweight and obese adolescents increased by $50 \%$ for non-Hispanic whites and $120 \%$ for non-Hispanic blacks and Hispanics. ${ }^{7}$ Soda use in adolescents is a major concern and risk factor for both adolescent caries and overweight. A relationship of $0.24 \mathrm{~kg} /$ meter-squared increase in body mass index and each additional sugarsweetened drink was shown in one study (after adjusting for anthropometrics, demographics, diet, and lifestyle covariates). ${ }^{8}$ Nevertheless, in a national study of 15,112 adolescents, lower parental education impacted obesity with a population attributable risk of $39 \%$. ${ }^{9}$ The population attributable risk of low household income and obesity was also strong (32\%). ${ }^{9}$ These findings indicate strong parental influences may still operate in parent/adolescent relationships. Family is reported to be an adolescent's primary influence with effects remaining into adulthood, ${ }^{2,10}$ even in the midst of the change in family structure. The average family in the United States in 1960 was the nuclear family with two biological parents. Since then, there has been an increasing trend in the number of single-parent families, from $13 \%$ in 1960 , to $25 \%$ in 2000 , and $27 \%$ in 2010 as well as a trend of fewer children in a family. ${ }^{11}$ The average household size was 2.62 in 2000 and was 2.59 in $2010 .^{11}$

In terms of oral hygiene and family structure, adolescents, living with a single mother or neither parent, self-reported less good oral health, and more gingival bleeding than those living with both parents, independent of other family characteristics. ${ }^{12}$ When family socioeconomic status (SES) is considered with oral health, the impact was reported to be substantial. A longitudinal study of the effect of family SES on adolescents, indicated that adolescents who had always lived in a poor family household had the worst profile of dental caries, but were not statistically different from either adolescents who moved from childhood poverty to non-poverty, or those who moved from non-poverty in childhood to poverty in adolescence. ${ }^{13}$ This study indicated low family SES in any one stage of childhood compromised dental health, a result in support of the models of risk accumulation. ${ }^{13}$ In the United States, over one-fifth of children under age 18 years lives in poverty $(23.2 \%$ in rural areas and $21.0 \%$ in urban areas across all categories of age, sex, and family status). ${ }^{14}$ In terms of SES and caries severity, there are few U. S. studies. A study in Pennsylvania indicated that the SES gradient was associated with caries and caries severity for adolescents in $9^{\text {th }}$ through $12^{\text {th }}$ grade, although caries was not accounted for by SES associated differences in the putative mediators of brushing, flossing, sealants, fluoride, or recent dental visits. ${ }^{15}$ A national study, indicated that adolescents (ages 15-18 years) with low SES and at least 1 filled or decayed tooth had similar in caries as compared with adolescents of higher SES who had at least 1 filled or decayed tooth. ${ }^{16}$

The prevalence of adolescent caries has decreased between the first and third National Health and Nutrition Examination Survey in the United States. ${ }^{17,18}$ However, in sub-group analysis, Mexican-Americans and those living between $100 \%$ and $199 \%$ of the Federal Poverty Level (FPL) did not have significant declines. ${ }^{18}$ There were $59 \%$ of U.S. adolescents, ages 12 to 19 years, with caries in permanent teeth. ${ }^{18}$ There were $23 \%$ of adolescents, ages 12 to 19 years, with untreated decay. ${ }^{18}$ The adolescents had a mean of .54 decayed or missing permanent surfaces. ${ }^{18}$ The hope is that progress is being made with caries reduction overall on a national 
level with adolescents. However family, regional, and cultural environments vary within the United States and globally. They may impact dental caries in many and complex manners. For example, rural/urban status for adolescents in Uganda, indicated a higher decayed missing and filled teeth (DMFT) index for rural adolescents. ${ }^{19}$ The rural/urban pattern was reversed in adolescents in India. ${ }^{20}$ Within the United States, overall, rural areas are described as areas where residents have the least likelihood of having had a dental visit in the previous year, ${ }^{21,22}$ however some specific rural areas have reasonably good access to dental care. ${ }^{23}$

One rural area of interest in adolescent oral health is Appalachia. The Appalachian region contains 205,000 square miles enveloping sections of the states of New York, Pennsylvania, West Virginia, Maryland, Ohio, Virginia, Maryland, Ohio, Virginia, Kentucky, Tennessee, North Carolina, South Carolina, Alabama, Georgia, and Mississippi. ${ }^{22}$ The region is $42 \%$ rural. $^{24}$ West Virginia is the sole state entirely enclosed the Appalachian Region, and much of it geographically isolated. The state has two main interstate corridors, north/south (I-79) and east/west (I-68); but many residents in the mountainous areas are homebound or do not travel far from home due to lack of transportation, or to weather-related road closures. Isolation has been a factor in the significant health and social challenges faced by the people in Appalachia, but the people in West Virginia have resilience, self-determination, spirituality, and connections to family and community, which may be health-protective. ${ }^{25}$

In Pennsylvania, the Appalachian counties are diverse. Many of the counties are rural, while there are also large urban areas within Appalachia Pennsylvania, including Pittsburgh and Erie. The north/south I-79 corridor continues into Pennsylvania Appalachia and two east/west interstates (I-80 and I-70/76) transverse the region. In 2012, Pennsylvania Appalachia identified 124 distressed areas. ${ }^{26}$ The Appalachian Mountain chain continues into Pennsylvania, and the same factors which isolate the people in West Virginia occur in Pennsylvania, however the rapidly rising mountain peaks and steep declines that make many roads impassable in West Virginia winters are less abrupt in Pennsylvania.

The transition from childhood to adulthood in Appalachia is thought to have has many cultural challenges in addition to the geographical challenges. This study's purpose was to determine the association of adolescent family structure, dental fear, and fatalism with oral health in terms of caries experience. There is a lack of oral health data concerning adolescents who reside in Appalachia. This study explored attitudes and family structure which may impact the delivery of dental care.

The research hypotheses were that West Virginia and Pennsylvania children, ages 14-17 years, 1) who were the first biological children were more likely to have low WHO DMFT severity dichotomized categories than a second biological child or niece/nephew/step-/grandchild in the home; 2) who were living with 2 parents in the same home were more likely to have low WHO DMFT dichotomized categories than those living in single parent homes; 3) who were fearful are more likely to have high WHO DMFT dichotomized categories as compared with those who had little or no fear; and 4) who were fatalistic were more likely to have high WHO DMFT dichotomized categories as compared with those who were not fatalistic. 
Although Appalachia may be defined as including specific counties, it may also be defined at the state level as including the thirteen states enveloping the Appalachian Mountains. In this study, the definition of Appalachia Pennsylvania and West Virginia are at the state level.

\subsection{Methods}

This study was approved by the West Virginia University Institutional Review Board (\#H-24094). It was funded by grants from the National Institute of Dental and Craniofacial Research (R01-DE014899, R01-DE014899-03S1, R01-DE014899-04S1, and U01-DE018903), the University of Pittsburgh, School of Dental Medicine, the West Virginia University School of Dentistry, and the West Virginia University Eberly College of Arts and Sciences.

The 2002-2009 Genetic Factors Contributing to Oral Health Disparities in Appalachia study (COHRA) data collected for the Center for Oral Health Research in Appalachia were used for this study. The COHRA protocols are presented elsewhere. ${ }^{27}$ The COHRA study was designed as a longitudinal study of the natural course of caries in which no interventions were developed. The study's intent was to examine risk factors for the disproportionate oral disease in Appalachia from a family-based perspective.

This study is a cross-sectional study of the adolescents in the COHRA study population.

\section{Study Population}

Eligibility requirements for the original COHRA study included that a participant (the index person) must have at least one biological child who was between the ages of 1 and 18 years who was also in the study. The participant's household members were all eligible to participate in the study. Biological, matrimonial, or other legal status was not required beyond the index person and biological child requirements. Candidates were excluded if he or she had neurological impairments, psychosis, severe physical or intellectual handicap and situations in which either the parent/child of the biological pair had impaired ability to clot or resist infection.

The families were recruited from West Virginia $(\mathrm{N}=813)$ and Pennsylvania $(\mathrm{N}=542)$, resulting in 1,355 families and 1818 participants. The evaluation of the family members included an oral clinical evaluation, questionnaires, and laboratory tests. Recruitment occurred through the media (newspapers, television, and radio) and through fliers and brochures distributed throughout the survey area. Pennsylvania study participants received $\$ 25$. West Virginia study participants received a $\$ 25$ gift card. If all family members participated in West Virginia, the family received an additional $\$ 100$ gift card. Children provided written assent, where appropriate, and parents provided consent for the children. Adult participants provided consent.

The adolescent subset was extracted from the original COHRA data of 219 adolescents aged 14-17 years. This study included adolescents with complete DMFT data (6 had missing data), family relationships to the index person, and responses to at least $20 \%$ of the fear and fatalism questions (22 were missing more than 20\%). There were 191 adolescents in this study. 


\section{Outcome of interest-caries experience}

Calibrated examiners (dentists and dental hygienists) completed the clinical evaluations. Inter-rater Cohen's Kappa was 0.83. ${ }^{27}$ The variable of interest was caries experience, the World Health Organization DMFT scale dichotomized into high and low categories. DMFT was derived from evaluation of the occlusal, mesial, distal, buccal and lingual tooth surfaces on all teeth present, except third molars under artificial lighting without radiographic support or the use of a dental explorer. Explorer use was permitted to determine suspicious, potential interproximal caries. The teeth were evaluated after drying with air or gauze. DMFT is a summation of the number of teeth with active caries, history of caries (restorations), and missing teeth due to caries, as reported by the participant. Since DMFT is confounded by age, definitions of very low, low, moderate and high caries categories vary by age. A World Health Organization and University of Pittsburgh definition of caries experience, based on DMFT for adolescents, was used.

For adolescents ages 14-17 years, the categories were: very low caries experience $(\mathrm{DMFT}=0-2)$; low caries experience $(\mathrm{DMFT}=3-5)$; moderate caries experience (DMFT $=6-8)$ and high caries experience (DMFT $\geq 9) .{ }^{28,29}$ For the generalized estimating equations, these were dichotomized into low $(\mathrm{DMFT}=0-5)$ and high $(\mathrm{DMFT} \geq 6)$.

\section{Variables of interest}

Family structure, dental fear, and fatalism were the variables of interest. For family structure, the question posed to the adolescents and used for the study was, "If you live with at least 1 parent, do you live with both of your parents in the same house?" Responses were yes/no/don't know. Additionally family relationship to the index person was reported by the index person as being a first biological child, second biological child, third biological child, fourth biological child, fifth biological child, seventh biological child, first step child, second step child, grandchild or niece/nephew.

Two dental fear instruments were used by the adolescents: the 20-question Dental Fear Survey; ${ }^{30-34}$ and the 9 -question Short Form Fear of Pain Questionnaire ${ }^{35-40}$ The participants responded to the items with the Likert-type options of: "Not afraid at all" (scored as "1" for each question with this response), "A little afraid," (scored as "2" for each question with this response), "Somewhat afraid,"(scored as "3" for each question with this response), "Pretty much afraid,"(scored as "4" for each question with this response) "Very afraid,"(scored as " 5 " for each question with this response) and "I don't know, because this never happened to me,"(scored as missing). Missing values had the median imputed (there were 58 imputations of 6351 possible responses- $.91 \%$--involving 18 participants). Both instruments were self-reports answered on paper or on a computer screen.

The values of the Dental Fear Survey and Short Form Fear of Pain Questionnaire responses were summed. Potential scores were from 20 (no fear) to 100 (very much afraid) for the Dental Fear Survey and from 9 (no fear) to 45 (very much afraid) for the Short Form Fear of Pain Questionnaire. Based upon previous research, the Dental Fear Survey was dichotomized to high and low. ${ }^{40}$ Similarly, the Short Form Fear of Pain Questionnaire was dichotomized to high and low. 
The Dental Fear Survey has internal consistency, test-retest reliability, and is used both in a clinic setting and for non-clinical research. ${ }^{30-34}$ The Dental Fear Survey is commonly utilized in dental research due to its validity. ${ }^{33,34}$ The Short Form Fear of Pain Questionnaire has internal consistency, good test-retest reliability and is used in clinical settings, and research settings. ${ }^{37}$

The fatalism instrument was a 12-item fatalism questionnaire (Fatalism Scale) ${ }^{39,40}$ that the adolescents responded to either on paper or on a computer screen. The basis for the instrument was the Multiphasic Assessment of Cultural Constructs Short Form in which items 1-8 of the Fatalism Scale were the fatalism subscale of the original cultural assessment. ${ }^{41}$ Items 9-12 of the Fatalism Scale are oral health related items. The possible responses were: "Definitely false," "Somewhat false," "Somewhat true," and "Definitely true." The missing values were replaced with the variable's mean value (there were 8 imputations of 2,292 possible responses- $0.31 \%$-involving 6 participants). Question 7 was reverse coded. The items were added. The possible scores were 12-48. The range was dichotomized into high and low.

Previous dental research has utilized the Fatalism scale ${ }^{39}$ and the specific dental items. The specific dental items were significantly correlated with the Dental Neglect Scale $(\beta=-.385) .{ }^{40}$

\section{Other variables}

Gender, race/ethnicity, household income, highest educational level in the household, age, site (location of home), and body mass index were considered for use in the multivariable model. Due to the high, non-Hispanic White population in Appalachia, race/ethnicity was dichotomized into White and minority. Normal weight was a body mass index (BMI) less than 25 , overweight was a BMI of 25 to 30 , and obese was a BMI of 30 and above. ${ }^{2}$ Highest education level in the household was a derived variable based upon relating index person with people living in the household. Education was dichotomized into less than high school and high school graduation vs. more than high school Household income was a derived variable based upon relating index person with people living in the household and was categorized as less than $\$ 15,000 ; \$ 15,000-\$ 49.999$; and $\$ 50,000$ and greater. Site was categorized as Pennsylvania (PA) or West Virginia (WV). Age was categorized as 14 years, 15 years, 16 years and 17 years.

\section{Statistical Analysis}

Study population characteristics, univariate analysis, and modeling were accomplished with SAS (version 9.2, Cary, NC). A priori statistical significance was defined as $p<0.05$. The study participants were described with frequencies and analyses comparing the variable of interest with the WHO DMFT severity levels. The comparisons were performed using CochranMantel-Haenzel mean score test, Mantel-Haenzel Chi Square test with standardized midrank scores, or Mantel-Haenzel Exact Chi Square test.

Due to non-independent units (family clusters), generalized estimating equation (GEE) regressions were used for family structure, fatalism, fear and DMFT categories. The exchangeable working correlation was utilized.

For the overall multivariable model, and gender-stratified multivariable models, potential confounding of race/ethnicity (minority vs. White), income $(\$ 15,000$ to $\$ 50,000$ and over 
$\$ 50,000$ vs. less than $\$ 15,000$ ), family education attainment (high school/less than high school vs. more than high school); age (17 years, 16 years, and 15 years vs. 14 years); body mass index (obese and overweight vs. normal weight); site (WV vs. PA), and, for the overall model, gender (female vs. male), against the family, fatalism, or fear variables was considered. A priori, a 10\% or greater change in the family, fatalism, or fear variables by the potential confounder was the criterion for inclusion in the model selection process with a backward selection at $\mathrm{p}=0.15$.

\subsection{Results}

Table 1 includes the descriptive characteristics of the study's participants. The participants were equally distributed in gender ( $46.6 \%$ males). The mean age was 15.2 years (standard deviation, 1.06) with 14 years, and 15 years representing 31.9\%, and $32.5 \%$, respectively. The participants were: primarily White (83.8\%); lived in West Virginia (61.3\%); and had a family income between $\$ 35,000$ and $\$ 49,999(17.8 \%)$. The highest educational degree in $40.5 \%$ was a high school degree; $53.5 \%$ lived in a single parent home; and $54.6 \%$ were the first biological child of the index person. There were $63.0 \%$ who were normal weight, $23.1 \%$ overweight and $13.9 \%$ who were obese. There were 47 participants $(24.6 \%)$ who had a DMFT of 0. The mean DMFT index was 3.82 (standard deviation, 3.8). A majority (63.9\%) reported little or no fear on the Dental Fear Survey. A majority reported some/pretty much/very much on the Short Form Fear of Pain Questionnaire (82.2\%). There were 43.5\% reporting high fatalism on the Fatalism Scale. In evaluating the association of family relationship with WHO DMFT severity, (with Cochran-Mantel-Haenzel mean score test) there were no significant associations.

Table 2 indicates the associations of the WHO DMFT severity categories of very low, low, moderate, and high caries experience with gender, race/ethnicity, site, family income, highest education in the family, family relationships to the index person, age, and body mass index. Three associations were significant: 1$)$ race/ethnicity $(\mathrm{p}=0.0117)$; site $(\mathrm{p}=0.0008)$; and age $(\mathrm{p}=<.0001)$.

Table 3 relates the associations of the 12 fatalism questions and WHO DMFT severity categories. The Fatalism Scale was not significantly related with WHO DMFT severity ( $\mathrm{p}=$ .8898).

Table 4 displays the Dental Fear Survey and the Short Form Fear of Pain Questionnaire results. There were no significant associations of either of the fear scales and WHO DMFT severity $(\mathrm{p}=.9035$, and .0581 , respectively).

\section{Unadjusted odds ratios, single variables, overall}

Table 5 indicates the generalized estimating equation for the unadjusted single factors. There were 191children, ages 14-17 years. The variables of interest failed to reach a significant association with the WHO DMFT dichotomized high vs. low categories. For single parent vs. both parents, same home, the unadjusted odds ratio (OR) was 0.94 (95\% CI: $0.47,1.87 ; \mathrm{p}=$ .8567). Second biological child vs. first biological child had an OR of 1.52 (95\% CI: 0.69, 3.34; $\mathrm{p}=.2958$ ). For relationships in the household which were nieces, nephews, grandchildren or step children vs. first biological child, the OR was 1.26 (95\% CI: 0.56, 2.86; $\mathrm{p}=.5796)$. For Fatalism Scale, the OR was 1.03 (95\% CI: 0.55, 1.92; $\mathrm{p}=.9214)$. For the Dental Fear Survey, 
the OR was 0.95 (95\% CI: 0.49, 1.83; $\mathrm{p}=0.8812)$. For the Short Form Fear of Pain Questionnaire, the OR was 0.99 (95\% CI: 0.45, 2.19; $\mathrm{p}=0.9794)$.

\section{Overall multivariable models}

Included in the initial, full model were: gender (female vs. male), race/ethnicity (minority vs. White), birth categories (second biological child, other vs. first biological child); single parent vs. both parents, same home; Fatalism Scale (high vs. low); Dental Fear Survey (high vs. low); Short Form Fear of Pain Questionnaire (high vs. low); income (less than $\$ 15,000, \$ 15,000$ to $\$ 50,000$ vs. $\$ 50,000$ and above), and family education attainment (high school/less than high school vs. more than high school); BMI (obese, overweight vs. normal weight); site (WV vs. PA), and age (17 years; 16 years; 15 years vs. 14 years).

The model used an exchangeable working correlation structure (-0.020239451). It had 151 clusters, and a Quasilikelihood under the Independence Model Criterion fit of 72.3658. The variables of interest failed to reach a significant association with the WHO DMFT dichotomized high vs. low categories. Single parent vs. both parents, same home had an adjusted odds ratio (AOR) of $0.59(95 \%$ CI: $0.19,1.86 ; \mathrm{p}=.3655)$. Second biological child vs. first biological child had an AOR of 2.27 (95\% CI: 0.76, 6.77; $\mathrm{p}=.1404)$. For relationships in the household which were nieces, nephews, grandchildren or step children vs. first biological child, the AOR was 1.93 (95\% CI: 0.62, 6.02; $\mathrm{p}=.2552)$. For Fatalism Scale, the AOR was 1.47 (95\% CI: 0.57, 3.74; $\mathrm{p}=$ $.4238)$. For the Dental Fear Survey, the AOR was 1.37 (95\% CI: 0.55, 3.42; $\mathrm{p}=.5042)$. For the Short Form Fear of Pain Questionnaire, the AOR was 0.51 (95\% CI: 0.17, 1.54; $\mathrm{p}=.2342$ ).

A reduced model was developed for more precision for the outcome variables of interest. The model adjusted for gender (female vs. male), age (17 years; 16 years; 15 years vs. 14 years), and family education (less than/high school vs. more than high school) based upon the strong confounding of these variables and previous epidemiological research. ${ }^{42,43}$ The variables of interest failed to reach a significant association with the WHO DMFT dichotomized high vs. low categories. Single parent vs. both parents, same home had an AOR of 0.88 (95\% CI: 0.41, 1.88; $\mathrm{p}=.7376$. For relationships in the household which were nieces, nephews, grandchildren or step children vs. first biological child, the AOR was 1.13 (95\% CI: 0.44, 2.85; $\mathrm{p}=.8013)$. Second biological child vs. first biological child had an AOR of 1.60 (95\% CI: 0.67, 3.84; = .2929). For Fatalism Scale, the AOR was $1.32(95 \%$ CI: 0.67, 2.74; $\mathrm{p}=.4563)$. For the Dental Fear Survey, the AOR was 1.10 (95\% CI: 0.51, 2.35; $\mathrm{p}=.8160)$. For the Short Form Fear of Pain Questionnaire, the AOR was 0.67 (95\% CI: 0.25, 1.77; $\mathrm{p}=.4219)$.

\section{Male multivariable models}

Table 6 presents the multivariable full model from the generalized estimating equation by gender, male. There were 89 males, ages 14-17 years. For the family, fear, and fatalism factors, there were 2 significant associations with WHO DMFT dichotomized high vs. low categories at the $\mathrm{p}=0.05$ level. The model included the same factors as the overall model (excluding gender). The model used an exchangeable working correlation structure (-0.020239451). It had 76 clusters, and a Quasilikelihood under the Independence Model Criterion fit of 72.3658. Single parent vs. both parents, same home had an AOR of 0.08 (95\% CI: 0.01, 0.42; $\mathrm{p}=.0249$ ). Second biological child vs. first biological child had an AOR of 14.08 (95\% CI: 0.70, 282.74; $\mathrm{p}=.0841$ ). For relationships in the household which were nieces, nephews, grandchildren or step children 
vs. first biological child, the AOR was 3.34 (95\% CI: 0.06, 183.43; $\mathrm{p}=.5549)$. For Fatalism Scale, the AOR was 0.19 (95\% CI: 0.02, 1.91; $\mathrm{p}=.1576)$. For the Dental Fear Survey, the AOR was 1.25 (95\% CI: 0.10, 15.46; $\mathrm{p}=.8602)$. For the Short Form Fear of Pain Questionnaire, the OR was 12.86 (95\% CI: $1.71,96.59 ; \mathrm{p}=0.0130)$.

A reduced model was developed for more precision for the outcome variables of interest. The model adjusted for age (17 years; 16 years; 15 years vs. 14 years), and family education (less than/high school vs. more than high school). The variables of interest failed to reach a significant association with the WHO DMFT dichotomized high vs. low categories. For single parent vs. both parents, same home the AOR was $1.08(95 \%$ CI: 0.22, 3.56; $p=.9046)$. For relationships in the household which were nieces, nephews, grandchildren or step children vs. first biological child, the AOR was $1.72(95 \% \mathrm{CI}: 0.38,7.70 ; \mathrm{p}=.4805)$. For second biological child vs. first biological child, the AOR was 2.64 (95\% CI: 0.81, 8.59; $\mathrm{p}=.1080)$. For Fatalism Scale, the AOR was 1.06 (95\% CI: 0.37, 3.05; $\mathrm{p}=.9135)$. For the Dental Fear Survey, the AOR was 0.80 (95\% CI: 0.26, 2.50; $\mathrm{p}=.7033)$. For the Short Form Fear of Pain Questionnaire, the AOR was 2.65 (95\% CI: 0.56, 12.49; $\mathrm{p}=.2180)$.

\section{Female multivariable model}

Table 7 presents the full multivariable model from the generalized estimating equation by gender, female. There were 102 females, ages 14-17 years. For the family, fear, and fatalism factors, there were 2 significant associations with WHO DMFT dichotomized high vs. low categories at the $\mathrm{p}=0.05$ level. The model included the same factors as the overall model (excluding gender). The model utilized an exchangeable working correlation structure with a value of -0.020239451. It had 92 clusters, and a Quasilikelihood under the Independence Model Criterion fit of 95.5859. Single parent vs. both parents, same home had an AOR of 0.94 (95\% CI: $0.22,3.99 ; p=.9291)$. Second biological child vs. first biological child had an AOR of 0.86 (95\% CI: $0.17,4.37 ; \mathrm{p}=.8629)$. For relationships in the household which were nieces, nephews, grandchildren or step children vs. first biological child, the AOR was 1.13 (95\% CI: 0.16, 7.87; p $=.9052)$. For Fatalism Scale, the AOR was $6.60(95 \%$ CI: 1.89, 9.64; $p=.0076)$. For the Dental Fear Survey, the AOR was 2.26 (95\% CI: 1.89, 9.64; $\mathrm{p}=.2720)$. For the Short Form Fear of Pain Questionnaire, the OR was 0.08 (95\% CI: 0.01, 0.55; $\mathrm{p}=0.0100)$.

A reduced model was developed for more precision for the outcome variables of interest. The model adjusted for age (17 years; 16 years; 15 years vs. 14 years), and family education (less than/high school vs. more than high school). The variable, Short Form Fear of Pain Questionnaire reached significance $(\mathrm{p}=0.0119)$; however the other variables of interest failed to reach a significant association with the WHO DMFT dichotomized high vs. low categories. For single parent vs. both parents, same home the AOR was 0.65 (95\% CI: 0.23, 1.49; p = .4168). For relationships in the household which were nieces, nephews, grandchildren or step children vs. first biological child, the AOR was 1.02 (95\% CI: 0.29, 3.62; p = .9709). For second biological child vs. first biological child, the AOR was 1.08 (95\% CI: 0.24, 4.86; p = .9188). For Fatalism Scale, the AOR was $1.88(95 \%$ CI: 0.60, 5.87; $\mathrm{p}=.2790)$. For the Dental Fear Survey, the AOR was 1.54 (95\% CI: 0.51, 4.63; $\mathrm{p}=.4427)$. For the Short Form Fear of Pain Questionnaire, the AOR was 0.16 (95\% CI: 0.04, 0.66; $\mathrm{p}=.0119)$. 


\subsection{Discussion}

This study's overall main findings concerning adolescents, ages 14-17 years, were that family relationships, in terms of birth categories (second biological child, niece, nephew, stepchild, or grandchild status in the home vs. first biological child) and single parent vs. both parents in the same home, were not significantly associated with WHO DMFT dichotomized categories in a multivariable model; additionally, fear and fatalism did not have overall effects. However, variations occurred in gender sub-group analysis: living with a single parent was protective for males, (AOR 0.08); and for females, Fatalism Scale had an AOR of 6.60. The Short Form Fear of Pain Questionnaire for males, had an AOR of 12.86, while it was 0.08 for females. There were 36.1\% reporting fear on the Dental Fear Survey; 63.9\% on the Short Form Fear of Pain Survey; and 43.5\% reporting fatalism on the Fatalism Scale. There were 54.6\% first biological children; $20.6 \%$ second biological children, and $24.8 \%$ with other family relationships; $53.5 \%$ lived in single parent homes.

The impact of parental influences on adolescents has been recognized as powerful and lasting long after an individual leaves his or her parents' home. ${ }^{10}$ However, parental influences on adolescent oral health has not been widely studied, and of those studies available, disparate results exist. Some previous research indicates that children living in nuclear families are less likely to be in poor overall health or to have gone without needed dental care in the previous 12 months due to cost than non-nuclear families; ${ }^{44}$ and single parent families, which are more likely to have severe economic disadvantages, have more adverse health as a result. ${ }^{2}$ For example, in an Indian study of adolescents, ages 12-15 years, adolescents without parents had poor oral health quality of life scores compared with those who had parents. ${ }^{45}$

However, other research has indicated that over a year, adolescent oral health (oral hygiene behavior) are no more affected by parental influence (authoritative parent model intervention) than traditional education of adolescents and behavior modification, or conventional behavior modification. ${ }^{46}$ A similar study in the United Kingdom, also evaluating preventive behavior (tooth brushing), indicated that in a multivariable model, family structure was not significantly associated with toothbrushing. ${ }^{47}$ As older adolescents are frequently away from home, they are less likely to share overall experiences, ${ }^{48}$ including attitudes toward oral health. A curious result was reported in one study in which, although self-reported social support was related to lower caries increments in adolescents, 15-16 years, the relevant support was from a special person, rather than peers or family (controlling for demographics, socioeconomics, and dental behavior). ${ }^{49}$

This study did not indicate dental health differences between a single parent vs. both parents in the same home in the overall analysis, and did indicate a single parent relationship as protective for males. Nationwide, the number of single parent homes has been increasing ${ }^{2}$ from $11 \%$ in 1970 to $32 \%$ in $2008 . .^{50}$ This study was higher in single parent homes with $53.5 \%$ reporting living in a single parent home as compared with both parents, same home. As the frequency of single parent homes increases, family trend differences may be tracking differently for this age group. 
Also, this study did not show sibling relationship to be significantly influential in caries experience in an overall adjusted multivariable model; however, though not to the level of significance, for males, being the second biological child vs. the first biological child had a 14.08 AOR of high caries experience. Research is only recently focusing upon sibling relationships, recognizing their enduring relational contexts across the life span. ${ }^{2}$ Previous studies have not shown siblings to have strong direct effects on adolescent development, and hypotheses vary from the contamination hypothesis (siblings have less effect on each other) to the compensation hypothesis (siblings have more effect on each other). ${ }^{2}$

Adolescence has been described as a socially-critical period in which stable patterns of preventive care, such as tooth brushing, are established. ${ }^{51}$ However, it is also the most difficult time to intervene with health promotion education as adolescents often view themselves invulnerable to health concerns and regard oral health less valuable than general health. ${ }^{50}$ The invulnerable/lack of fear aspect of adolescent beliefs is an important consideration. In this study, overall, no/low fear on the fear summary score was expressed by $63.9 \%$ of the adolescents with the Dental Fear Survey Instrument, although 82.2\% reported fear of pain on the Short Form Fear of Pain Questionnaire. Although the Short Form Fear of Pain Questionnaire was not significant in the overall multivariable analysis, it was in gender analysis - for males the AOR was 12.86 and for females it was 0.08 .

Although more research is needed to explain this result, a possible explanation has been proposed that since industrialized countries have had marked decreases in caries experience in children, there is an associated decrease in frequency of dental procedures (beyond prophylaxis and evaluation), ${ }^{52}$ resulting in the possibility of dental care not being perceived as a fearprovoking experience for an increasing number of adolescents. However, it does not explain the high relationship of the Short Form Fear of Pain Questionnaire and caries experience for males.

This study's results with the Dental Fear Survey supports a similar study in which fear was not significantly related to overall dental caries in this age group. ${ }^{53}$ Nevertheless, a study in New Zealand had results indicating fear increases the potential for greater caries experience in late adolescence (15-18 years). ${ }^{54}$ And, adolescents in Singapore, who had painful dental treatment or perceived lack of control in a dental setting, were more likely to have high fear levels and less likely to be willing to return for dental treatment, indicating the potential for increased future dental need and severity. ${ }^{55}$ Nevertheless, a larger sample would have provided more precision in the analysis. Cultural differences, and instrumentation differences may be future areas of research to explore to explain the differences.

This study has the strength of being a recent, comprehensive evaluation of adolescents, ages 14-17 years, in an area of the United States which has not been adequately studied for oral health. This study had a cross-sectional design. Such designs preclude the possibility of establishing causal relationships or temporal sequencing of WHO DMFT dichotomized categories and dental fear, fatalism and family relationships. Adolescence is a difficult developmental stage for many children. It is a time of the establishment of dental habits which may last over the life-course. To achieve improvements in dental health, emphasis and research should continue as to how to address and reduce poor oral health consequences in adolescents. 


\section{Acknowledgement}

This project was funded by National Institute of Dental and Craniofacial Research (R01DE014899, R01-DE014899-03S1, R01-DE014899-04S1, and U01-DE018903). The study was also made possible by support of the University of Pittsburgh, School of Dental Medicine, the West Virginia University School of Dentistry, and the West Virginia University Eberly College of Arts and Sciences. Gratitude is extended to the researchers and staff at the University of Pittsburgh and West Virginia University. 


\title{
Chapter 4
}

Cross-sectional analyses of family structure, fear, and fatalism upon caries experience in West Virginia and Pennsylvania Appalachia adults, ages 18 years and above

\begin{abstract}
Adults in the Appalachian Region have many oral health problems. There are many epidemiologic factors which influence their oral health.

Purpose: The intent of this study was to consider family structure social support (as marital/cohabitation status), dental fear, and fatalism upon dental caries experience. The study population consisted of adults, ages 18 years and above, living in Appalachia West Virginia or Pennsylvania.

Method: The study used data collected in 2002-2009 by the Genetic Factors Contributing to Oral Health Disparities in Appalachia study of the Center for Oral Health Research in Appalachia (COHRA etiology study). Data were analyzed with generalized estimating equations in multivariable analysis.

Results: Fatalism, family structure social support, and the Short Form Fear of Pain Questionnaire were not significantly related to caries experience in a multivariable model. A high Dental Fear Survey score was associated with a high caries experience. The adjusted odds ratio (AOR) was $1.76(95 \% \mathrm{CI}: 1.29,2.40 ; \mathrm{p}=.0003)$. It remained significant for females $(\mathrm{AOR}=2.11[95 \% \mathrm{CI}: 1.41,3.14 ; \mathrm{p}=0.0003])$. In sub-group analysis, for males, those never married, divorced, widowed, separated, or had other living arrangements vs. married/domestic partnering had an AOR of 0.12 (95\% CI: 0.04, 0.36; $\mathrm{p}=.0002)$. There were $50.9 \%$ reporting fear on the Dental Fear Survey and $81.6 \%$ on the Short Form Fear of Pain Questionnaire. There were $29.9 \%$ with high fatalism on the Fatalism Scale. There were $71.2 \%$ who were married/domestic partnering.

Conclusion: Adults in Appalachia who were more fearful on the Dental Fear Survey had high caries experiences in terms of decayed, missing and filled teeth. Interventions in Appalachia to improve oral health should address adult patient fear as well as target oral health programs to men who are married or have a domestic partner to improve their potential for improved oral health.
\end{abstract}

\subsection{Introduction}

The conscription requirements 70 years ago for World War II included a minimum of 6 opposing teeth. ${ }^{1}$ The difficulty finding such candidates highlighted the need to address dental disease in adults and was an impetus for the formation of the National Institute of Dental Research. ${ }^{1}$ Dental disease in adults remains a public health concern with many conditions showing little or no improvement. In 2004, $43.9 \%$ of U.S. adults had one or more permanent tooth/teeth extracted, and in 2010, the percentage was $43.6 \% .^{2}$ In $2004,29.1 \%$ of U.S. adults did not visit the dentist or dental clinic within the previous year and $29.9 \%$ did not in $2010 .{ }^{2}$ Of the U.S. adults over age 65 years, $21.3 \%$ were edentulous in 2004 and $16.9 \%$ were in $2010 .^{2}$ 
The most prevalent oral health issue reported by adults is toothache. ${ }^{3}$ Toothache pain interferes with eating, swallowing and talking. ${ }^{3}$ Periodontal disease is also a concern. Severe periodontal disease affects about $14 \%$ of adults, ages 45 to 54 years. ${ }^{3}$ Periodontal disease is a concern as severe periodontal disease has been independently associated with increased plasma levels of the inflammatory markers, tumor necrosis factor- $\alpha$ and C-reactive protein, controlling for known risk factors for increased concentrations of the markers. ${ }^{4}$ Additionally, almost $25 \%$ of adults reported some form of facial pain in the past 6 months. ${ }^{3}$

The oral health of older adults is a public health issue. The percentage of U.S. citizens above age 65 years has quadrupled since 1900 (from $4.1 \%{ }^{5}$ to $17.5 \%$ in $2009^{6}$ ). The national median age is 36.8 years, and the states with the highest median ages are Maine (42.0 years), Vermont (42.0 years) and West Virginia (41.2 years). ${ }^{7}$ West Virginia also has $65.6 \%$ of its population who are adults, ages 65 years and above, with 6 or more missing teeth, compared to $43.1 \%$ nationally. West Virginia has $37.8 \%$ of the population who are adults, ages 65 years and above, who are edentulous, as compared to $18.1 \%$ nationally. ${ }^{8}$

Although older adults bear much of the chronic disease burden, including oral health problems, ${ }^{7}$ the rise in proportion of older adult population has been associated with a rise in proportion of older adults with some natural teeth. ${ }^{5,9}$ Tooth count is used as an indicator of oral health, but the usefulness of the teeth in terms of oral health is determined more by the functionality of the teeth than the number. 9,10 Additionally, as the retention of teeth increases, so does the prevalence of caries. ${ }^{9}$ This is due in part to a longer exposure to a deleterious oral environment, shifts in diet from complex to simple carbohydrates, multiple medications with xerostomic effects, abrasion/abfractures leading to the entrapment of food, debilitation leading to difficulty in properly conducting oral hygiene self-care, and depression or other psychological conditions resulting in self-neglect. ${ }^{9}$

In terms of overall health, tooth count is important. Tooth loss has been associated with a variety of conditions and risk factors for other diseases. The incidence of ischemic stroke has been associated with periodontal disease and tooth loss with a hazard ratio of 1.57 (95\% CI: 1.24,1.98) in men with fewer than 24 teeth. ${ }^{11}$ There is an increased risk of chronic disease with tooth loss due to dietary change (fewer fruits, vegetables and their fiber and vitamins), ${ }^{12,13}$ even though total calories may be maintained. ${ }^{14}$ An Asian population showed an increased risk of total death $(18 \%(95 \% \mathrm{CI}: 9 \%, 18 \%))$ and death from upper gastrointestinal cancer $(35 \%(95 \%$ CI: $14 \%, 59 \%))$, heart disease (28\% (95\% CI: 17\%,40\%)), stroke (12\% (95\% CI: $2 \%, 23 \%))$ and tooth loss. ${ }^{16}$ And poorer quality of life has been associated with individuals who have fewer than 24 teeth. ${ }^{16}$ Fortunately, most oral disease is preventable. ${ }^{17}$ Population research has identified many causal factors of poor oral health as well as many preventive factors for good oral health.

Public health and public health research is concerned with the ecosocial predictors of disparities in health, including oral health, such as the impact of income, race/ethnicity, gender, place of residence and age upon health status. ${ }^{18,19}$ Research has indicated a socioeconomic gradient of oral health with those having a lower SES generally having poorer oral health. ${ }^{20}$ Tooth loss also has been related, ecologically, with state income inequity using the Gini coefficient (one-half of the mean of the absolute differences between all pairs of income, 
normalized on the mean) with results showing a 5\% change in the state Gini coefficient resulting in almost a $20 \%$ higher odds of greater tooth loss. ${ }^{21}$

In terms of place of residence, previous studies have indicated adult rural residence is associated with a lower quality of life, more reports of fair or poor general health, (rather than good or excellent) and living in or near poverty, than urban residence in the United States. ${ }^{5,22}$ The U.S. Department of Health and Human Services, HHH, recognizes that health disparities exist in many contexts, including regions. In its Healthy People 2020 health goal program, the HHH identified health disparities on the basis of race or ethnicity, sex, sexual identity, age, disability, socioeconomic status, and geographical location, with a goal of improving the health of all disparate groups. ${ }^{23}$ Healthy People 2020 defines health disparity as "a particular type of health difference that is closely linked with social, economic and/or environmental disadvantage." 21 Eliminating health disparities and creating health equity, which is the attainment of the highest level of health for all, had been the agency's goal for the past 20 years. ${ }^{22}$ As the determinants of health (factors which influence an individual's or population's health) are not fully understood, Healthy People 2020 will work to provide epidemiological research and demographics, including rural/urban and geographic data. ${ }^{21}$ Though progress is being made, there is a lack of epidemiological research and literature for rural areas, a situation described as a data disparity. ${ }^{24}$ Adding to the complexity of the research is the recognition that rural regions are heterogenous. ${ }^{25}$ One unique region is Appalachia. It consists of West Virginia, Alabama, Georgia, Kentucky, Maryland, Mississippi, New York, North Carolina, Ohio, Pennsylvania, South Carolina, Tennessee, and Virginia. ${ }^{26}$ The Appalachian Region has a 42\% rural population whereas the U.S. nationally has a $20 \%$ rural population. ${ }^{6}$ Many factors have been implicated in the reception of essential dental care: access, cost, lack of providers, fear, limited oral health literacy and understanding, socioeconomic status, and education. ${ }^{27,28}$ The new decade brought with it a need to understand the effects of social predictors on health, and the need to consider broad population-level effects and unique regional effects. ${ }^{29}$

The oral health of adults in Appalachia is a concern. In 2010, the national prevalence for adults with any permanent teeth extracted was $44.0 \%$; the prevalence of edentulous older adults was 17\%; and the prevalence of adults not visiting a dentist/dental clinic within the past year was $30.2 \%$. $^{2}$ West Virginia led the nation in the number of adults with one or more permanent tooth/teeth extracted $(60.1 \%)$, in the number of edentulous older adults $(36.0 \%)$, and was third to Oklahoma and Mississippi in residents not visiting the dentist $(39.5 \%){ }^{2}$ The prevalence for adults with any permanent teeth extracted in Pennsylvania was 51.5\%; the prevalence of edentulism in older adults in Pennsylvania was $18.0 \%$; and $27.7 \%$ did not visit a dentist/dental clinic within the past year.

The Appalachian culture has been described as unique due to its geographic isolation. The purpose of this study was to explore World Health Organization severity of caries experience, utilizing the decayed, missing and filled teeth (DMFT) index, in adults in Appalachia West Virginia and Pennsylvania in terms of fatalistic life outlook, dental fear, and family structure social support (marital/cohabitation status).

The research hypotheses for this study were that West Virginia and Pennsylvania adults, ages 18 years and above, 1) who were married or had domestic partners were more likely to have lower WHO DMFT severity than other living arrangements; 2) who were fearful were more 
likely to have increased WHO DMFT severity than those who had little or no fear; and 3) who were fatalistic were more likely to have severe WHO DMFT than those who were not fatalistic. As previously mentioned, Appalachia may be defined at a state level as one of the thirteen states including the Appalachian Mountains. In this study, the definition of Appalachia Pennsylvania and West Virginia are at the state level.

\subsection{Methods}

This study was approved by the West Virginia University Institutional Review Board (H24094). It was supported in part by grants from the National Institute of Dental and Craniofacial Research (R01- DE014899, R01-DE014899-03S1, R01-DE014899-04S1, and U01-DE018903). The study was also made possible by support of the University of Pittsburgh, School of Dental Medicine, the West Virginia University School of Dentistry, and the West Virginia University Eberly College of Arts and Sciences. The data were provided from the Center for Oral Health Research in Appalachia (COHRA) etiology study for years 2002-2009, in a longitudinal study, Genetic Factors Contributing to Oral Health Disparities in Appalachia. The protocols for the study are presented in detail elsewhere. ${ }^{28}$ The COHRA study was conducted to follow the natural course of oral disease and identify factors to explain the prevalence of oral disease in Appalachia Pennsylvania and West Virginia. The innovation of the study was the use of family as a unit of study.

In this study, cross-sectional analyses of the adult social relationships, fear, and fatalism variables from the COHRA data base were analyzed.

\section{Study Population}

The requirements for participation in this analysis of COHRA data were that an individual was 1) 18 years or older, 2) living in a household with a COHRA index participant (and/or the biological parent or child). Household members were eligible regardless his or her legal or biological relationship with the index person. Excluded from the study were individuals who had conditions impacting the neurological, physical, or intellectual ability to complete the study or had conditions of decreased clotting or immunity.

From West Virginia, there were 813 families in the COHRA study and from Pennsylvania there were 542 families. There were 1319 adults. Adults were queried concerning fear, and fatalism. Oral evaluations occurred. The survey was conducted with questionnaires, clinical examinations, and laboratory tests of participating non-institutionalized, civilian adults. Recruitment occurred through advertisements in newspapers, commercials on television, and radio, and through fliers and pamphlets. The participants in West Virginia were given a \$25 gift card, and if all family members completed the study, the family received a $\$ 100$ gift card. In Pennsylvania, the participants received $\$ 25$. Every adult provided consent for participation. This study used a cross-sectional analysis design.

The adult subset was extracted from the COHRA data of 1319 adults, ages 18 years and above. This study included adults with complete DMFT data (there were 67 with missing data), family relationships to the index person, and responses to at least $20 \%$ of the fear and fatalism 
items (there were 127 with greater than $20 \%$ missing fear and fatalism data). The sample size of this study was 1125 .

\section{Outcome of interest-caries experience}

The oral evaluations were performed by dentists or dental hygienists (Cohen's Inter-rater Kappa $=0.83) .{ }^{28}$ The decayed, missing, and filled teeth index (DMFT) was derived from the evaluation of all teeth, excluding wisdom teeth. Occlusal, buccal, lingual, mesial and distal tooth surfaces were visually examined with a mouth mirror under operatory lighting with the use of air or gauze to dry the teeth, if needed. Radiography and tactile examination were not utilized, however an exception was issued to use an explorer for suspicious interproximal areas of potential caries. The DMFT index is a summative index of existing decay, history of decay (the presence of restorations/filled teeth; and missing teeth due to decay). DMFT has been categorized by a modified World Health Organization/University of Pittsburgh definition of caries experience for adults as: very low caries experience $(\mathrm{DMFT}=0-4)$; low caries experience $($ DMFT $=5-8)$; moderate caries experience $($ DMFT $=9-13)$; severe caries experience $(\mathrm{DMFT}>$ $13) .{ }^{29,30}$ In the multivariable analysis the categories were low caries experience (DMFT $\left.=0-8\right)$ and high caries experience (DMFT $\geq 9)$.

\section{Variables of interest}

This study used 2 dental fear self-report instruments. The adults were presented (either on paper or on screen) the 20-question Dental Fear Survey; ${ }^{31-35}$ and the 9-question Short Form Fear of Pain Questionnaire ${ }^{36-41}$ The options for the Likert-type responses to the items were: "Not afraid at all" (scored as " 1 " for each question with this response), "A little afraid," (scored as " 2 " for each question with this response), "Somewhat afraid,"(scored as " 3 " for each question with this response), "Pretty much afraid,"(scored as "4" for each question with this response) "Very afraid,"(scored as " 5 " for each question with this response) and "I don't know, because this never happened to me,"'(scored as missing). The median was imputed for missing values (There 260 imputations of a possible 32,625 responses- $0.80 \%$--involving 95 participants).

The Likert-style scores of the Dental Fear Survey and Short Form Fear of Pain Questionnaire responses were added. Potential summation scores were from 20 (no fear) to 100 (very much afraid) for the Dental Fear Survey and from 9 (no fear) to 45 (very much afraid) for the Short Form Fear of Pain Questionnaire. Based upon previous research, the Dental Fear Survey was dichotomized. ${ }^{41}$ Similarly, the Short Form Fear of Pain Questionnaire was dichotomized.

The Dental Fear Survey has internal consistency, test-retest reliability, and is used both in a clinic setting and for non-clinical research. ${ }^{31-35}$ The Dental Fear Survey is commonly utilized in dental research due to its validity. ${ }^{34,25}$ The Short Form Fear of Pain Questionnaire has internal consistency, good test-retest reliability and is used both in clinical settings and for non-clinical rsearch. $^{38}$

The fatalism instrument consisted of 12 self-reported items, the Fatalism Scale, ${ }^{40,41}$ The scale was either presented on paper or on screen. The basis for the instrument was the Multiphasic Assessment of Cultural Constructs Short Form. ${ }^{42}$ The Multiphasic Assessment of Cultural Constructs Short Form's fatalism subscale had 8 items. The items 1-8 of the Fatalism 
Scale (General Fatalism) were the fatalism subscale of the original cultural assessment. ${ }^{42}$ Items 9-12 of the Fatalism Scale are oral health related items. The possible Likert-style responses to the fatalism items were: "Definitely false," "Somewhat false," "Somewhat true," and "Definitely true." The missing values were replaced with the variable's mean value (there were 45 imputations of 13,500 potential responses - $0.33 \%$--involving 42 participants). Question 7 was reverse coded. The items were summed. Potential scores were from 12-48. The range was dichotomized into low and high.

Previous dental research has utilized the Fatalism scale. ${ }^{40}$ The dental specific items were significantly correlated with the Dental Neglect Scale $(\beta=-.385){ }^{41}$

\section{Other variables}

Gender, race/ethnicity, household income, highest educational level in the household, age, site (location of home), and body mass index were considered for use in the multivariable model. Due to the high, non-Hispanic White population in Appalachia, race/ethnicity was dichotomized into White and minority. Normal weight was a body mass index (BMI) less than 25 , overweight was a BMI of 25 to 30 , and obese was a BMI of 30 and above. ${ }^{2}$ Highest education level in the household was a derived variable based upon relating index person with people living in the household. Education was dichotomized into less than high school and high school graduation vs. more than high school Household income was a derived variable based upon relating index person with people living in the household and was categorized as less than $\$ 15,000 ; \$ 15,000-\$ 49.999$; and \$50,000 and greater. Site was categorized as Pennsylvania (PA) or West Virginia (WV). Age was categorized as 18-24 years, 25-44 year, 45 years and above.

\section{Statistical Analysis}

Study population characteristics, univariate analysis, and modeling were accomplished with SAS (version 9.2, Cary, NC). A priori statistical significance was defined as $\mathrm{p}<0.05$. The study participants were described with frequencies and analyses comparing the variable of interest with the WHO DMFT severity levels. The comparisons were performed using CochranMantel-Haenzel mean score test, Mantel-Haenzel Chi Square test with standardized midrank scores, or Mantel-Haenzel Exact Chi Square test.

Due to non-independent units (family clusters), generalized estimating equation (GEE) regression models were used for family structure, fatalism, fear and DMFT categories. The exchangeable working correlation was utilized.

For the overall multivariable model, and gender-stratified multivariable models, potential confounding of race/ethnicity (minority vs. White), income ( $\$ 15,000$ to $\$ 50,000$ and over $\$ 50,000$ vs. less than $\$ 15,000$ ), family education attainment (high school/less than high school vs. more than high school); age (25-44 year, 45 years and above vs. 18-24 years); body mass index (obese and overweight vs. normal weight); site (WV vs. PA), and, for the overall model, gender (female vs. male), against the family, fatalism, or fear variables was considered. A priori, a $10 \%$ or greater change in the family, fatalism, or fear variables by the potential confounder would be the criterion for inclusion into the model selection process and a backward selection at $\mathrm{p}=0.15$ was planned. 


\subsection{Results}

Table 1 provides the descriptive characteristics of the study sample. The sample was primarily ages $25-44$ years $(73.1 \%$, mean 34.3 years, Standard deviation \pm 9.53$)$; white $(89.3 \%)$; female $(63.6 \%)$; and married $(61.1 \%)$. Most of the participants lived in West Virginia (66.0\%), and had high school graduation as the highest household degree $(38.6 \%)$. There were $16.9 \%$ who had a family income of less than $\$ 10,000$. Most of the participants were obese $(42.2 \%)$ with a mean BMI of 30.0, standard deviation \pm 7 . 8. There were 60 participants $(6.0 \%)$ who had a DMFT of 0, and 16 who had a DMFT of $28(1.4 \%)$. The mean DMFT was 9.3 (Standard deviation, 6.4). The majority reported low fatalism (70.1\%) on the Fatalism Scale, 50.9\% reported fear on the Dental Fear Survey and $81.6 \%$ reported fear on the Short Form Fear of Pain Questionnaire.

Table 2 relates the severity of caries experience vs. descriptive characteristics. For nominal characteristics, the Chochran-Mantel-Haenzel mean score test with standardized midrank scores was used. For ranked characteristics (income, education, and BMI), the MantelHaenzel Chi Square test with standardized midrank scores was used. Race/ethnicity, and age were significant. For race/ethnicity, p was 0.0478, and for age, p was less than .0001.

Table 3 presents the severity of caries experience and the Fatalism Scale. MantelHaenzel Chi Square Exact test with standardized midrank scores was used. The Fatalism Scale was not significant $(\mathrm{p}=0.3107)$.

Table 4 provides the severity of caries experience vs. dental fear. Manel-Haenzel Chi Square Exact test with standardized midrank scores was used. Adults had significant caries experience associated with the Dental Fear Survey $(\mathrm{p}<.0001)$. The Short Form Fear of Pain Questionnaire was not significantly associated with caries experience $(\mathrm{p}=.6240)$.

\section{Unadjusted results, overall}

Table 5 indicates the generalized estimating equation for the unadjusted single factors. There were 1125 adults, ages 18 years and above. Dental Fear Survey was the only variables of interest to reach a significant association with the WHO DMFT dichotomized high vs. low categories. For never married, divorced, widowed, separated, other vs. married, domestic partner, the unadjusted odds ratio (OR) was 0.91 (95\% CI: 0.70, 1.19; $\mathrm{p}=.4941)$. For Fatalism Scale, the OR was 1.17 (95\% CI: 0.89, 1.53; $\mathrm{p}=.2678)$. For the Dental Fear Survey, the OR was 1.67 (95\% CI: 1.32, 2.12; $\leq .00001)$. For the Short Form Fear of Pain Questionnaire, the OR was 1.05 (95\% CI: 0.77, 1.42; $\mathrm{p}=0.7750)$.

\section{Overall multivariable model}

Included in the initial model were: gender (female vs. male), race/ethnicity (minority vs. White); never married, divorced, widowed, separated, other vs. married, domestic partner, Fatalism Scale (high vs. low); Dental Fear Survey (high vs. low); Short Form Fear of Pain Questionnaire (high vs. low); income (less than $\$ 15,000, \$ 15,000$ to $\$ 50,000$ vs. $\$ 50,000$ and 
above), and family education attainment (high school/less than high school vs. more than high school); BMI (obese, overweight vs. normal weight); site (WV vs. PA), and age (25-44 year, 45 years and above vs. 18-24 years).

The model used an exchangeable working correlation structure (0.0325836919). It had 547 clusters, and a Quasilikelihood under the Independence Model Criterion fit of 1078.1685. Dental Fear Survey was the only variable of interest to reach a significant association with the WHO DMFT dichotomized high vs. low categories. Never married, divorced, widowed, separated, other vs. married, domestic partner had an adjusted odds ratio (AOR) of 0.85 (95\% CI: $0.59,1.23 ; p=.3822)$. For Fatalism Scale, the AOR was 1.25 (95\% CI: 0.89, 1.76; $\mathrm{p}=$ .1918 ). For the Dental Fear Survey, the AOR was 1.76 (95\% CI: 1.29, 2.40; $\mathrm{p}=.0003)$. For the Short Form Fear of Pain Questionnaire, the AOR was 0.74 (95\% CI: 0.49, 1.11; $\mathrm{p}=.1504)$.

\section{Male multivariable model}

Table 6 presents the multivariable model from the generalized estimating equation by gender, male. There were 410 males, ages 18 years and above. For the family, fear, and fatalism factors, there was 1 significant association with WHO DMFT dichotomized high vs. low categories at the $\mathrm{p}=0.05$ level. The model included the same factors as the overall model (excluding gender). The model used an exchangeable working correlation structure which was equal to 0.3245493223. It had 342 clusters, and a Quasilikelihood under the Independence Model Criterion fit of 402.6360. Never married, divorced, widowed, separated, other vs. married, domestic partner had an AOR of 0.12 (95\% CI: 0.04, 0.36; $\mathrm{p}=.0002)$. For Fatalism Scale, the AOR was 1.49 (95\% CI: 0.84, 2.62; $\mathrm{p}=.1711)$. For the Dental Fear Survey, the AOR was 1.25 (95\% CI: 0.74, 2.11; $\mathrm{p}=.4021)$. For the Short Form Fear of Pain Questionnaire, the OR was 0.84 (95\% CI: $0.46,1.52 ; \mathrm{p}=.5600)$.

\section{Female multivariable model}

Table 7 presents the multivariable model from the generalized estimating equation by gender, female. There were 1715 females, ages 18 years and above. For the family, fear, and fatalism factors, there was 1 significant association with WHO DMFT dichotomized high vs. low categories at the $\mathrm{p}=0.05$ level. The model included the same factors as the overall model (excluding gender). The model utilized an exchangeable working correlation structure with a value of -0.092415803. It had 519 clusters, and a Quasilikelihood under the Independence Model Criterion fit of 670.7900. Never married, divorced, widowed, separated, other vs. married, domestic partner had an AOR of 1.18 (95\% CI: 0.75, 1.84; $\mathrm{p}=.4742)$. For Fatalism Scale, the AOR was $1.17(95 \%$ CI: $0.75,1.83 ; \mathrm{p}=.4844)$. For the Dental Fear Survey, the AOR was 2.11 (95\% CI: 1.41, 3.14; $\mathrm{p}=.0003)$. For the Short Form Fear of Pain Questionnaire, the OR was 0.75 (95\% CI: $0.42,1.32 ; \mathrm{p}=.3120)$.

\subsection{Discussion}

The principle findings of this study of adults, ages 18 years and above, from Pennsylvania and West Virginia were: fatalism, family structure social support, and the Short Form Fear of Pain Questionnaire were not significantly related to caries experience in a multivariable model. A high Dental Fear Survey score was associated with a high caries 
experience $(\mathrm{AOR}=1.76)$. It remained significant for females in sub-group analysis $(\mathrm{AOR}=$ 2.11). In sub-group analysis, for males, those never married, divorced, widowed, separated, or had other living arrangements vs. married/domestic partnering had an AOR of 0.12. There were $50.9 \%$ reporting fear on the Dental Fear Survey and $81.6 \%$ on the Short Form Fear of Pain Questionnaire. There were $29.9 \%$ with high fatalism on the Fatalism Scale. There were $71.2 \%$ who were married/domestic partnering.

Similar research was not available for comparative purposes for the impact of adult living circumstances upon oral health. Males were more likely to have low caries experience when never married, divorced, widowed, separated, or have other living circumstances than marriage or a domestic partner. Further research is needed to explore this phenomenon. Trend data is indicating an increase in the number of women not marrying. The National Center for Health Statistics reported that from 2006-2010, nearly 4 in 10 women, ages 15 to 44 years, have never married (38\%). ${ }^{43}$ The percentage was $33 \%$ in $1995 .{ }^{43}$ There were $36 \%$ in a first marriage, as compared with $44 \%$ in 1982, and $52 \%$ of first marriages survived at least 20 years. ${ }^{43}$ Women with at least a bachelor's degree were more likely to be married for 20 years (78\%) compared with those with a some college $(49 \%)$, and for high school graduates $(41 \%) .{ }^{43}$ Women were delaying marriage and there was an increase in cohabitation. ${ }^{43}$

Previous research has implicated dental fear as a psychological state which may lead to dental care avoidance, poor oral health quality of life, poor overall quality of life including social, sleep and psychological well-being. ${ }^{44}$ The findings of this study of Pennsylvania and West Virginia adults support dental fear, as measured with the Dental Fear Survey, resulting in poor oral health quality of life in terms of WHO DMFT severity. Nationwide, fear prevalence in adults has been relatively stable for the last half century with variations shown in a review of the literature in which the prevalence of participants reporting "some fear" in 1986 was 35.2\%; in 1988, it was 20.4\%; and in 1997, it was 19.9\%. ${ }^{45}$ A computer-assisted telephone survey of adults in Australia, controlling for age, gender, income, employment status, education, dental insurance and oral hygiene, indicated that dental fear was associated with an increased DMFT index, increased number of decayed teeth and increased number of missing teeth while there was an inverted "U" association of fear and filled teeth; whereas periodontitis and gingivitis were not associated with dental fear. ${ }^{46}$ A similar study evaluated if those with fear were underrepresented in epidemiological studies due to the fear, however the findings were that those with fear were not appreciably under-represented. ${ }^{47}$ The large number of people in this study $(50.9 \%$ indicating fear on the Dental Fear Survey) supports the result that the people with fear are adequately represented in epidemiological studies, and indicates a larger prevalence than determined in other studies. Further research is needed to determine why dental fear is so intransigent.

Genetic factors may have a role in dental fear. For example, female gender has been associated with dental fear. ${ }^{48-50}$ This study supports a strong association of adult female gender and fear in that fear was not significant in gender subgroup analysis for men, but was significant for women. Additionally, genetic variants of the melanocortin-1 receptor gene (generally in people with red hair) are also related to resistance to subcutaneous local anesthetics and adults with melanocortin-1 receptor gene variants reported more dental fear, more dental care avoidance behavior than those without melanocortin- 1 receptor gene variants. ${ }^{51}$ Similar factors 
may be creating genetic predispositions in this population and genetic and epigenetic research is being conducted to determine if specific genes or epigenetic factors may be involved.

Dental fear has been shown to develop with oral surgical procedures with pre-operative anxiety, particularly the extraction of wisdom teeth in young adults (predisposed to increased dental anxiety and in the presence of pain severity) which may progress to symptoms of posttraumatic stress disorder. ${ }^{52}$ Heightened anxiety, and the nature of past poor dental experiences in combination with the common surgical procedure of wisdom teeth removal are important factors that influence the establishment of prolonged dental fear. ${ }^{52}$ Similar research has indicated adverse circumstances increase the risk for psychological distress (such as dental fear) after a traumatic event to a greater effect in women than men. ${ }^{53}$ The consideration that wisdom teeth extraction often occurs as a person is entering adulthood may predispose young adults to become more dentally fearful. The authors of the wisdom teeth study noted that until their research, the psychological impact of oral surgery received little attention, perhaps due to what was acceptable to be defined as a "traumatic stressor." 52 In a study of dental extractions of patients entering a university oral and maxillofacial surgery clinic for emergent care, all patients exaggerated their recall of pain at 2 weeks post-operatively, and highly anxious patients additionally exaggerated their recall of anxiety. ${ }^{54}$ The greater likelihood of extractions during adulthood may have a role in the establishment of the dental fear trait. Dental fear is important to consider with adults in that access to care issues also include pain, fear, and anxiety. However, dental fear research needs to consider that some approaches that diminish dental issues to alleviate fear may compromise care. For example, terms or phrases intended to be less fearful such as "mild" periodontal disease, a red lesion that is "probably nothing, but should be followed-up," may not convey the urgency of needed treatment in the process of attempting to reduce fear.

The majority (70.1\%) reported low fatalism on the Fatalism Scale. Fatalism was not a factor in WHO DMFT severity for adults in the overall statistical multivariable model or in subgroup analysis. Most prior research concerning fatalism is qualitative in nature (ethnographic, interview or focus group). Early research into Appalachia by Thomas Ford in 1958 refuted the existence of fatalism traditionally associated with Appalachia. ${ }^{55}$ Instead, he described a dynamic culture adapting to the social and economic environments. ${ }^{55} \mathrm{He}$ studied fatalism, religiousity, individualism, and self-reliance, ${ }^{45}$ not medical or dental health, per se. A qualitative focus group based study in Southern West Virginia did not find fatalism to be a strong theme that emerged in the discussion of cultural norms (faith, family values, and patriarchy), ${ }^{55}$ and although results are presented concerning the medical discussion, fatalism toward oral health was not presented as part of the discussion. However, another study, involving in-depth interviews of Appalachia West Virginia and Kentucky women and cervical cancer screenings, indicated that the women did hold and expressed fatalistic attitudes, but the interviews also revealed attempts at agency despite constrained choices. ${ }^{56}$

Age remained significantly associated with WHO DMFT severity in the overall multivariable model and sub-group analyses by gender. The literature cites similar outcomes as a result of the accumulation of risk over time. For example, a study of edentulism and race/ethnicity (the ultimate in missing teeth) reported age as a significant factor. ${ }^{57}$ Similarly in birth cohort life-course study of oral health, oral health was found to be continuously exposed to environmental and behavioral risks that lead to accumulated diseases in the dental tissues. ${ }^{58}$ Age 
was also a related to DMFT in other studies in the data presented. ${ }^{59,60}$ Clinical evaluations of oral health in one study in Canada indicated that although the oral health of younger adults (preseniors) was better than older adults (seniors), the perceived impact was poorer, indicting expectations and experiences can influence satisfaction with oral health. ${ }^{61}$

This study has the strength of being a recent, comprehensive evaluation of Appalachian adults. This study had a cross-sectional design. Such designs preclude the possibility of establishing causal relationships or temporal sequencing of WHO DMFT severity and dental fear, fatalism and family relationships. Adult dental fear remained independently significant in the multivariable analysis. In sub-group analysis, men, who were never married, divorced, widowed, separated or had other living arrangements were more likely to have low caries experience than those married or who had a domestic partner. Future research in dental health for this population should address interventions focusing upon adult dental fear so that caries experience can be controlled. Additionally, research into the factors related to married men and men with domestic partners having high caries experience should also be explored.

\subsection{Acknowledgement}

This project was funded by National Institute of Dental and Craniofacial Research (R01DE014899, R01-DE014899-03S1, R01-DE014899-04S1, and U01-DE018903). The study was also made possible by support of the University of Pittsburgh School of Dental Medicine, the West Virginia University School of Dentistry, and the West Virginia University Eberly College of Arts and Sciences. Gratitude is extended to the researchers and staff at the University of Pittsburgh and West Virginia University. 


\section{Chapter 5 Summary of the Research}

\subsection{Conclusions}

The purpose of this life-course population analysis project was to provide information concerning the oral health of residents of Appalachia to enhance understanding of the effects of various family living arrangements, dental fear and fatalism with oral health. The embodiment (development or assimilation) of caries has many ecosocial, sociobehavioral and environmental pathways, including poor living conditions, unhealthy lifestyles (poor diet, nutrition, oral hygiene, use of tobacco and alcohol), limited availability and limited access to professional care. ${ }^{1}$ For example, children living in poverty have almost twice the caries prevalence (in primary teeth) of children in homes with an income of twice the poverty level. ${ }^{2}$

The ecosocial theoretical framework for this study proposes that the embodiment and multiple pathways of dental caries involve exposure to an etiologic bacterial biofilm, susceptibility, resistance, accountability, and agency (action) within individual, household, area, regional, national and global processes, production, exchange, and consumption over time (historical, generational, in utero, infancy, childhood and adulthood) within racial, ethnic, class, and gender contexts. ${ }^{3}$ It has been suggested that we should create models in which teeth are integrated in individuals, individuals in groups or social context, and that there should be an examination of tooth, individual, group variables and interactions in accounting for the distribution of disease. ${ }^{4}$ The reason for such an approach is illustrated by the dramatic shifts in smoking and HIV/AIDs prevalence in the United States in the twentieth century. Initially those of higher SES had higher smoking rates and HIV/AID rates than those of lower SES. ${ }^{3}$ A reversal occurred at the end of the century, indicating disease distribution cannot only be reduced to fundamental causes/disease mechanisms as they do not explain why rates and patterns change temporally and spacially. ${ }^{3}$

In another discipline, political ecology, which is similarly complex and dynamic, admonitions exist that such a widely inclusive approach is subject to being unmanageable and theoretically incoherent. ${ }^{3}$ In response, it is agreed that including all of the diverse pathways would not be realistic in any one study, but rather than reducing or repressing complexity, one should evaluate many factors at specific points in time and space which will allow for some degree of scientific generalization. ${ }^{3}$ Such was the basis for this study. Specific points in the lifecourse were evaluated for the embodiment of caries with regard to family structure, fatalism and fear in states with Appalachian culture. How do the people in West Virginia and Pennsylvania come to embody caries as a disease state?

\section{Antecedent ecosystem conditions}

\section{Population}

The entire state of West Virginia lies in Appalachia. West Virginia's total land mass is $24,038.21$ square miles. ${ }^{5}$ The 2010 population was $1,852,994 .^{5}$ The population density is 77.1 people per square mile. ${ }^{5}$ Most of the population is White $(93.9 \%) .{ }^{5}$ There are $3.4 \%$ Black, $1.2 \%$ Hispanic, $0.7 \%$ Asian, and 0.2\% American Indian or Alaska Native. Most of the population has 
a high school diploma $(81.6 \%) .^{5}$ The median income is $\$ 37,423 .^{5}$ The percentage of people in West Virginia below the poverty level is $17.8 \% .^{5}$ Fifteen percent of the population did not have health insurance. ${ }^{6}$ The 2012 unemployment rate is $6.9 \% .^{7}$

Pennsylvania has a land mass of $44,742.70$ square miles. ${ }^{5}$ The 2010 population of Pennsylvania was $12,702,379 .^{5}$ The population density is 283.9 per square mile. Most of the population is White $(83.8 \%){ }^{5}$ There are $11.3 \%$ Black, $5.9 \%$ Hispanic, $2.9 \%$ Asian, and $0.3 \%$ American Indian or Alaska Native. ${ }^{5}$ Most of the population has a high school diploma $(87.4 \%) .^{5}$ The median income is $\$ 50,398 .^{5}$ The percentage of people in Pennsylvania below the poverty level is $12.4 \% .^{5}$ There were $9.9 \%$ who did not have health insurance in $2009 .^{8}$ The 2012 unemployment rate $7.4 \% .^{7}$

\section{Historical antecedents}

Hundreds of years ago, the land which became West Virginia and Pennsylvania was a hunting region for Native Americans, and, as such, many areas were not permanently occupied until European settlements in the 1700's. Many conflicts occurred with the Native Americans. Farming was difficult and small farms were common in the eighteenth and nineteenth centuries. In southern West Virginia, floods and rocky soil impacted farming and hunting was necessary to supplement diets. Generally, the small farmers did not have slaves. When the Civil War began, Pennsylvania was a Union state and West Virginia, in 1863, seceded from Virginia in support of the Union. Many Civil War battles were fought in the two states. After the war, millions of immigrants arrived in the United States, many making Pennsylvania their home. At the beginning of the $20^{\text {th }}$ century, steel production expanded in Pennsylvania, but it collapsed by the end of the century. After the Civil War, in West Virginia, mining for salt, coal and iron ore began in earnest, as well as the harvesting of the forested mountains. Its steel industry also collapsed by the end of the $20^{\text {th }}$ century.

\section{Arrangements of power and property}

Pennsylvania and West Virginia had coal and steel "barons" who took advantage of land owners for the mineral rights, and took advantage of abundant, low-wage immigrant or local workers. In the early part of the $20^{\text {th }}$ century, there were no land use or zoning plans of consequence. Many of the mineral excavations and tree harvestings resulted in hazardous exposures of workers. Additionally, people living near coal production sites have increased risk for cardiopulmonary disease, chronic lung disease, hypertension, kidney disease, and poorer health, controlling for covariates. ${ }^{9-16}$ The natural environment in many areas of West Virginia has been destroyed. Floods, runoff, soil erosion, environmental damage, disrespect of surface owner land rights have been common ${ }^{17}$ as well as the presence of air and water pollution. Controversies remain concerning the pollution and health impacts of mining, and the mountain top removal of coal. Most recently, the mountains of Pennsylvania and West Virginia are being drilled for Marcellus shale natural gas with concerns remaining about the hydraulic fracturing process being used to access the gas.

\section{Accountability and agency in overall oral health: the tobacco industry example}

In assessing oral health, as with other health conditions, it is important to ask "who, among social groups or individuals, is responsible for the occurrences of development/embodiment?"18 
Oral health encompasses oral cancers, pre-natal periodontal disease, early childhood caries, intimate partner violence, child endangerment, as well as overall health. Considering oral cancers, and the tobacco industry, West Virginia farm tobacco production, in 2002, included 544 farms involving 1373 acres. ${ }^{19}$ There were 1000 Pennsylvania farms growing tobacco with approximately 6100 acres in production. ${ }^{20}$

However, $25.6 \%$ of the West Virginia population smoke (tied with Kentucky for the highest prevalence in the nation) and $8.5 \%$ of the population use smokeless tobacco (second in the nation to Wyoming). ${ }^{21}$ The prevalence of male high school students in West Virginia who use smokeless tobacco is $25.5 \% .^{22}$ The tobacco industry's estimated marketing budget for West Virginia is $\$ 121.2$ million annually. ${ }^{22}$ In 2010, $18.4 \%$ of adult Pennsylvanians smoked. ${ }^{23}$ The prevalence of male high school students in Pennsylvania who used smokeless tobacco was $12.9 \% .^{24}$ The tobacco industry's estimated marketing budget for Pennsylvania is $\$ 452.8$ million annually. ${ }^{24}$ West Virginia has the highest smoking rate in the nation for women who smoke during pregnancy, $27.0 \%$ compared to $10.7 \%$, nationwide. ${ }^{6}$

Accountability and agency for oral health encompasses not only the tobacco industry, but also the food and soft drink industry and their marketing, the companies providing employment (as the employment relates to employee exposures to stress, overwork, limited time for proper exercise, rest, and nutrition), health and dental insurance industries, government (state, local, national and global) policies and decisions, as well as individual, community, social group, and families, and encompasses psychological factors (fear, fatalism), as well as biological agents.

\subsection{Significance}

\section{Specific Accountability and agency in WHO DMFT severity: family, fear, fatalism}

The term "family" is defined by the U.S. government for social programs, taxation, and policy decisions. Although it has a loose definition in general society, the U.S. Census Bureau identifies a family as "a group of two people or more (one of whom is the householder) related by birth, marriage, or adoption and residing together; all such people (including related subfamily members) are considered as members of one family." 25 The term family household more closely aligns with the lay definition of a family. The U.S. Census Bureau defines a family household as a "household maintained by a householder who is in a family (as defined above), and includes any unrelated people (unrelated subfamily members and/or secondary individuals) who may be residing there." 25

Some previous research has shown that single parent families have increased overall health risks, including increased risk of adverse deliveries, low birth weight babies, increased risk of infant mortality, and increased risk of the children living in poverty. ${ }^{26}$ Research in Australia has indicated that very young children in single parent households have a 2.3 times higher incidence of early childhood caries than children from two-parent families; and that interventions reduced their caries experience 3.5-fold compared with a 7-fold caries reduction in children from two-parent families. ${ }^{27}$ Although the disadvantage was still 4 times greater than children from two-parent families, anticipatory guidance interventions do help reduce some of 
the caries risk. ${ }^{27}$ Oral health, in terms of smoking, was also related to single-parent homes. ${ }^{28}$ Similar results are reported for drinking and drug use and single-parent homes, as well as lower achievement in school, increased psychological stress, increased vulnerability to health problems and engaging in problem behaviors; however, when multigenerational households were considered, the teenagers did as well as teenagers from two-parent households. ${ }^{29}$ Family influences are long-lasting and complex. ${ }^{30}$ And although single-parent homes are associated with an increase in family problems, exposure to childhood sexual and physical abuse, exposure to parental illicit drug use, criminal offenses, and lower scores on standardized intelligence tests, when these factors are controlled, exposure to single-parent homes is relatively unrelated to adjustments in young adulthood. ${ }^{30}$

The importance of family structure for oral health outcomes, which was the research hypotheses, was not evident in this series of studies. On the contrary, the one association with family for adults (never married, divorced, widowed, separated, other vs. married, domestic partner) was protective of caries experience in male sub-group analysis for the never married, divorced, widowed, separated, and other. Children who indicated some dental fear and fatalism had increased WHO DMFT severity. The association of WHO DMFT severity and dental fear and fatalism was not significant in multivariable analysis in adolescence. Fear re-emerged as significant in adulthood. In the three studies presented, WHO DMFT severity and children, ages 11-13 years, the birth categories (second biological child vs. first biological child, and niece/nephew/step-/grandchild vs. first biological child) did not have significant associations with WHO DMFT severity. Similarly, for adolescents, ages 14-17 years, the birth categories, and single parent vs. both parents, same home, did not have significant associations. In adults, ages 18 years and above, never married, divorced, widowed, separated, other vs. married, or domestic partner also did not have significant associations with WHO DMFT severity.

Fear summary score was not significant for children, ages 11-13 years, nor for adolescents, ages 14-17 years, however, adults, ages 18 years and above, did have an increase of WHO DMFT severity with an increasing fear summary score. The adjusted odds ratio was 1.49. For children, ages 11-13 years, fear when learning of a dental appointment was significantly associated with WHO DMFT (adjusted odds ratio 2.97 for those with high fear vs. low fear). For adolescents, fear of pain of falling down a flight of concrete steps was protective of WHO DMFT severity (adjusted odds ratio 0.39 for those with high fear vs. low fear). Overall, $37.9 \%$ of the children, ages $11-13$ years; $36.1 \%$ of the adolescents, ages $14-17$ years, and $49.2 \%$ of adults, ages 18 years and above, reported some/pretty much/ very much fear on the fear summary score.

Fatalism summary score was not significantly associated with WHO DMFT severity for children, ages 11-13 years, nor for adolescents, ages 14-17, nor for adults, ages 18 years and above. For children, ages 11-13 years, fatalism to preventive care was significantly associated with WHO DMFT severity (adjusted odds ratio of 2.74 for those with high fatalism vs. low fatalism). Overall, 71.9\% of the children, ages 11-13 years; $57.9 \%$ of the adolescents, ages 1417 years, and $35.1 \%$ of adults, ages 18 years and above, reported high fatalism on the fatalism summary score. 


\subsection{Strengths and Limitations}

The research was secondary data analysis of a moderately sized, comprehensive study of oral disease etiology conducted by the Center for Oral Health Research in Appalachia. The study specifically addressed family composition and was recent (2002-2009). Gender sub-group analysis was possible with the sample. As the data were clustered in families, multivariable analysis was completed with generalize estimating equations to allow for the clustering.

The research, being cross-sectional, may not be used to infer if family structure, dental fear, or fatalism causes increased WHO DMFT experience. Also, it is not possible to infer temporal associations between family, fear, fatalism and increased WHO DMFT.

\subsection{Future Research}

Currently underway is the second wave of family research with the Center for Oral Health Research in Appalachia. It involves a longitudinal, non-intervention study of pre-natal mothers through delivery and two year follow-up. Their infants will also have oral evaluations to age 2 years. Incident caries development will be monitored in both the mother and child.

The WHO DMFT experience and fear associations in these studies requires further exploration for potential interventions to help people with dental fear to appropriately access dental care. Both a clinical intervention and public health intervention should be considered. There is a distinction between what a clinician needs in addressing the individual who presents before him or her and what is needed for the community as a whole. The clinician needs to meet a specific individual's needs, and determine that individual's specific treatment plan. Also, the clinician can appraise which patient already has the knowledge and skills to brush and floss, to eat a healthful diet, to exercise, and get enough sleep, to avoid drugs and tobacco products, and limit alcohol use, to avoid stress, to avoid overexposure to the sun, to wear a seatbelt in a car, etc. A clinician tailors individual, evidence-based treatment plans based on patients' specific needs; however, the evidence available for effective, acceptable preventive interventions and addressing fear is limited.

From the public health aspect, public service announcements are provided for oral health improvement. For some people, there is, in fact, a lack of knowledge. Although many patients in Appalachia choose extractions over the salvation of a tooth, expense and fear are often the driving forces, rather than the lack of knowledge or the belief that tooth loss was inevitable as was historically believed. ${ }^{31}$ (This belief was once entrenched and marital dowries were given for full mouth extractions and the fabrication of dentures). ${ }^{31}$

However, public service announcements which provide oral health information imply that, when people have the information, problems will be solved. Such approaches only address one element of oral health. Lack of knowledge may drive some issues, but many people already know that they should eat well, but cannot afford quality food, or be in a location with limited access to quality food. ${ }^{32}$ Many people already know that they should avoid tobacco, but were the target of mass marketing when they were young, or use tobacco as an anxiolytic due to 
overwork/stress, and have become addicted to tobacco. ${ }^{33}$ Many people already know that they should exercise and get enough sleep, but the commute to work, hours at work, few breaks, or similar impairments limit the hours available to exercise or sleep. Many people already know that they should brush with a soft-bristled brush after meals with a fluoridated toothpaste, and floss their teeth daily, but may not have the resources to purchase a toothbrush, floss, and toothpaste. Knowledge is necessary, but not enough.

Public health efforts are needed in genetic research, epidemiology, and cariology to provide policy-makers with current, accurate prevalences of caries, periodontal disease, and oral cancer, as well as provide effective interventions which will improve oral health and to which policy-makers can support. Researched interventions that are effective, financially feasible, and acceptable are needed. ${ }^{34}$ Funding of preventive services should be paramount, but school-based educational programs, as well as sealant programs are needed. ${ }^{31}$ Community effort is needed to engage obstetricians and pediatricians in educating their patients and making dental referrals. Many professionals are needed to address the oral health epidemic. ${ }^{31}$ 


\section{Chapter 1 References}

1. Dickens, C. A Christmas Carol: A Ghost Story of Christmas. Project Gutenberg, E-book 46,2004.Available at http://www.gutenberg.org/files/46/46-h/46-h.htm.

2. Preamble to the U.S. Constitution.

3. Krieger, Nancy. Epidemiology and the People's Health. New York: Oxford University Press, 2011.

4. Viseltear AJ. CEA Winslow and the early years of Public Health. Yale Journal of Biology and Medicine at Yale. 1982;55:137-151. Available at http://www.ncbi.nlm.nih.gov/pmc/articles/PMC2596005/pdf/yjbm00109-0062.pdf.

5. Goins RT, Spencer M, Williams K. Lay Meanings of Health Among Rural Older Adults in Appalachia. Journal of Rural Public Health. 2010;27:13-19.

6. Mann JM. Health and human rights: Protecting human rights is essential for promoting health. BMJ. 1996;12:924. Available at: http://www.bmj.com/content/312/7036/924.extract.

7. Preamble to the Constitution of the World Health Organization as adopted by the International Health Conference, New York, 19 June-22 July. Available at 1946http://www.who.int/suggestions/faq/en/.

8. Definition of Public Health. Medicine Net. Com. Available at http://www.medterms.com/script/main/art.asp?articlekey=5120.

9. Oakes JM, Kaufman JS. Methods in Social Epidemiology. San Francisco, CA: Jossey-Bass, 2006. Available at http://www.tc.umn.edu/ oakes007/Files/Book/intro\%20proofs.pdf.

10. Harper S, King NB, Meersman SC, Reichman ME, Breen N, Lynch J. Implicit Value Judgments in the Measurement of Health Inequalities. The Milbank Quarterly. 2010; 88:4-29.

11. Krieger N. The Ostrich, the Albatross, and Public Health: An Ecosocial Perspective - Or Why an Explicit Focus on Health Consequences of Discrimination and Deprivation is Vital for Good Science and Public Health Practice. Public Health Reports. 2001;116:419-421.

12. Fejerskov O. Changing Paradigms in Concepts on Dental Caries: Consequences for Oral Health Care. Caries Res. 2004;38:182-191.

13. Satcher D. Oral Health in America: A report of the Surgeon General. U.S. Public Health Services bulletin 2000. Available at: http://www2.nidcr.nih.gov/sgr/sgrohweb/home.htm].

14. Pierce KM, Rozier RG, Vann WF. Accuracy of Pediatric Primary Care Providers' Screening And Referral for Early Childhood Caries. Pediatrics. 2002;109:e82-89. Available at: http://www.pediatrics.org/cgi/content/full/109/5/e82.

15. Vargas CM, Ronzio CR. Disparities in Early Childhood Caries. BMC Oral Health. 2006;6:about 3 screens. Available at: http://www.biomedcentral.com/1472- 6831/6/S1/S3.

16. Oral health improving for most Americans, but tooth decay among preschool children on the rise. 2007; about 2 screens. Available at: http://www.cdc.gov/nchs/pressroom/07newsreleases/oralhealth.htm.

17. Kaste LM, Selwitz RH, Oldakowski RJ, Brunell JA, Winn DM, Brown LJ. 
Coronal caries in the primary and permanent dentition of children and adolescents 1-17 years of age: United States 1988-1991. J Dent Res. 1996;75:631-4. Available at: http://www.ncbi.nlm.nih.gov/pubmed/8594087.

18. Palmer C. Prevalence of periodontitits: CDC survey is "high burden" of disease among Adults. ADA News. 2012;42:4.

19. National Cancer Institute Cancer Trends Progress Report 2009-2010 Update. Available at: http//progressreport.cancer.gov/doc_detail.asp?pid=1\&did=2009\&chid=96\&coid=930 \&mid=.

20. Joshipura KJ, Hung H, Rimm EB, Willett WC, Ascherio A. Periodontal disease, tooth loss and incidence of ischemic stroke. Stroke. 2003;34:47.

21. Hung H, Willett W, Ascherio A, Rosner E, Rim E, Joshipura K. Tooth loss and dietary intake. JADA. 2003;134:1185-92.

22. Lee JS, Weyant RJ, Corby P, Kritchevsky SB, Harris TB, Rooks R, Rubin SM, Newman AB. Edentulism and nutritional status in a biracial sample of well-functioning, community-dwelling elderly: the Health, Aging, and Body Composition Study. Am J Clin Nutr. 2004;79:295-302.

23. Abnet C, Qiao Y, Dawsey SM, Dong Z, Taylor PR, Mark SD. Tooth loss is associated with increased risk of total death and death from upper gastrointestinal cancer, heart disease, and stroke in a Chinese population-based cohort. International Journal of Epidemiology. 2005;34:467-474.

24. Steele JG, Sanders AE, Glade GD, Allen PF, Lahti S, Nuttall N, Spencer AJ. How do age and tooth loss affect quality of life? Community Dentistry and Oral Epidemiology. 2004;32:107.

25. Heathy People 2020 Disparities. Available at: http://www.healthypeople.gov/2020/about/DisparitiesAbout.aspx.

26. Rockett IRH, Wand S, Stack S, DeLeo D, Frost JL, Ducatman AM, Walker RL, Kapusta ND. Race/ethnicity and potential suicide misclassification: window on a minority suicide paradox? BMC Psychiatry. 2010;10:35.

27. Appalachian Regional Commission. Available at: http://www.arc.gov/appalachian_region/The AppalachianRegion.asp.

28. Oral Health Resources CDC Behavioral Risk Factor Surveillance System (multiple year data). Available at http://apps.nccd.cdc.gov/BRFSS/list.asp?cat=OH\&yr=2010\&qkey=6606\&state=All

29. Healthy People 2010: 21 Oral Health. CDC Atlanta, GA. Available at: http://www.healthypeople.gov/Document/HTML/Volume2/21Oral.htm.

30. Pold DE, Weyant RJ, Crout RJ, McNeil DW, Tarter RE, Thomas JG, Marazita ML. Study Protocol of the Center for Oral Health Research in Appalachia (COHRA) etiology study. BMC Oral Health. 2008;8:18.

31. Antunes JLF, Peres MA, Mello TRC, Waldman EA. Multilevel assessment of determinants of dental caries experience in Brazil. Community Dent Oral Epidemiol. 2006;34:146-152.

32. Al-Shammery AR. Caries experience of urban and rural children in Saudi Arabia. Journal of Public Health Dentistry. 1999;59:64.

33. Kallestal C, Wall S. Socio-economic effect on caries. Incidence data among 
Swedish 12-14-year-olds. Community Dentistry and Oral Epidemiology. 2002;30:108-114.

34. Vargas CM, Dye BA, Hayes KL. Oral health status of rural adults in the United States. JADA. 2002;133:1672-1681.

35. Liu J, Probst JC, Martin AB, Wang J, Salinas CF. Disparities in Dental Insurance Coverage and Dental Care Among US Children: The National Survey of Children's Health. Pediatrics. 2007;119:S12-S21.

36. Fitzpatrick, Joyce J and Stevenson Joanne S, editors. Annual Review of Nursing Research: Focus on Significant Clinical Issues. New York:Springer Publishing Company, 1994.

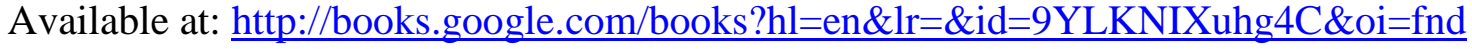
$\& p g=P A 65 \& d q=$ edentulism+rural+south+dakota\&ots=zivdlubCrM

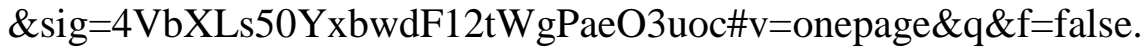

37. Klein BE, Klein R, Knudtson MD. Life-style correlates of tooth loss in an adult Midwestern Population. Journal of Public Health Dentistry. 2004;64:145-149.

38. Goodman E, Slap GB, Huang B. The Public Health Impact of Socioeconomic Status on Adolescent Depression and Obesity. American Journal of Public Health. 2003;93:1844-1850.

39. The Precede-Proceed Model of Health Program Planning and Evaluation. Available at: http://www.lgreen.net/precede.htm.

40. Hartley D. Rural Health Disparities, Population Health and Rural Culture. American Journal of Public Health. 2004;94:1675-1678.

41. Huttlinger K, Schaller-Ayers J, Lawson T. Health Care in Appalachia: A

42. McDonald RE, Avery DR, Dean JA. Dentistry for the Child and Adolescent. St. Louis, MO:Mosby;2000:177.

43. Oral Health Initiative, A program of the American Academy of Pediatrics. Oral Health Risk Assessment: Training for Pediatricians and Other Health Professionals. Available at: http://www.aap.org/oralhealth/cme/page4.htm.

44. Groft JN, Hagen B, Miller NK, Cooper N, Brown S. Adolescent health: a rural community's approach. Rural and Remote Health. 2005;5:336.

45. Behavior Change Theories and Models. Available at: www.csupomona.edu/ jvgrizzell/best_practices/bctheory.html.

46. Diclemente RJ, Santelli JS, Crosby RA, editors. Adolescent Health: Understanding and Preventing Risk Behaviors. San Francisco; John Wiley and Sons: 2009.

47. Population Profile of the United States: Dynamic Version: Older adults in 2005. Available at: http://www.census.gov/population/www/pop-profile/files/dynamic/OLDER.pdf].

48. McNeil DW. Even the most sophisticated oral health interventions and Technologies are of no help unless people accept and use them. Journal of Public Health Dentistry. 2011;71:581-582.

\section{Chapter 2 References}

1. National Institute of Dental and Craniofacial Research Oral Health in America: A report of the Surgeon General. Bethesda, MD: 2000. 
2. Acs G, Shulman R, Ng MW, Chussid S. The effect of dental rehabilitation on the body weight of children with early childhood caries. Pediatric Dentistry. 1999;21:109.

3. Wolram alpha ${ }^{\mathrm{TM}}$ Dental caries: number of deaths. Available at: http://www.wolframalpha.com/input/?i=dental+caries\&a=*C.dental+caries- *Death\&buttonstates $=\% 7 \mathrm{~B} \% 22$ Regional+properties\%22+-\%3E+\%7B\%7B1\%2C+2\%7D \% $\%$ 7D

4. Newacheck PW, Hughes DC, Hung Y, Wong S, Stoddard PW. The unmet health needs of America's children. Pediatrics. 2000;105:989-997.

5. Wang X, Shaffer JR, Weyant RJ, Cuenco KT, DeSensi RH, Crout R, McNeil DW, Marazita ML. Genes and their effects on dental caries may differ between primary and permanent dentitions. Caries Res. 2010;44:277-284.

6. Slayton RL, Cooper ME, Marazita ML. Tuftelin, mutans streptococci, and dental caries susceptibility. J Dent Res. 2005;84:711-714

7. Deeley K, Letra A, Rose EK, Brandon CA, Resick JM, Marazita ML, Vieira A. Possible association of amelogenin to high caries experience in GuatemalanMayan population. Caries Res. 42:8-13.

8. Wendell S, Wang X, Brown M, Cooper ME, DeSensi RS, Weyant RJ, Crout R, McNeil DW, Marazita ML, Taste Genes Associated with Dental Caries. JDR. 2010;89:1198-1202.

9. Mattila M-L, Rautava P, Sillanpaa M, Paunio P. Caries in five-year-old children and associations with family related factors. J Dental Research. 2000;79: 875.

10. Moynihan P, Petersen PE. Diet, Nutrition, and the Prevention of Dental Disease. Public Health Nutrtion. 2004;7:201-226.

11. Bramlett MD, Blumberg SJ. Family structure and children's physical and mental health. Health Aff. 2007;26:549-558.

12. Pau A, Baxevanos KG, Croucher R. Family structure is associated with oral pain in 12-year-old Greek schoolchildren. Int J of Paediatric Dent. 2007;17;345-351.

13. Listl S. Family composition and children's dental health behavior: evidence from Germany. J Public Health Dental. 2011;71:91-101.

14. Krieger N. Theories for social epidemiology in the $21^{\text {st }}$ century: an ecosocial perspective. International Journal of Epidemiology 2001;30:668-677.

15. Auad SM, Waterhouse PJ, Nunn JH, Moynihan PJ. Dental caries and its association with sociodemographics, erosion, and diet in schoolchildren from southeast Brazil. Pediatr Dent. 2009;31:229-35.

16. Klejka J, Swanzy M, Whistler B, Jones C. Bruce MG, Hennessy TW, Bruden D, Rolin S, Beltran Aguila E, Byrd K, Husain F. Dental Caries in Rural Alaska: Alaska, 2008. MMWR. 2011;60:1275-1278.

17. Martin AB, Vyavaharkar M, Veschusio, Kirby H. Rural-Urban Differences in Dental Service Utilization Among an Early Childhood Population Enrolled in South Carolina. Matern Child Health J. 2010; December 14.

18. Nicolau B, Marcenes W, Allison P, Sheiham A. The life course approach: explaining the association between height and dental caries in Brazilian adolescents.

Community Dent and Oral Epidemiology. 2005;33:93-98.

19. Delgado AM, Molina N, Totongi M, Bordoni N, Fernandez C. Oral health of children from rural excluded villages (Trancas Calchaqui valleys. Tucuman, Argentina). Acta 
Odontol Latinoam. 1999;12:31-43.

20. Lo EC, Holmgren CJ, Hu DY, Wan HC. Dental caries status and treatment needs of 12-13-year-old children in Sichuan Province, southwestern China. Community Dent Health. 1999;16;114-116.

21. MacIntyre UE, duPlessis JB, Dietary intakes and caries experience in children in Limpopo Province, South Africa. SADR. 2006;61:58-63.

22. Fisher-Owens SA, Baker JC, Adams S, Chung LH, Gansky SA, Weintraub JA. Giving policy some teeth: routes to reducing disparities in oral health. Health Affairs. 2008;27:404-412.

23. The Appalachian Region. Appalachian Regional Commission. Available at http://www.arc.gov/appalachian_region/TheAppalachianRegion.asp.

24. Lutfiyya MN, Medley K, Young D, Black G. West Virginia Oral Needs Assessment: Dental Survey of School-Aged Children. Epidemiological Snapshot. Office of Maternal and Child Health. 1999;3:1-7.

25. Wiener RC, Crout RJ, Wiener MA. Toothpaste use by children, oral hygiene, and nutritional Education: An assessment of parental performance. $J D H$. 2009;83:141-145.

26. Frisbee SJ, Chambers CB, Frisbee JC, Goodwill AG, Crout RJ. Self-reported dental hygiene, obesity, and systemic inflammation in a pediatric rural community cohort. BMC Oral Health. 2010;10:21.

27. National Oral Health Surveillance System. Centers for Disease Control and Prevention. Available at: http://apps.nccd.cdc.gov/nohss/statemap.asp.

28. National Survey of Children's Health. NSCH 2007. Child and Adolescent Health Measurement Initiative, Data Resource Center for Child and Adolescent Health website. Available at: www.nschdata.org.

29. Polk DE, Weyant RJ, Crout RJ, McNeil DW, Tarter RE, Thomas JG, Marazita ML. Study protocol of the Center for Oral Health Research in Appalachia (COHRA) etiology study. BMJ Oral Health. 2008;8:18.

30. Vieiral AR, Marazita ML, Goldstein-McHenry T. Genome-wide scan finds suggestive caries loci. JDR;87:435-439.

31. Petersen PE, Bourgeois D, Ogawa H, Estupinan-Day S, Ndiaye C. The global burden of oral diseases and risks to oral health. Bull World Health Organ. 2005;83:661-669.

32. Kleinknect R, Klepac R, Alexander LD. Origins and characteristics of fear of Dentistry. JDR 1973;86:842-848.

33. Kleinknect R, Thorndike RM, McGlynn FD, Harkavy J. Analysis of the dental fear survey with cross-validation. JADA. 1984;108:59-61.

34. McGlynn FD, McNeil DW, Gallagher SL, Vrana S. Factor structure, stability, and internal consistency of the dental fear survey. Behavioral Assessment. 1987; 9:57-66.

35. Smith T, Moore RA. Repression of dental anxiety. JDR. 1995;74:144.

36. Wilson JF, Sinisko SA. Increased self-reported dental anxiety following completion of a dental history questionnaire. Psychological Reports. 1997;81:59-62.

37. McNeil DW, Rainwater AJ. Development of the fear of pain questionnaire-III. Journal of Behavioral Medicine. 1998;21:389-410.

38. Osman A, Breitenstein JL, Barrios FX, Guiterrez PM, Kopper BA. The fear of 
pain questionnaire-III: Further reliability and validity with nonclinical samples. Journal of Behavioral Medicine. 2001;25:155-173.

39. Roelofs J, Peters ML, Deutz J, Spijker C, Vlaeyen JW. The fear of pain questionnaire (FPQ): Further psychometric examination in a non-clinical sample. Pain. 2005;116:339-346.

40. Hamissi J, Hamissi H, Ghoudosi A, Gholami S. Factors affecting dental anxiety and beliefs in an Iranian population. International Journal of Collaborative Research on Internal Medicine \& Public Health. 2012;5:585-593.

41. McNeil DW, Crout RJ, Lawrence SM, Shah P, Rupert N. Oral health values in Appalachia: Specific dental-related fatalism? JDR. 2004;83:A-203 [Abstract].

42. McNeil DW. Dental Fear Survey; Fatalism Scale;. COHRA Instrumentation. 2007. www.dental.pitt.edu/Instrumentation\%20Checklist\%20(6).doc.

43. Cuellar I, Arnold B, Gonzalez G. Cognitive referents of acculturation: Assessment of cultural constructs in Mexican Americans. Journal of Community Psychology. 1995;23:339-356.

44. Woolf SH, Johnson RE, Phillips RL Jr, Philipsen M. Giving Everyone the Health: Of the Educated: An Examination of Whether Social Change Would Save More Lives Than Medical Advances. American Journal of Public Health. 2007;97: 679-683.

45. Royse D, Dignon M. Fatalism and Cancer Screening in Appalachian Kentucky. Family and Community Health. 2011;34:126-133.

46. Finlayson T, Siefert K, Ismail A, Delva J, Sohn W. Reliability and Validity of Brief Measures of Oral Health Related Knowledge, Fatalism, and Self-Efficacy in Mothers of African-American Children. Pediatric Dentistry. 2005;27:422-428.

47. Walker R, Lucas W, Crespo R. The West Virginia rural cancer prevention project. Cancer Pract. 1994;2:421-426.

48. Deskins S, Harris C, Bradlyn A, Cottrell L, Coffman J, Olexa J, Neal W. Preventive Care in Appalachia: Use of the Theory of Planned Behavior to Identify Barriers to Participation in Cholesterol Screenings Among West Virginians. Journal of Rural Health. 2006;22:367-374.

49. Benigeri M, Brodeur JM, Olivier M, Bedos C. Knowledge and perceptions of adolescents regarding oral health. Can J Public Health. 2002;93:54-58.

50. Jokovic A, Locker D, Stephens M, Guyatt G. Agreement between mothers and children aged 11-14 years in rating child oral health-related quality of life. Community Dent Oral Epidemiol. 2003; 5:335-43.

51. Ferreira MC, Goursand D, Bendo CB, Ramos-Jorge ML, Pordeus IA, Paiva SM. Agreement of oral health-related quality of life. Brazilian Oral Research. 2012;26:112-118.

52. Eiser C, Morse R. Can parents rate their child's health-related quality of life? Results of a systematic review. Qual Life Res. 2001;10(4):347-57.

53. Paula JS, Leite IC, Aimeida AB, Ambrosano GM, Pereira AC, Mialhe FL. The influence of oral health conditions, socioeconomic status and home environment factors on schoolchildren's self-perception of quality of life. Health Qual Life Outcomes. 2012;10:6.

54. Ray J, Bowman UW, Bodin L, Berggren U, Lichtenstein P, Broberg AG. Heritability Of Dental Fear. JDR. 2010;89:297-301.

55. Carrillo-Diaz M, Crego A, Romero-Maroto M. The influence of gender on the 
relationship between dental anxiety and oral health-related emotional well being. Int J Paediatr Dent. 2012. doi: 10.1111/j.1365-263X.2012.1242.x.

56. Barbosa T, Castelo P, Leme M, Gaviao M. Associations between oral health-related quality of life and emotional statuses in children and preadolescents. Oral Dis. 2012. doi: 10.1111/j.1601-0825.2012.012914.x.

57. Brogardh-Roth S, Stjerngvist K, Matsson L, Klingberg G. Dental fear and anxiety And oral health behavior in 12-14 year-olds born preterm. Int J Paediatr Dent. 2010;20:391-399.

\section{Chapter 3 References}

1. Groft JN, Hagen B, Miller NK, Cooper N, Brown S. Adolescent health: a rural community's approach. Rural and Remote Health. 2005;5:336.

2. Diclemente RJ, Santelli JS, Crosby RA, editors. Adolescent Health: Understanding and Preventing Risk Behaviors. San Francisco; John Wiley and Sons: 2009.

3. Steinberg L, Gardner M. Peer influence on risk taking, risk preference, and risky decision making in adolescence and adulthood: an experimental study. 2005;41:625-635.

4. Greene K, Krcmar M, Walters LH, Rubin DL, Hale J, Hale L. Targeting adolescent risk-taking behaviors: the contribution of egocentrism on sensation seeking. J Adolescence. 2000;23:439-461.

5. Carroll ST, Riffenburgh RH, Roberts TA, Myhre EB. Tattoos and body piercings as indicators of adolescent risk-taking behaviors. Pediatrics. 2002;109:1021-1027.

6. Steinberg L. A social neuroscience perspective on adolescent risk-taking. Dev Rev. 2008;28:78-106.

7. Swallen KC, Reither EN, Haas SA, Meier AM. Overweight, obesity, and health-related quality of life among adolescents: The national longitudinal study of adolescent health. Pediatrics. 2005;115:340-347.

8. Ludwid DS, Peterson KE, Gortmaker SL. Relation between consumption of sugar-sweetened drinks and childhood obesity: a prospective, observational analysis. Lancet. 2001;357:505-508.

9. Goodman E, Slap GB, Huang B. The Public Health Impact of Socioeconomic Status on Adolescent Depression and Obesity. American Journal of Public Health. 2003;93:1844-850.

10. Novak G, Pelaez M. Childhood and adolescent development: A behavioral systems approach. Thousand Oaks, CA: Sage; 2004.

11. America's Families and Living Arrangements:2010. Census Bureau News. Available at

http://www.prnewswire.com/news-releases/census-bureau-news----americas-families-andliving-arrangements-2010-107041258.html

12. Ostberg AL, Lindblad U, Halling A. Self-perceived oral health in adolescents associated with family characteristics and parental employment status. Community Dent Health. 2003;20:159-64.

13. Peres MA, Peres KG, de Barros AJD, Victora CG. The relation between family socioeconomic trajectories from childhood to adolescence and dental caries and associated oral behaviours. J Epidemiol Community Health. 2007;61:141-145. 
14. Clark SJ, Savitz LA, Randolph RK. Rural children's health. West J Med. 2001; 174:142-147.

15. Polk DE, Weyant RJ, Manz MC. Socioeconomic factors in adolescents' oral health: Are they mediated by oral hygiene behavior or preventive intervention? Community Dent Oral Epidemiol. 2010;38:1-9.

16. Vargas CM, Crall JJ, Schneider DA. Sociodemographic distribution of pediatric dental caries: NHANES III, 1988-1994. JADA. 1998;129:1229-38.

17. National Center for Health Statistics, Centers for Disease Control and Prevention. Data source: The First National Health and Nutrition Examination Survey (NHANES 1) 1971-1975, and the Third National Health and Nutrition Examination (NHANES III) 1988-1994.

Available at: http://drc.hhs.gov/report/dqs_tables/pdf/Table1_3_1.pdf.

18. Dental Caries (Tooth Decay) in Adolescents (Age 12 to 19). National Institute of Dental and Craniofacial Research. Available at: http//www.nidcr.nih.gov/ DataStatistics/FindDataByTopic/DentalCaries/DentalCariesAdolescents12to19.

19. Okulla I, Astrom AN, Haugejorden O, Rwenyonyi CM. Variation in caries experience and sugar intake among secondary school students in urban and rural Uganda. Acta Odontologica Scandinavia. 2003;61:197-202.

20. Mandal KP, Tewari AB, Chawla HS, Gauba KD. Prevalence and severity of dental caries and treatment needs among population in the Eastern States of India. J Indian Soc Pedod Prev Dent. 2001;19:85-91.

21. Glasser M, Holt N, Hall K, Mueller B, Norem J, Pickering J, Brown, K, Peters K. Meeting the Needs of Rural Populations Through Interdisciplinary Partnerships. Fam Community Health. 2003;26:230-245.

22. Vargas CM, Ronzio CR, Hayes KL. Oral Health Status of Children and Adolescents by Rural Residence, United States. Journal of Rural Health. 2003;19:260-268.

23. Woods CR, Arcuray TA, Powers JM, Preisser JS, Gesler WM. Results from the Mountain Accessibility Project Survey Determinants of Health Care Use by Children in Rural Western North Carolina. Pediatrics. 20003;112:143-153.

24. Appalachian Regional Commission. Available at: http://www.arc.gov/appalachian_region/The AppalachianRegion.asp.

25. Martin CA, McNeil DW, Crout RJ, Ngan PW, Weyant RJ, Heady H, Marazita ML. Oral health disparities in Appalachia: Orthodontic treatment need and demand. JADA. 2008;139:598-604.

26. County Economic Status and Distressed Areas in Appalachia. Appalachian Regional Commission Available at: http://www.arc.gov/images/appregion/economic_status FY2012/CountyEconomicStatusand DistressAreasFY2012Pennsylvania.pdf.

27. Polk DE, Weyant RJ, Crout RJ, McNeil DW, Tarter RE, Thomas JG, Marazita ML. Study protocol of the Center for Oral Health Research in Appalachia (COHRA) etiology study. BMJ Oral Health. 2008;8:18.

28. Vieiral AR, Marazita ML, Goldstein-McHenry T. Genome-wide scan finds suggestive caries loci. JDR;87:435-439.

29. Petersen PE, Bourgeois D, Ogawa H, Estupinan-Day S, Ndiaye C. The global burden of oral diseases and risks to oral health. Bull World Health Organ. 
2005;83:661-669.

30. Kleinknect R, Klepac R, Alexander LD. Origins and characteristics of fear of Dentistry. JDR 1973;86:842-848.

31. Kleinknect R, Thorndike RM, McGlynn FD, Harkavy J. Analysis of the dental fear survey with cross-validation. JADA. 1984;108:59-61.

32. McGlynn FD, McNeil DW, Gallagher SL, Vrana S. Factor structure, stability, and internal consistency of the dental fear survey. Behavioral Assessment. 1987; 9:57-66.

33. Smith T, Moore RA. Repression of dental anxiety. JDR. 1995;74:144.

34. Wilson JF, Sinisko SA. Increased self-reported dental anxiety following completion of a dental history questionnaire. Psychological Reports. 1997;81:59-62.

35. McNeil DW, Rainwater AJ. Development of the fear of pain questionnaire-III. Journal of Behavioral Medicine. 1998;21:389-410.

36. Osman A, Breitenstein JL, Barrios FX, Guiterrez PM, Kopper BA. The fear of pain questionnaire-III: Further reliability and validity with nonclinical samples. Journal of Behavioral Medicine. 2001;25:155-173.

37. Roelofs J, Peters ML, Deutz J, Spijker C, Vlaeyen JW. The fear of pain questionnaire (FPQ): Further psychometric examination in a non-clinical sample. Pain. 2005;116: 339-346.

38. Hamissi J, Hamissi H, Ghoudosi A, Gholami S. Factors affecting dental anxiety and beliefs in an Iranian population. International Journal of Collaborative Research on Internal Medicine \& Public Health. 2012;5:585-593.

39. McNeil DW, Crout RJ, Lawrence SM, Shah P, Rupert N. Oral health values in Appalachia: Specific dental-related fatalism? JDR. 2004;83:A-203 [Abstract].

40. McNeil DW. Dental Fear Survey; Fatalism Scale;. COHRA Instrumentation. 2007. www.dental.pitt.edu/Instrumentation\%20Checklist\%20(6).doc.

41. Cuellar I, Arnold B, Gonzalez G. Cognitive referents of acculturation: Assessment of cultural constructs in Mexican Americans. Journal of Community Psychology. 1995;23:339-356.

42. Woolf SH, Johnson RE, Phillips RL Jr, Philipsen M. Giving Everyone the Health: Of the Educated: An Examination of Whether Social Change Would Save More Lives Than Medical Advances. American Journal of Public Health. 2007;97: 679-683.

43. Krieger N. Theories for social epidemiology in the 21st century: an ecosocial perspective. International Journal of Epidemiology 2001;30:668-677.

44. Blackwell DL. Family structure and children's health in the United States: Findings from the National Health Interview Survey 2001-2007. Vital Health Stat. 2010, series 10 (246);1-166.

45. Kumar S, Goyal A, Tadakamadla J, Tibdewal H, Duraiswamy P, Kulkarni S. Oral health related quality of life among children with parents and those with no parents. Comm Dent Health. 2011;3:227-231.

46. Brukiene V, Aleksejuniene J. Is the authoritative parenting model effective in changing oral hygiene behavior in adolescents? Health Educ Research. 2012. Available at: http://her.oxfordjournals.org/content/early/2012/06/21/her.cys074.short.

47. Levin KA, Currie C. Adolescent toothbrushing and the home environment 
sociodemographic factors, family relationships and mealtime routines and disorganization. Community Dent Oral Epidemiol. 2010;38:10-18.

48. Wallander JL, Schmitt M, Koot HM. Quality of life measurement in children and adolescents: issues, instruments, and applications. J Clin Psychol. 2001;57:571-585.

49. Bernabe E, Stansfeld SA, Marcenes W. Roles of different sources of social support on caries experience and caries increment in adolescents in East London. Caries Research. 2011;45:400-407.

50. McKenzie JF, Pinger RR, Kotecki JE. An Introduction to Community Health, $7^{\text {th }}$ edition. Sudbury, MA: Jones and Bartlett Learning;2012.

51. Brukiene V, Aleksejuniene J. Theory-based oral health education in adolescents. Stomatologija, Baltic Dental and Maxilofacial Journal. 2010;12:3-9.

52. Kawamura M, Takase N, Sasahara H, Okada M. Teenagers' oral health attitudes and behavior in Japan: Comparison by sex and age group. Journal of Oral Science. 2008;50:167-174.

53. Taani DQ, El-Qaderi SS, Alhaija ESJ. Dental anxiety in children and its relationship to dental care and gingival condition. International Journal of Dental Hygiene. 2005;3:83-87.

54. Kruger E, Thomson WM, Poulton R, Davies S, Brown RH, Silva PA. Dental caries and changes in dental anxiety in late adolescence. Community Dentistry and Oral Epidemiology. 1998;26:355-359.

55. Milgrom $P$, Vingnehsa $H$, Weinstein P. Adolescent fear and control: Prevalence and theoretical implications. Behaviour Research and Therapy. 1992;30:367-273.

56. Wilson JH. Report about the status of dental health-West Virginia. WV Dent J. 1985;59:20-21.

57. Centers for Disease Control and Prevention Oral Health Resources: State Profiles, CDC Water Fluoridation Reporting System. Available at: http://apps.nccd.cdc.gov/nohss/statemap.asp.

58. McNeil DW, Crout RJ, Marazita ML. "Chapter 13. Oral Health" in Appalachian Health and Well-Being. Ludke RL, Obermiller PJ, editors. Lexington, KY: University Press of Kentucky;2012.

\section{Chapter 4 References}

1. Anderson M. Risk assessment and epidemiology of dental caries: review of the literature. Pediatric Dentistry. 2002;24:377-385.

2. Oral Health-2010 Behavioral Risk Factor Surveillance System. CDC Division of Oral Health Promotion, Atlanta, GA. Available at: http://apps.nccd.cdc.gov/brfss/page.asp?cat=OH\&yr=2010\&state=UB\#OH

3. Oral Health for Adults. CDC Division of Oral Health National Center for Chronic Disease Prevention and Health Promotion, Atlanta, GA 2006. Available at: http://www.cdc.gov/oralhealth/publications/factsheets/adult.htm.

4. Bretz WA, Weyant RJ, Corby PM, Ren D, Weissfeld L, Kritchevsky SB, Harris T, Kurella M, Satterfield S, Visser M, Newman AB. Systemic Inflammatory Markers, Periodontal Disease, and Periodontal Infections in an Elderly Population. JAGS. 2005;53:1532-1537.

5. Vargas CM, Yellowitz JA, Hayes KL. Oral health status of older rural adults 
in the United States. J Am Dent Assoc. 2003;134:479-486.

6. U.S. Department of Health and Human Services, Centers for Disease Control. Behavioral Risk Factor Surveillance System. Prevalence and Trends: Demographics 2009. Available at: http://apps.nccd.cdc.gov/brfss/list.asp?cat=DE\&yr=2009\&qkey=187\&state=All.

7. U.S. Census Bureau. 2010. Available at: http://fcatfinder2.census.gov/faces/tableservices/jsf/pages/productview.xhtml?pid=PEP 2008GCTT02R.US01PR\&prodType=table.

8. National Oral Health Surveillance System, 2008 BRFSS. CDC. Available at: http://apps.nccd.cdc.gov/nohss/ListV.asp?qkey=7\&DataSet=2.

9. Shah N, Sundaram KR. Impact of socio-demographic variables, oral hygiene practices, oral habits and diet on dental caries experience of Indian elderly: a community-based study. Gerontology. 2004;21:43-50.

10. Steele JG, Ayatollahi SMT, Walls AWG, Murray JJ. Clinical factors related to reported satisfaction with oral function amongst dentate older adults in England. Community Dent Oral Epidemiol. 1997;25:143-149.

11. Joshipura KJ, Hung H, Rimm EB, Willett WC, Ascherio A. Periodontal disease, tooth loss and incidence of ischemic stroke. Stroke. 2003;34:47.

12. Abnet C, Qiao Y, Dawsey SM, Dong Z, Taylor PR, Mark SD. Tooth loss is associated with increased risk of total death and death from upper gastrointestinal cancer, heart disease, and stroke in a Chinese population-based cohort. International Journal of Epidemiology. 2005;34:467-474.

13. Moynihan P, Petersen PE. Diet, Nutrition, and the Prevention of Dental Disease. Public Health Nutrtion. 2004; 7:201-226.

14. Lee JS, Weyant RJ, Corby P, Kritchevsky SB, Harris TB, Rooks R, Rubin SM, Newman AB. Edentulism and nutritional status in a biracial sample of well-functioning, community-dwelling elderly: the Health, Aging, and Body Composition Study. Am J Clin Nutr. 2004;79:295-302.

15. Hung H, Willett W, Ascherio A, Rosner E, Rim E, Joshipura K. Tooth loss and dietary intake. JADA. 2003;134:1185-92.

16. Steele JG, Sanders AE, Glade GD, Allen PF, Lahti S, Nuttall N, Spencer AJ. How do age and tooth loss affect quality of life? Community Dentistry and Oral Epidemiology. 2004;32:107.

17. Oral Health: preventing cavities, gum disease, tooth loss, and oral cancer. CDC 2010. Available at:

//www.cdc.gov/chronicdisease/resources/publications/aag/pdf/2010/oral_health_aag.pdf.

18. Krieger N. The ostrich, the albatross, and public health: An ecosocial persectiveor Why an explicit focus on health consequences of discrimination and deprivation is vital for good science and public health practice. Public Health Reports. 2001;16:419-421.

19. Klein BE, Klein R, Knudtson MD. Life-style correlates of tooth loss in an adult Midwestern Population. Journal of Public Health Dentistry. 2004;64:145-149.

20. Listl S. Income-related inequalities in dental service utilization by Europeans aged 50+. J Dent Res. 2011;90:717-723.

21. Bernabe E. Marcenes W. Income inequality and tooth loss in the United States. J Dent Res. 2011;90:724-729. 
22. Glasser M, Holt N, Hall K, Mueller B, Norem J, Pickering J, Brown, K, Peters K. Meeting the Needs of Rural Populations Through Interdisciplinary Partnerships. Fam Community Health. 2003;26:230-245.

23. Heathy People 2020 Disparities. Available at: http://www.healthypeople.gov/2020/about/DisparitiesAbout.aspx.

24. Rockett IRH, Wand S, Stack S, DeLeo D, Frost JL, Ducatman AM, Walker RL, Kapusta ND. Race/ethnicity and potential suicide misclassification: window on a minority suicide paradox? BMC Psychiatry. 2010;10:35.

25. Fitzpatrick, Joyce J and Stevenson Joanne S, editors. Annual Review of Nursing Research: Focus on Significant Clinical Issues. New York:Springer Publishing Company, 1994. Available at: http://books.google.com/books?hl=en\&lr=\&id=9YLKNIXuhg4C\&oi=fnd $\& p g=$ PA65\&dq=edentulism+rural+south+dakota\&ots=zivdlubCrM \&sig=4VbXLs50YxbwdF12tWgPaeO3uoc\#v=onepage \&q\&f=false].

26. The Appalachian Region. Appalachian Regional Commission. Available at: http://www.arc.gov/appalachian_region/TheAppalachianRegion.asp.

27. Healthy People 2010: 21 Oral Health. CDC Atlanta, GA. Available at: http://www.healthypeople.gov/Document/HTML/Volume2/21Oral.htm.

28. Polk DE, Weyant RJ, Crout RJ, McNeil DW, Tarter RE, Thomas JG, Marazita ML. Study protocol of the Center for Oral Health Research in Appalachia (COHRA) etiology study. BMJ Oral Health. 2008;8:18.

29. Vieiral AR, Marazita ML, Goldstein-McHenry T. Genome-wide scan finds suggestive caries loci. JDR;87:435-439.

30. Petersen PE, Bourgeois D, Ogawa H, Estupinan-Day S, Ndiaye C. The global burden of oral diseases and risks to oral health. Bull World Health Organ. 2005;83:661-669.

31. Kleinknect R, Klepac R, Alexander LD. Origins and characteristics of fear of Dentistry. JDR 1973;86:842-848.

32. Kleinknect R, Thorndike RM, McGlynn FD, Harkavy J. Analysis of the dental fear survey with cross-validation. JADA. 1984;108:59-61.

33. McGlynn FD, McNeil DW, Gallagher SL, Vrana S. Factor structure, stability, and internal consistency of the dental fear survey. Behavioral Assessment. 1987; 9:57-66.

34. Smith T, Moore RA. Repression of dental anxiety. JDR. 1995;74:144.

35. Wilson JF, Sinisko SA. Increased self-reported dental anxiety following completion of a dental history questionnaire. Psychological Reports. 1997;81:59-62.

36. McNeil DW, Rainwater AJ. Development of the fear of pain questionnaire-III. Journal of Behavioral Medicine. 1998;21:389-410.

37. Osman A, Breitenstein JL, Barrios FX, Guiterrez PM, Kopper BA. The fear of pain questionnaire-III: Further reliability and validity with nonclinical samples. Journal of Behavioral Medicine. 2001;25:155-173.

38. Roelofs J, Peters ML, Deutz J, Spijker C, Vlaeyen JW. The fear of pain questionnaire (FPQ): Further psychometric examination in a non-clinical sample. Pain. 2005;116: 339-346.

39. Hamissi J, Hamissi H, Ghoudosi A, Gholami S. Factors affecting dental anxiety and beliefs in an Iranian population. International Journal of Collaborative 
Research on Internal Medicine \& Public Health. 2012;5:585-593.

40. McNeil DW, Crout RJ, Lawrence SM, Shah P, Rupert N. Oral health values in Appalachia: Specific dental-related fatalism? JDR. 2004;83:A-203 [Abstract].

41. McNeil DW. Dental Fear Survey; Fatalism Scale;. COHRA Instrumentation. 2007. www.dental.pitt.edu/Instrumentation\%20Checklist\%20(6).doc.

42. Cuellar I, Arnold B, Gonzalez G. Cognitive referents of acculturation: Assessment of cultural constructs in Mexican Americans. Journal of Community Psychology. 1995;23:339-356.

43. Jayson S. Nearly 4 in 10 women have never married. USA Today. March 22, 2011;22;1.

44. Schuller AA, Willumsen T, Holst D. Are there differences in oral health behavior between individuals with high and low dental fear? Community Dent Oral Epidemiol. 2003;31:116-121.

45. Smith TA, Heaton LJ. Fear of dental care: are we making any progress? JADA. 2003;134:1101-1108.

46. Armfield JM. Slade GD, Spencer AJ. Dental fear and adult oral health in Australia. Community Dent Oral Epidemiol. 2009;37:220-230.

47. Armfield JM, Slade GD, Spencer AJ. Are people with dental fear under-represented in oral epidemiological surveys? Soc Psychiatry Psychiatr Epidemiol. 2009;44:495-500.

48. Heft MW, Meng X, Bradley MM, Lang PJ. Gender differences in reported dental fear and fear of dental pain. Community Dent Oral Epidemiol. 2007;35:421-428.

49. Berggren U, Meynert G. Dental Fear and avoidance: causes, symptoms, and Consequences. JADA. 1984:109;247-251.

50. Oosterink FM, deJongh A, Hoogstraten J. Prevalence of dental fear and phobia relative to other fear and phobia subtypes. Eur J Oral Sci. 2009;117:135-143.

51. Binkley CJ, Beacham A, Neace W, Gregg RG, Liem EB, Sessler DI. Genetic variations associated with red hair color and fear of dental pain, anxiety regarding dental care. JADA. 2009;140:896-905.

52. deJongh A, Olff M, van Hoolwerft H, Aartman IHA, Broekman B. Anxiety and post-traumatic stress symptoms following wisdom tooth removal. Behav Res Ther. 2008;46:1305-1310.

53. Breslau N, Anthony JC. Gender differences in the sensitivity to posttraumatic stress disorder: an epidemiological study of urban young adults. Journal of Abnormal Psychology. 2007;116:607-611.

54. McNeil DW, Heifer AJ, Weaver BD, Graves RW, Kyle BN, Davis AM. Memory of Pain and Anxiety Associated with Tooth Extraction. JDR. 2011;90:220-224.

55. Coyne CA, Demain-Popescu C. Social and Cultural Factors Influencing Health in Southern West Virginia: A Qualitative Study. Prev Chronic Dis. 2006;3:A124.

56. Drew EM, Schoenberg NE. Deconstructing Fatalism: Ethnographic Perspectives on Women's Decision Making about Cancer Prevention and Treatment. Med Anthropol Q. 2011;25:164-182.

57. Wu B, Liang J, Plassman BL, Remle RC, Bai L. Oral health among white, black, and Mexican-American elders: an examination of edentulism and dental caries. Journal of Public Health Dentistry. 2011;71:308-317. 
58. Holst D, Schuller AA. Oral Health in a life-course: birth cohorts from 1929-2006 Norway. Community Dent Health. 2012;29:134-143.

59. Mamai Homata E, Topitsoglu V, Oulis C, Margaritis V, Polychronopoulou A. Risk indicators of coronal and root caries in Greek middle aged adults and senior citizens. BMC Public Health. 2012;12:484.

60. Houshmand M, Holtfreter B, Berg MH, Schwahn C, Meisel P, Biffar R, Kindler S, Kocher T. Refining definitions of periodontal disease and caries for prediction models of incident tooth loss. Journal of Clinical Periodontology. 2012;39:635-644.

61. Kotzer RD, Lawrence HP, Clovis JB, Matthews DC. Oral health-related quality of life in an aging Canadian population. Health and Quality of Life Outcomes. 2012;10:50.

\section{Chapter 5 References}

1. Petersen PE, Bourgeois D, Ogawa H, Estupinan-Day S, Ndiaye C. The global burden of oral diseases and risks to oral health. Bull World Health Organ. 2005;83:12 screens. Available at: www.scielosp.org/scielo.php?pid+S0042-96862005000900011\&script=sci_arttext\&lng=pt

2. Edelstein, B. L. (2006) The dental caries pandemic and disparities problems. BMC Oral Health, 2006;6(Suppl. 1):S2.

3. Krieger, Nancy. Epidemiology and the People's Health. New York: Oxford, 2011.

4. Baelum V. Periodontal epidemiology: towards social science or molecular biology? Community Dentistry and Oral Epidemiology. 2004;32:239-249.

5. U. S. Census Bureau State and County Quick Facts. 2010. Available at http://quickfacts.census.gov/qfd/states/54000.html.

6. State of West Virginia Needs Assessment Summary. West Virginia Department of Health and Human Services. 2011. Available at http://www.wvdhhr.org/mcfh/blockgrant/Block_Needs_Assessment_Summary_2010.pdf.

7. United States Department of Labor Bureau of Statistics. Available at: http://www.bls.gov/eag/eag.pa.htm.

8. Fishlock D. Number of adults without health insurance is rising in Pennsylvania. The Patriot News. 10.4.2010.

9. Hendryx M, Ahern MM. Relations Between Health Indicators and Residential Proximity to Coal Mining in West Virginia. American Journal of Public Health. 2008;98:669-671.

10. Hendryx M, O’Donnell KO, Horn K. Lung Cancer Mortality is Elevated in Coal Mining Areas of Appalachia. Lung Cancer. 2008;62:1-7.

11. Hendryx M, Ahern MM. Mortality in Appalachian Coal Mining Regions: The Value of Statistical Life Lost. Public Health Rep. 2009;124:541-550.

12. Hendryx M. Mortality from heart, respiratory, and kidney disease in coal mining areas of Appalachia. Int Arch Occup Environ Health. 2009;82:243-249.

13. Hendryx M, Zullig KJ. Higher coronary heart disease and heart attack morbidity in Appalachian coal mining regions. Preventive Medicine. 2009;49:355-359.

14. Hendryx M, Ahern MM, Nurkiewicz TR. Hospitalization Patterns Associated with Appalachian Coal Mining. Journal of Toxicology and 
Environmental Health. 2007;2064-2070.

15. Hendryx M, Fedorko E, Anesetti-Rothermel A. A geographical information system-based analysis of cancer mortality and population exposure to coal mining activities inWest Virginia, United States of America. Geospatial Health. 2010;4:243-256.

16. Palmer MA, Bernhardt ES, Schlesinger WH, Eshleman KN, Foufoula-Georgiou E, Hendryx M, Lemly AD, Likens GE, Loucks OL, Power ME, White PS, Wilcock PR. Mountaintop Mining Consequences. Science. 2010;327:148-149.

17. Lewis RL. Transforming the Appalachian Countryside. University of North Carolina Press, 1998.

18. Yamada S, Palmer W. An Ecosocial Approach to the Epidemic of Cholera in the Marshall Islands. Social Medicine. 2007;2:79-85.

19. Capehart T. Trends in U.S. Tobacco Farming. USDA. 2004. Available at: http://m.usda.mannlib.cornell.edu/usda/ers/TBS/2000s/2004/TBS-11-082004_Special_Report.pdf.

20. Commonwealth Foundation Joins Farmers in Fight Against Higher Taxes. 2009 news release. Available at: http://www.commonwealthfoundation.org/research/detail/commonwealthfoundation-joins-farmers-in-fight-against-higher-taxes

21. McClave A, Rock V, Thorne S, Malarcher A. State-Specific Prevalence of Cigarette Smoking and Smokeless Tobacco Use Among Adults-United States, 2009 (Centers for Disease Control). JAMA. 2011:305:143-146.

22. Campaign for tobacco-free kids. Toll of tobacco in the United States: West Virginia. Available at: http://www.tobaccofreekids.org/facts_issues/toll_us/west_virginia

23. Prevalence and Trends Data. Centers for Disease Control and Prevention Behavioral Risk Factor Surveillance. Available at: http://apps.nccd.cdc.gov/BRFSS/display.asp?cat=TU\&yr=2010\&qkey=4396\&state=PA

24. Campaign for tobacco-free kids. Toll of tobacco in the United States:

Pennsylvania. Available at:

http://www.tobaccofreekids.org/facts_issues/toll_us/pennsylvania

25. U. S. Census Bureau, Population Division. Current Population Survey (CPS)

Definitions and Explanations. 2011 Available at: http://www.census.gov/population/www/cps/cpsdef.html.

26. McKenzie JF, Pinger RR, Kotecki JE. An Introduction to Community Health. $7^{\text {th }}$ ed. Sudbury, MA: Jones and Bartlett Learning; 2012.

27. Plutzer K, Keirse MJNC. Incidence and prevention of early childhood caries in one- and two-parent families. Child Care Health and Development. 2011;37:5-10.

28. Covey LS, Tam D. Depressive Mood, the Single-Parent Home, and Adolescent Cigarette Smoking. Am J Public Health. 1990; 80:1330-1333.

29. Deleire T, Kalil A. Good Things Come in Threes: Single-Parent Multigenerational Family Structure and Adolescent Adjustment. Demography. 2002;39:393-413.

30. Diclemente RJ, Santelli JS, Crosby RA, editors. Adolescent Health: Understanding and Preventing Risk Behaviors. San Francisco; John Wiley and Sons: 2009.

31. McNeil DW, Crout RJ, Marazita. Oral Health. In: Ludke RL, Obermiller 
JP, editors. Appalachian Health and Well-Being. Lexington, KY: University of Kentucky Press; 2012. p .275-289.

32. Chubinski J, Carrozza MA. Obesity and Food Insecurity. In: Ludke RL, Obermiller JP, editors. Appalachian Health and Well-Being. Lexington, KY: University of Kentucky Press; 2012. p .149-166.

33. Dunn MS. Behringer BA, Bowers KH. Substance Abuse. In: Ludke RL, Obermiller JP, editors. Appalachian Health and Well-Being. Lexington, KY: University of Kentucky Press; 2012. p .251-274.

34. McNeil DW. Even the most sophisticated oral health interventions and Technologies are of no help unless people accept and use them. Journal of Public Health Dentistry. 2011;71:S81. 


\section{Chapter 2: Table 1}

\section{Parent-reported Oral Health Status in Children aged 1-17 years}

\begin{tabular}{|c|c|c|c|}
\hline \multirow{2}{*}{$\begin{array}{l}\text { Child's condition of teeth or oral health } \\
\text { in past } 6 \text { months }\end{array}$} & Pennsylvania & West Virginia & National \\
\hline & $\mathrm{n}$ (weighted \%) & ) $\mathrm{n}$ (weighted\%) & $\mathrm{n}($ weighted \%) \\
\hline Fair/poor overall & $108(7.4)$ & $78(5.1)$ & $4,984(8.4)$ \\
\hline 1 oral health problem & 290 (19.6) & $292(17.4)$ & $14,969(18.3)$ \\
\hline $2+$ oral health problems & $118(6.8)$ & $25(7.9)$ & $6,163(8.4)$ \\
\hline
\end{tabular}

Data Source: National Survey of Children's Health. NSCH 2007. Child and Adolescent Health Measurement Initiative, Data Resource Center for Child and Adolescent Health website. : www.nschdata.org]. 
Chapter 2: Table $2 \quad$ Descriptive Characteristics Children Ages 11-13 years

Genetic Factors Contributing to Oral Health Disparities in Appalachia, 2002-2009, N = 237

Sample N (\% or standard deviation)

\begin{tabular}{llcc}
\hline Gender & & & \\
& Males & 117 & $(49.6 \%)$ \\
& Females & 119 & $(50.4 \%)$ \\
& Missing 1 & & \\
Age & & & \\
& 11 & & \\
12 & 76 & $(32.1 \%)$ \\
& 13 & 75 & $(31.7 \%)$ \\
& Mean & 86 & $(36.3 \%)$ \\
& & 12.04 & $( \pm .83)$ \\
Race/Ethnicity & & \\
White & & \\
Black & 194 & $(82.2 \%)$ \\
Other & 34 & $(14.4 \%)$ \\
Missing 1 & 8 & $(3.4 \%)$ \\
& & &
\end{tabular}

Site

$\begin{array}{lrr}\text { Pennsylvania } & 83 & (35.0 \%) \\ \text { West Virginia } & 154 & (65.0 \%)\end{array}$

Family Income

$\begin{array}{lrr}\text { Less than } \$ 10,000 & 49 & (22.5 \%) \\ \$ 10,000-\$ 14,999 & 29 & (13.3 \%) \\ \$ 15,000-\$ 24,999 & 31 & (14.2 \%) \\ \$ 25,000-\$ 34,999 & 30 & (13.8 \%) \\ \$ 35,000-\$ 49,999 & 32 & (14.7 \%) \\ \$ 50,000-\$ 74,999 & 23 & (10.6 \%) \\ \$ 75,000-\$ 99,999 & 11 & (5.0 \%) \\ \$ 100,000-\$ 149,999 & 5 & (2.3 \%) \\ \$ 150,000-\text { and above } & 8 & (3.7 \%)\end{array}$

Highest education in the family

$\begin{array}{lll}\text { Less than High School } & 12 & (5.3 \%) \\ \text { High School degree } & 87 & (38.2 \%) \\ \text { Technical School degree } & 49 & (21.5 \%) \\ \text { Some College } & 30 & (13.2 \%) \\ \text { Undergraduate degree } & 34 & (14.9 \%) \\ \text { Graduate degree } & 16 & (7.0 \%)\end{array}$

Missing 9

Continued 
Chapter 2: Table $2 \quad$ Descriptive Characteristics Children Ages 11-13 years

Genetic Factors Contributing to Oral Health Disparities in Appalachia, 2002-2009, N = 237

Sample N (\% or standard deviation)

Family Relationships to index person

First Child

Second Child

$106 \quad(44.7 \%)$

Third Child

$76 \quad(32.1 \%)$

Fourth Child

$30 \quad(12.7 \%)$

First Step Child

$7 \quad(3.0 \%)$

Second Step Child

( $3.0 \%)$

Other

( $1.3 \%)$

( $3.2 \%)$

Body Mass Index

Normal $159 \quad(72.9 \%)$

Overweight $\quad 35 \quad$ (16.1\%)

Obese $24 \quad$ (11.0\%)

Missing 19

Mean

$22.55( \pm 6.39)$

Total Decayed Missing Filled Teeth

$\begin{array}{llr}0 & 80 & (33.8 \%) \\ 1 & 43 & (18.1 \%) \\ 2 & 37 & (15.6 \%) \\ 3 & 15 & (6.3 \%) \\ 4 & 25 & (10.6 \%) \\ 5 & 15 & (6.3 \%) \\ 6 & 22 & (9.3 \%) \\ \text { Mean } & 2.17 & ( \pm .2 .58)\end{array}$

Dental Fear Survey (cut point 33)

Little/no fear $\quad 147 \quad$ (62.0\%)

Some/pretty much/very $\quad 90 \quad$ (38.0\%)

Short Form Fear of Pain Questionnaire (cut point 15)

Little/no fear $47 \quad$ (19.8\%)

Some/pretty much/very $\quad 190 \quad$ (80.2\%)

Fatalism Scale

$\begin{array}{lrr}\text { Low } & 90 & (38.0 \%) \\ \text { High } & 147 & (62.0 \%)\end{array}$


Chapter 2: Table $3 \quad$ Decayed Missing and Filled Teeth Children Ages 11-13 years Genetic Factors Contributing to Oral Health Disparities in Appalachia, 2002-2009

$$
\mathbf{N}=237 \mathrm{~N} \text { (row \%) }
$$

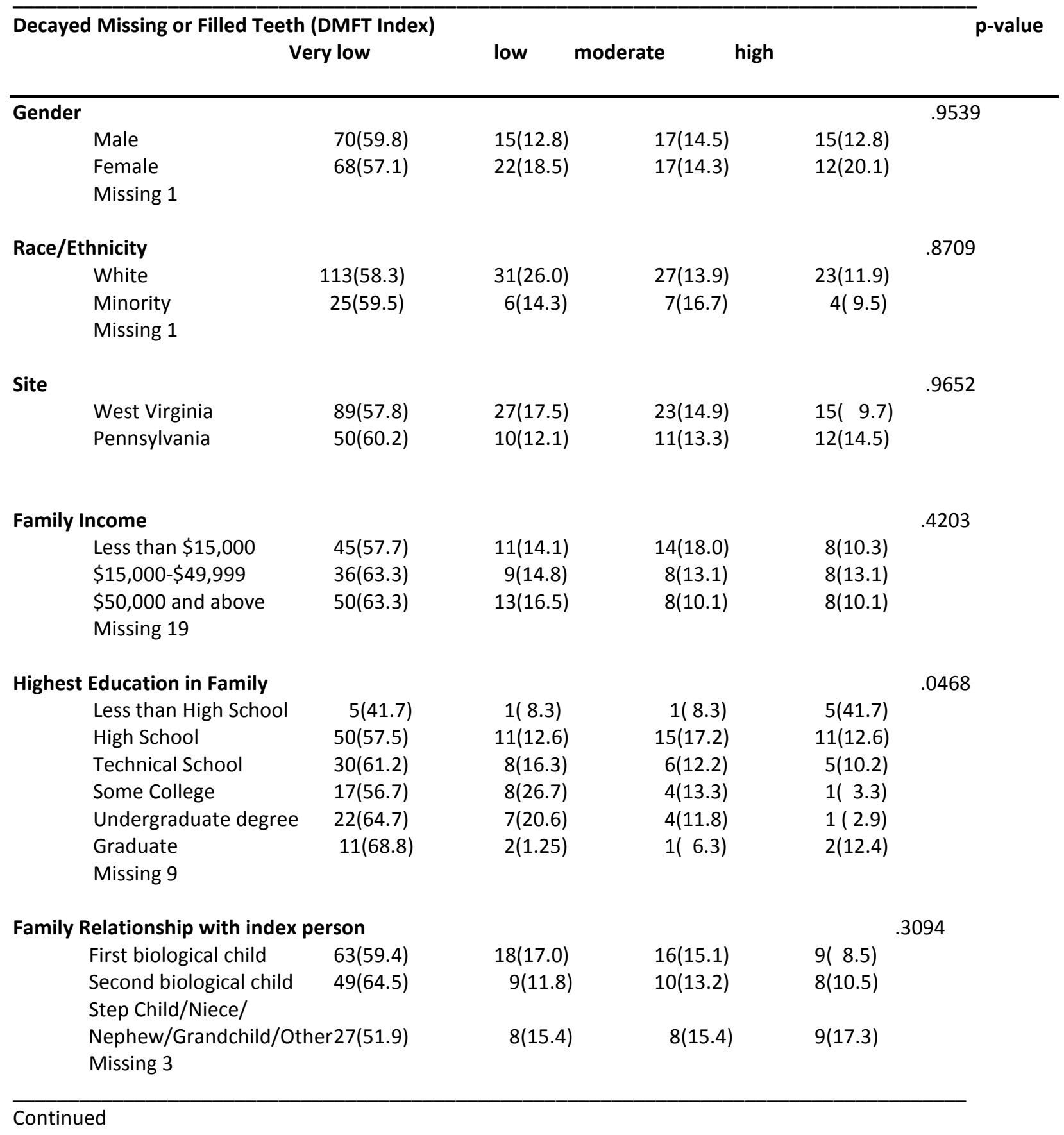


Chapter 2: Table 3

Decayed Missing and Filled Teeth Children Ages 11-13 years

Genetic Factors Contributing to Oral Health Disparities in Appalachia, 2002-2009

$N=237 N$ (row \%)

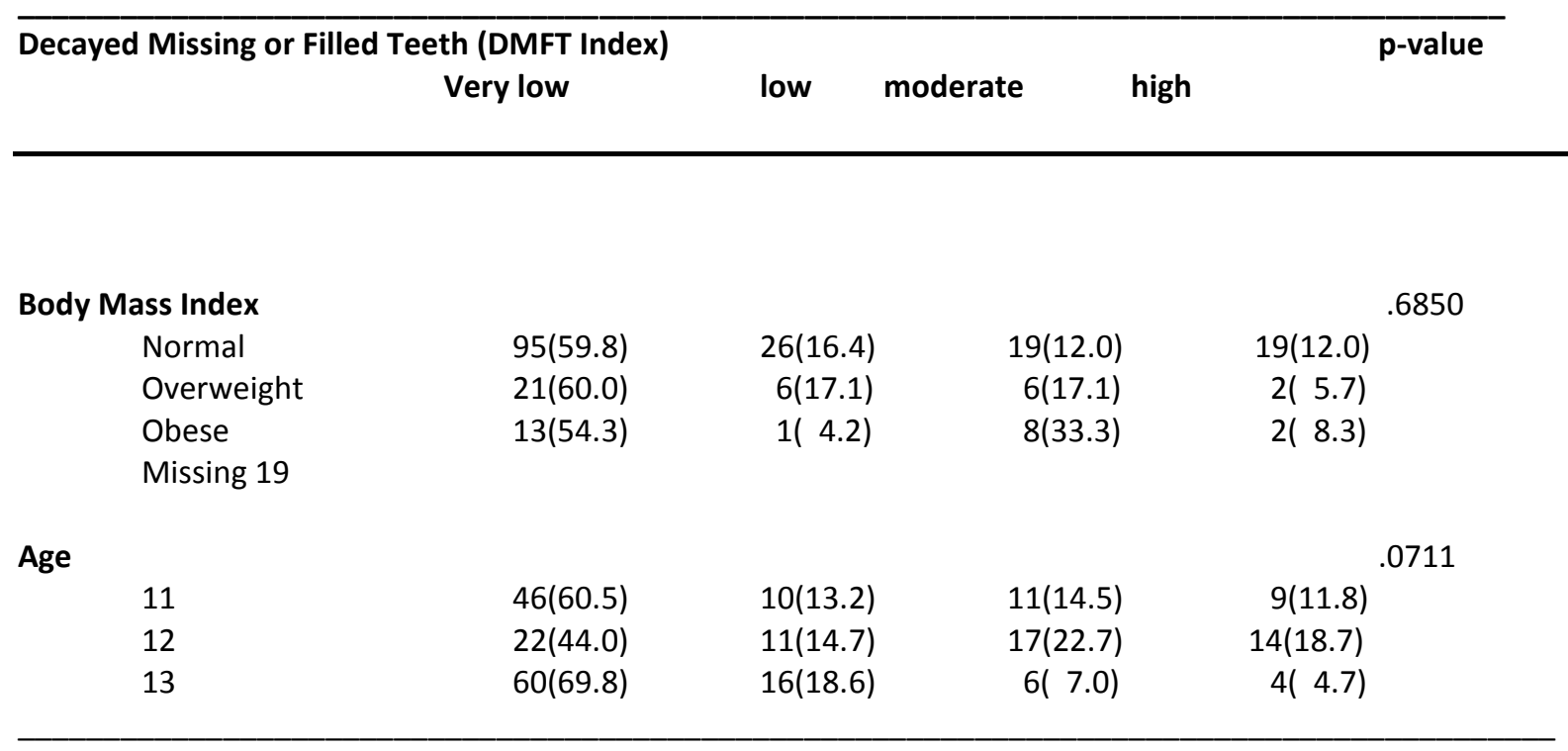

Based on 237 children, ages 11-13 years. Participants did not respond to all questions, so number of participants does not always equal the total number of participants. Cochran-Mantel-Haenzel mean score test was used (with standardized midrank scores) for gender, race/ethnicity, site, family relationship with index person. MantelHaenzel Chi Square (with standardized midrank scores) for family income, highest education in the family, BMI and age.

DMFT Index for $11-12$ years was: very low $=0,1$; low $=2$; moderate $=3,4$; high $=5+$.

DMFT Index for 13 years was: very low $=0-2$; low $=3-5$; moderate $=6-8$; high $=9+$. 
Chapter 2: Table 4

Fatalism and Decayed Missing and Filled Teeth Children Ages 11-13 years

Genetic Factors Contributing to Oral Health Disparities in Appalachia, 2002-2009

$N=237 N$ (row \%)

\begin{tabular}{|c|c|c|c|c|c|}
\hline \multicolumn{5}{|c|}{ Decayed Missing or Filled Teeth (DMFT Index) } & \multirow[t]{2}{*}{ p-value } \\
\hline & very low & low & moderate & high & \\
\hline Fatalism Scale & & & & & .4592 \\
\hline Low & $56(62.2)$ & $13(14.4)$ & $10(11.1)$ & $11(12.2)$ & \\
\hline High & $83(56.5)$ & $24(16.3)$ & $24(16.3)$ & 16(10.9) & \\
\hline
\end{tabular}

Based on 237 children, ages 11-13 years. Participants did not respond to all questions, so number of participants does not always equal the total number of participants.

Mantel-Haenzel Chi Square Exact test was used (with standardized midrank scores).

DMFT Index for 11-12 years was: very low =0,1; low $=2$; moderate $=3,4$; high $=5+$.

DMFT Index for 13 years was: very low $=0-2$; low $=3-5$; moderate $=6-8$; high $=9+$. 
Chapter 2: Table 5 Fear and Decayed Missing and Filled Teeth Children Ages 11-13 years

Genetic Factors Contributing to Oral Health Disparities in Appalachia, 2002-2009

$\mathbf{N}=237 \mathbf{N}$ (row \%)

\begin{tabular}{rrrr}
\hline $\begin{array}{l}\text { Decayed Missing or Filled Teeth } \\
\text { very low }\end{array}$ low & moderate & high \\
\hline
\end{tabular}

\section{Dental Fear Survey}

$\begin{array}{lcccc}\text { Little/no fear } & 83(56.5) & 23(15.7) & 22(15.0) & 19(12.9) \\ \text { Some/pretty much/very } & 56(62.2) & 14(15.6) & 12(13.3) & 8(8.9)\end{array}$

Short Form Fear of Pain Questionnaire

\begin{tabular}{|c|c|c|c|c|}
\hline Little/no fear & $26(55.3)$ & $7(14.9)$ & $6(12.8)$ & $8(17.0)$ \\
\hline Some/pretty much/very & $113(59.5)$ & $30(15.8)$ & $28(14.7)$ & 19(10.0) \\
\hline
\end{tabular}

Based on 237children, ages 11-13 years. Participants did not respond to all questions, so number of participants does not always equal the total number of participants. Exact Cochran-Mantel-Haenzel mean score test was used (with standardized midrank scores).

DMFT Index for $11-12$ years was: very low $=0,1$; low $=2$; moderate $=3,4$; high $=5+$.

DMFT Index for 13 years was: very low $=0-2$; low $=3-5$; moderate $=6-8$; high $=9+$. 
Chapter 2: Table 6 Odds Ratios and Adjusted Odds Ratios for Decayed Missing and Filled Teeth and Family Relationships, Fatalism, and Fear from Generalized Estimating Equations for children 11-13 years

Genetic Factors Contributing to Oral Health Disparities in Appalachia, 2002-2009

\begin{tabular}{|c|c|c|c|}
\hline $\begin{array}{r}\text { Unadj } \\
\text { Singl } \\
{[9} \\
p-1\end{array}$ & $\begin{array}{l}\text { sted OR } \\
\text { variable } \\
\% \mathrm{Cl}] \\
\text { lue }\end{array}$ & $\begin{array}{l}\text { Adjusted OR } \\
\text { full model } \\
{[95 \% \mathrm{CI}]} \\
\text { p-value }\end{array}$ & $\begin{array}{l}\text { Adjusted OR } \\
\text { reduced model } \\
{[95 \% \mathrm{Cl}]} \\
\text { p-value }\end{array}$ \\
\hline \multicolumn{4}{|l|}{ Birth categories } \\
\hline \multirow[t]{2}{*}{ Second biological child vs. First biological child } & $\begin{array}{l}1.03 \\
{[0.53,1.97]}\end{array}$ & $\begin{array}{l}0.99 \\
{[0.42,2.32]}\end{array}$ & $\begin{array}{l}1.22 \\
{[0.56,2.64]}\end{array}$ \\
\hline & .9405 & .9726 & .6223 \\
\hline \multicolumn{4}{|l|}{ Niece/Nephew/Step-/Grandchild/Other vs. } \\
\hline \multirow[t]{3}{*}{ First biological child } & 1.61 & 2.10 & 2.08 \\
\hline & {$[0.78,3.32]$} & {$[0.79,5.54]$} & {$[0.91,4.74]$} \\
\hline & .1941 & .1359 & .0817 \\
\hline \multirow[t]{3}{*}{ Fatalism Scale (high vs. low) } & 1.23 & 1.01 & 1.05 \\
\hline & {$[0.66,2.66]$} & {$[0.48,2.14]$} & {$[0.53,2.06]$} \\
\hline & .5140 & .9760 & .8939 \\
\hline \multirow[t]{3}{*}{ Dental Fear Survey (high vs. low) } & 0.74 & 0.74 & 0.78 \\
\hline & {$[0.39,1.39]$} & {$[0.32,1.71]$} & {$[0.38,1.61]$} \\
\hline & .3501 & .4867 & .5036 \\
\hline \multicolumn{2}{|c|}{ Short Form Fear of Pain Questionnaire (high vs. low) 0.78} & 0.96 & 1.20 \\
\hline & {$[0.37,1.63]$} & {$[0.34,2.77]$} & {$[0.46,3.14]$} \\
\hline & .5036 & .9468 & .7104 \\
\hline \multicolumn{4}{|c|}{$\begin{array}{l}\text { Note: Based on } 237 \text { children, ages } 11-13 \text { years, with an exchangeable working correlation structure. } \\
\text { DMFT Index for } 11-12 \text { years was: very low }=0-1 ; \text { low }=2 ; \text { moderate }=3-4 ; \text { high }=5+; \text { dichotomized to } 0-2 \text { and } \geq 3 \text {. } \\
\text { DMFT Index for } 13 \text { years was: very low }=0-2 ; \text { low }=3-5 ; \text { moderate }=6-8 ; \text { high } \geq 9+\text {;ichotomized to } 0-5 \text { and } \geq 6 \text {. } \\
\text { OR-odds ratio; Cl-confidence interval }\end{array}$} \\
\hline \multicolumn{4}{|c|}{$\begin{array}{l}\text { Reduced model has variables of interest listed above and is adjusted for: gender (female vs. male); age (13 years; } \\
12 \text { years vs. } 11 \text { years); and family education (less than/high school vs. more than high school). }\end{array}$} \\
\hline \multicolumn{4}{|c|}{$\begin{array}{l}\text { Full Model additionally adjusted for: race/ethnicity (minority vs. White); income }(\$ 15,000 \text { to } \$ 50,000 \text {; less than } \\
\$ 15,000 \text { vs. } \$ 50,000 \text { and greater); site (WV vs. PA); and BMI (obese, overweight vs. normal weight). The model had } \\
187 \text { clusters, an exchangeable working correlation of }-0.210276812 \text {, and a QIC fit of } 216.1571 \text {. }\end{array}$} \\
\hline \multicolumn{4}{|c|}{ Combining birth categories vs. first biological child- unadjusted OR: $1.24(0.70,2.18 ; p=.4608)$} \\
\hline \multicolumn{4}{|c|}{ Full model AOR:1.41 $(0.66,3.01 ; p=.3691)$} \\
\hline & Reduced AOR: & $56(0.77,3.02 ;$ & $.3691)$ \\
\hline
\end{tabular}


Chapter 2: Table 7

Odds Ratios and Adjusted Odds Ratios for Decayed Missing and Filled Teeth and Family Relationships, Fatalism, and Fear from Generalized Estimating Equations: Males 11-13 years

Genetic Factors Contributing to Oral Health Disparities in Appalachia, 2002-2009

\begin{tabular}{|c|c|c|c|}
\hline Variables & $\begin{array}{l}\text { Jnadjusted OR } \\
\text { Single variable } \\
\text { [95\% Cl] } \\
\text { p-value }\end{array}$ & $\begin{array}{l}\text { Adjusted OR } \\
\text { full model } \\
{[95 \% \mathrm{Cl}]} \\
\text { p-value }\end{array}$ & $\begin{array}{l}\text { Adjusted OR } \\
\text { reduced model } \\
{[95 \% \mathrm{Cl}]} \\
\text { p-value }\end{array}$ \\
\hline \multicolumn{4}{|l|}{ Birth categories } \\
\hline \multirow[t]{3}{*}{ Second biological child vs. First biological child } & 0.66 & 0.37 & 0.62 \\
\hline & {$[0.24,1.79]$} & {$[0.06,2.25]$} & {$[0.20,1.91]$} \\
\hline & .4150 & .2811 & .4099 \\
\hline \multicolumn{4}{|l|}{ Niece/Nephew/Step-/Grandchild/Other vs. } \\
\hline \multirow[t]{3}{*}{ First biological child } & 1.99 & 2.72 & 2.88 \\
\hline & {$[0.73,5.39]$} & {$[0.62,11.0]$} & {$[0.90,9.22]$} \\
\hline & .1741 & .1857 & .0750 \\
\hline \multirow[t]{3}{*}{ Fatalism Scale (high vs. low) } & 1.79 & 3.42 & 1.29 \\
\hline & {$[0.36,4.08]$} & {$[1.41,16.44]$} & {$[0.46,3.63]$} \\
\hline & .1926 & .1250 & .6343 \\
\hline \multirow[t]{3}{*}{ Dental Fear Survey (high vs. low) } & 1.07 & 1.08 & 1.65 \\
\hline & {$[0.75,4.30]$} & {$[0.29,4.10]$} & {$[0.60,4.60]$} \\
\hline & 1926 & .9075 & .3397 \\
\hline \multicolumn{2}{|c|}{ Short Form Fear of Pain Questionnaire (high vs. low) 1.39} & 0.58 & .80 \\
\hline & {$[0.58,3.31]$} & {$[0.12,15.73]$} & {$[0.25,2.62]$} \\
\hline & .4522 & .4977 & .7188 \\
\hline
\end{tabular}

Note: Based on 117 males, ages 11-13 years, with an exchangeable working correlation structure.

DMFT Index for 11-12 years was: very low= 0-1; low=2; moderate $=3-4$; high = 5+; dichotomized to 0-2 and $\geq 3$. DMFT Index for 13 years was: very low $=0-2$; low $=3-5$; moderate $=6-8$; high $\geq 9+$; dichotomized to $0-5$ and $\geq 6$.

OR-odds ratio; $\mathrm{Cl}$-confidence interval

Reduced models has variables of interest listed above and is adjusted for: age (13 years; 12 years vs. 11 years); and family education (less than/high school vs. more than high school).

Full Model additionally adjusted for: race/ethnicity (minority vs. White); income $(\$ 15,000$ to $\$ 50,000 ;$ less than $\$ 15,000$ vs. $\$ 50,000$ and greater); site (WV vs. PA); and BMI (obese, overweight vs. normal weight). The model had 105 clusters, an exchangeable working correlation of -.56780622, and a QIC fit of 102.5924.

Combining birth categories vs. first biological child- unadjusted OR: $1.08(0.48,2.46 ; p=.8477)$

Full model AOR:1.04 $(0.32,3.38 ; \mathrm{p}=.9422)$

Reduced SAS could not compute variance function 
Chapter 2: Table 8

Odds Ratios and Adjusted Odds Ratios for Decayed Missing and Filled Teeth and Family Relationships, Fatalism, and Fear from Generalized Estimating Equations: Females 11-13 years

Genetic Factors Contributing to Oral Health Disparities in Appalachia, 2002-2009

\begin{tabular}{|c|c|c|c|}
\hline Variables & $\begin{array}{l}\text { Inadjusted OR } \\
\text { Single variable } \\
\text { [95\% Cl] } \\
\text { p-value }\end{array}$ & $\begin{array}{l}\text { Adjusted OR } \\
\text { full model } \\
{[95 \% \mathrm{Cl}]} \\
\text { p-value }\end{array}$ & $\begin{array}{l}\text { Adjusted OR } \\
\text { reduced model } \\
{[95 \% \mathrm{Cl}]} \\
\text { p-value }\end{array}$ \\
\hline \multicolumn{4}{|l|}{ Birth categories } \\
\hline \multirow[t]{3}{*}{ Second biological child vs. First biological child } & 1.32 & 1.57 & 1.16 \\
\hline & {$[0.61,2.89]$} & {$[0.46,5.29]$} & {$[0.32,4.19]$} \\
\hline & .4846 & .4685 & .8235 \\
\hline \multicolumn{4}{|l|}{ Niece/Nephew/Step-/Grandchild Other vs. } \\
\hline \multirow[t]{3}{*}{ First biological child } & 1.40 & 1.67 & 2.22 \\
\hline & {$[0.49,4.01]$} & {$[0.92,6.29]$} & {$[0.76,6.48]$} \\
\hline & .5256 & .4516 & .1458 \\
\hline \multirow[t]{3}{*}{ Fatalism Scale (high vs. low) } & 0.90 & 0.74 & 0.75 \\
\hline & {$[0.39,2.04]$} & {$[0.25,2.25]$} & {$[0.26,2.14]$} \\
\hline & .7964 & 6009 & .5869 \\
\hline \multirow[t]{3}{*}{ Dental Fear Survey (high vs. low) } & 0.38 & 0.54 & 0.49 \\
\hline & {$[0.15,0.96]$} & {$[0.16,1.85]$} & {$[0.16,1.51]$} \\
\hline & .0404 & .3289 & .2138 \\
\hline \multicolumn{2}{|c|}{ Short Form Fear of Pain Questionnaire (high vs. low) 1.03} & 1.14 & 2.14 \\
\hline & {$[0.33,3.23]$} & {$[0.22,5.76]$} & {$[0.42,10.79]$} \\
\hline & .9662 & .8764 & .3577 \\
\hline
\end{tabular}

Note: Based on 119 females, ages 11-13 years, in an exchangeable working correlation structure.

DMFT Index for 11-12 years was: very low= 0-1; low=2; moderate =3-4; high = 5+; dichotomized to 0-2 and $\geq 3$.

DMFT Index for 13 years was: very low = 0-2; low = 3-5; moderate =6-8; high $\geq 9+;$ dichotomized to 0-5 and $\geq 6$.

OR-odds ratio; $\mathrm{Cl}$-confidence interval

Reduced model has variables of interest listed above and is adjusted for: age (13 years; 12 years vs. 11 years); and family education (less than/high school vs. more than high school).

Full Model additionally adjusted for: race/ethnicity (minority vs. White); income $(\$ 15,000$ to $\$ 50,000 ;$ less than $\$ 15,000$ vs. $\$ 50,000$ and greater); site (WV vs. PA); and BMI (obese, overweight vs. normal weight). The model had 103 clusters, an exchangeable working correlation of -.127767533 and a QIC fit of 119.6609 .

Combining birth categories vs. first biological child- unadjusted OR: $1.36(0.66,3.01 ; p=.3991)$

Full model AOR: $1.61(0.56,4.66 ; p=.3691)$

Reduced AOR: $1.64(0.64,4.21 ; p=.3691)$ 
Chapter 3: Table 1

Descriptive Characteristics Children Ages 14-17 years

Genetic Factors Contributing to Oral Health Disparities in Appalachia, 2002-2009, N=191

\begin{tabular}{|c|c|c|}
\hline & Sample N & ( \% or standard deviation) \\
\hline \multicolumn{3}{|l|}{ Gender } \\
\hline Males & 89 & $(46.6 \%)$ \\
\hline Females & 102 & $(53.4 \%)$ \\
\hline \multicolumn{3}{|l|}{ Age } \\
\hline 14 & 61 & $(31.9 \%)$ \\
\hline 15 & 62 & $(32.5 \%)$ \\
\hline 16 & 35 & $(18.3 \%)$ \\
\hline 17 & 33 & $(17.3 \%)$ \\
\hline Mean & 15.2 & $( \pm 1.06)$ \\
\hline \multicolumn{3}{|l|}{ Race/Ethnicity } \\
\hline White & 160 & $(83.8 \%)$ \\
\hline Black & 26 & $(13.6 \%)$ \\
\hline Other & 5 & $(2.6 \%)$ \\
\hline \multicolumn{3}{|l|}{ Site } \\
\hline Pennsylvania & 74 & $(38.7 \%)$ \\
\hline West Virginia & 117 & $(61.3 \%)$ \\
\hline \multicolumn{3}{|l|}{ Family Income } \\
\hline Less than $\$ 10,000$ & 22 & $(12.2 \%)$ \\
\hline$\$ 10,000-\$ 14,999$ & 27 & $(15.0 \%)$ \\
\hline$\$ 15,000-\$ 24,999$ & 29 & $(16.1 \%)$ \\
\hline$\$ 25,000-\$ 34,999$ & 19 & $(10.6 \%)$ \\
\hline$\$ 35,000-\$ 49,999$ & 32 & $(17.8 \%)$ \\
\hline$\$ 50,000-\$ 74,999$ & 24 & $(13.3 \%)$ \\
\hline$\$ 75,000-\$ 99,999$ & 9 & $(5.0 \%)$ \\
\hline$\$ 100,000-\$ 149,999$ & 5 & ( $2.8 \%)$ \\
\hline$\$ 150,000$-and above & 13 & $(7.2 \%)$ \\
\hline Missing 11 & & \\
\hline \multicolumn{3}{|l|}{ Highest education in the family } \\
\hline No degree & 17 & ( $9.0 \%)$ \\
\hline High School degree & 77 & $(40.5 \%)$ \\
\hline Technical School degree & 23 & $(12.1 \%)$ \\
\hline Some College & 25 & $(13.1 \%)$ \\
\hline Undergraduate degree & 27 & $(14.2 \%)$ \\
\hline Graduate degree & 21 & $(11.1 \%)$ \\
\hline Missing 1 & & \\
\hline
\end{tabular}


Chapter 3: Table 1 Descriptive Characteristics Children Ages 14-17 years

Genetic Factors Contributing to Oral Health Disparities in Appalachia, 2002-2009, N=191

\begin{tabular}{|c|c|c|}
\hline & Sample N & ( \% or standard deviation) \\
\hline \multicolumn{3}{|l|}{ Family Relationship } \\
\hline Single parent home & 91 & $(53.5 \%)$ \\
\hline Both parents, same house & 79 & $(46.5 \%)$ \\
\hline Missing 21 & & \\
\hline \multicolumn{3}{|l|}{ Family Relationships to index person } \\
\hline First Child & 106 & $(54.6 \%)$ \\
\hline Second Child & 40 & $(20.6 \%)$ \\
\hline Third Child & 19 & ( $9.8 \%)$ \\
\hline Fourth Child & 5 & ( $2.6 \%)$ \\
\hline First Step Child & 12 & $(6.2 \%)$ \\
\hline Second Step Child & 4 & $(2.1 \%)$ \\
\hline Other & 6 & $(3.1 \%)$ \\
\hline \multicolumn{3}{|l|}{ Body Mass Index } \\
\hline Normal & 109 & $(63.0 \%)$ \\
\hline Overweight & 40 & $(23.1 \%)$ \\
\hline Obese & 24 & $(13.9 \%)$ \\
\hline Mean & 23.0 & $( \pm 8.3)$ \\
\hline Missing 18 & & \\
\hline \multicolumn{3}{|l|}{ Total Decayed Missing Filled Teeth } \\
\hline 0 & 47 & $(24.6 \%)$ \\
\hline 1 & 19 & (10.0\%) \\
\hline 2 & 24 & (12.6\%) \\
\hline 3 & 19 & $(10.0 \%)$ \\
\hline 4 & 17 & ( 8.9\%) \\
\hline 5 & 13 & ( 6.8\%) \\
\hline 6 & 13 & ( $6.8 \%)$ \\
\hline 7 & 7 & $(3.7 \%)$ \\
\hline 8 & 14 & ( $7.3 \%)$ \\
\hline 9 & 1 & $(0.5 \%)$ \\
\hline 10 & 5 & ( $2.6 \%)$ \\
\hline 11 & 1 & $(0.5 \%)$ \\
\hline 12 & 5 & ( $2.6 \%)$ \\
\hline 13 & 1 & ( $0.5 \%)$ \\
\hline 14 & 1 & $(0.5 \%)$ \\
\hline 15 & 1 & ( $0.5 \%)$ \\
\hline 17 & 2 & $(1.1 \%)$ \\
\hline 21 & 1 & $(0.5 \%)$ \\
\hline Mean & 3.82 & $( \pm 3.8 \%)$ \\
\hline
\end{tabular}




\section{Chapter 3: Table $1 \quad$ Descriptive Characteristics Children Ages 14-17 years}

Genetic Factors Contributing to Oral Health Disparities in Appalachia, 2002-2009, N=219

\begin{tabular}{lrl}
\hline & Sample N & ( \% or standard deviation) \\
\hline $\begin{array}{l}\text { Dental Fear Survey } \\
\text { Little/no fear }\end{array}$ & & \\
Some/pretty much/very & 69 & $(63.9 \%)$ \\
& & \\
Short Form Fear of Pain Questionnaire & & \\
$\quad$ Little/no fear & 34 & $(17.8 \%)$ \\
Some/pretty much/very & 157 & $(82.2 \%)$ \\
& & \\
Fatalism Scale & & \\
Low & 108 & $(56.5 \%)$ \\
High & 83 & $(43.5 \%)$ \\
& & \\
\hline
\end{tabular}

Participants did not respond to all questions, so number of participants does not always equal the total number of participants. 
Chapter 3: Table 2 Decayed Missing and Filled Teeth Children Ages 14-17years

Genetic Factors Contributing to Oral Health Disparities in Appalachia, 2002-2009

$\mathbf{N}=191 \quad \mathrm{~N}$ (row \%)

\begin{tabular}{|c|c|c|c|c|c|}
\hline \multicolumn{5}{|l|}{ Decayed Missing or Filled Teeth } & \multirow[t]{2}{*}{ p-value } \\
\hline ver & low & low & moderate & high & \\
\hline \multicolumn{5}{|l|}{ Gender } & .8353 \\
\hline Male & $41(46.1)$ & $25(28.1)$ & $18(20.2)$ & $5(5.6)$ & \\
\hline Female & $49(48.0)$ & $24(23.5)$ & $16(15.7)$ & $13(12.8)$ & \\
\hline \multicolumn{5}{|l|}{ Race/Ethnicity } & .0117 \\
\hline White & $69(43.1)$ & $44(27.5)$ & 29(18.1) & $18(11.3)$ & \\
\hline Minority & $21(67.7)$ & $5(16.1)$ & $5(16.1)$ & 0 & \\
\hline \multicolumn{5}{|l|}{ Site } & .0008 \\
\hline West Virginia & $44(37.6)$ & $34(29.1)$ & $21(18.0)$ & 18(15.4) & \\
\hline Pennsylvania & $46(62.2)$ & $15(20.3)$ & 13(17.6) & 0 & \\
\hline \multicolumn{5}{|l|}{ Family Income } & .0661 \\
\hline Less than $\$ 15,000$ & $20(40.8)$ & $11(22.5)$ & $12(24.5)$ & $6(12.2)$ & \\
\hline$\$ 15,000-\$ 49,999$ & $22(45.8)$ & $13(27.1)$ & $9(18.8)$ & $4(8.3)$ & \\
\hline$\$ 50,000$ and above & $45(54.2)$ & $21(25.3)$ & $10(12.1)$ & $7(8.4)$ & \\
\hline Missing 11 & & & & & \\
\hline \multicolumn{5}{|l|}{ Highest Education in Family } & .5680 \\
\hline Less than High School & $5(29.4)$ & $5(29.4)$ & $5(29.4)$ & $2(11.8)$ & \\
\hline High School & $31(40.3)$ & $22(28.6)$ & $14(18.2)$ & $10(13.0)$ & \\
\hline Technical School & $12(52.2)$ & $5(21.7)$ & $5(21.7)$ & $1(4.4)$ & \\
\hline Some College & $11(44.0)$ & $6(24.0)$ & $5(20.0)$ & $3(12.0)$ & \\
\hline Undergraduate degree & $17(63.0)$ & $7(25.9)$ & $2(7.4)$ & $1(3.7)$ & \\
\hline Graduate & $14(66.7)$ & $3(14.3)$ & $3(14.3)$ & $1(4.8)$ & \\
\hline Missing 1 & & & & & \\
\hline \multicolumn{5}{|l|}{ Family Relationship } & .8439 \\
\hline Single Parent & $43(47.3)$ & $23(25.3)$ & $16(17.6)$ & 9( 9.9) & \\
\hline Both parents, same hom & $36(45.6)$ & $20(25.3)$ & $16(20.3)$ & $7(8.9)$ & \\
\hline Missing 21 & & & & & \\
\hline \multirow{2}{*}{\multicolumn{5}{|c|}{$\begin{array}{l}\text { Family Relationship } \\
\text { to index person }\end{array}$}} & \\
\hline & & & & & .1473 \\
\hline First Child & $57(54.3)$ & $23(21.9)$ & $18(17.1)$ & $7(6.7)$ & \\
\hline Second Child & $15(37.5)$ & $12(30.0)$ & $8(20.0)$ & $5(12.5)$ & \\
\hline Other & $16(41.0)$ & $12(30.8)$ & $6(15.4)$ & $5(12.8)$ & \\
\hline Missing 7 & & & & & \\
\hline
\end{tabular}


Chapter 3: Table 2 Decayed Missing and Filled Teeth Children Ages 14-17years

Genetic Factors Contributing to Oral Health Disparities in Appalachia, 2002-2009

$N=191 \quad N($ row \%)

\begin{tabular}{rrrr}
\hline Decayed Missing or Filled Teeth & & & p-value \\
very low & low & moderate & high \\
\hline
\end{tabular}

Body Mass Index

Normal

Overweight

Obese

Missing 18

Age

14
15
16
17

$\begin{array}{ll}53(48.6) & 26(23.9) \\ 17(42.5) & 15(37.5) \\ 13(54.2) & 4(16.7)\end{array}$

15(24.6)

16(35.8)

10(28.6)

8(24.2)

$\begin{array}{rr}18(16.5) & 12(11.0) \\ 4(10.0) & 4(10.0) \\ 5(20.8) & 2(8.3)\end{array}$

.8583

$\begin{array}{rr}10(16.4) & 0 \\ 13(21.0) & 2(3.2) \\ 6(17.1) & 4(11.4) \\ 5(15.2) & 12(36.4)\end{array}$

$<.0001$

( 3.2$)$

12(36.4)

Based on 191 children, ages 14-17 years. Participants did not respond to all questions, so number of participants does not always equal the total number of participants. Cochran-Mantel-Haenzel mean score test was used (with standardized midrank scores) for gender, race/ethnicity, site, family relationship with index person. MantelHaenzel Chi Square (with standardized midrank scores) for family income, highest education in the family, BMI, and age.

DMFT Index for 14-17 years was: very low = 0-2; low = 3-5; moderate = 6-8; high = 9+. 


\author{
Chapter 3: Table 3 \\ Fatalism and Decayed Missing and Filled Teeth Children Ages 14-17 years \\ Genetic Factors Contributing to Oral Health Disparities in Appalachia, 2002-2009 \\ $\mathrm{N}=191 \quad \mathrm{~N}$ (row \%)

\begin{tabular}{ccccc}
\hline $\begin{array}{l}\text { Decayed Missing or Filled Teeth } \\
\text { very low }\end{array}$ & low & moderate & \multicolumn{1}{c}{ high } \\
\hline & & & & \\
Fatalism Scale & & & \\
Low & $51(47.2)$ & $28(25.9)$ & $16(14.8)$ & $13(12.0)$ \\
High & $39(47.0)$ & $21(25.3)$ & $18(21.7)$ & $5(6.0)$
\end{tabular} \\ Based on 219 children, ages 14-17 years. Participants did not respond to all questions, so number of participants \\ does not always equal the total number of participants. \\ Mantel-Haenzel Chi Square Exact test was used (with standardized midrank scores). \\ DMFT Index for 14-17 years was: very low $=0-2 ;$ low $=3-5 ;$ moderate $=6-8 ;$ high $=9+$.
}


Chapter3: Table 4

Fear and Decayed Missing and Filled Teeth Children Ages 14-17 years

Genetic Factors Contributing to Oral Health Disparities in Appalachia, 2002-2009

$\mathbf{N}=191$

N (row \%)

\begin{tabular}{|c|c|c|c|c|c|}
\hline \multicolumn{3}{|c|}{ Decayed Missing or Filled Teeth } & \multirow[b]{2}{*}{ moderate } & \multicolumn{2}{|r|}{ p-value } \\
\hline & very low & low & & high 5 & \\
\hline \multicolumn{6}{|l|}{ Dental Fear Survey } \\
\hline & & & & & .9035 \\
\hline Little/no fear & $58(47.0)$ & $30(24.6)$ & 24(19.7) & $10(8.2)$ & \\
\hline Some/pretty much/very & $32(46.4)$ & $19(27.5)$ & $10(14.5)$ & $8(11.6)$ & \\
\hline \multicolumn{6}{|c|}{ Short Form Fear of Pain Questionnaire } \\
\hline & & & & & .0581 \\
\hline Little/no fear & $9(26.5)$ & $15(44.1)$ & $7(20.6)$ & $3(8.8)$ & \\
\hline Some/pretty much/very & $81(51.6)$ & $34(21.7)$ & $27(17.2)$ & $15(9.6)$ & \\
\hline
\end{tabular}

Based on 219 children, ages 14-17 years. Participants did not respond to all questions, so number of participants does not always equal the total number of participants.

Exact Mantel-Haenzel Chi Square (with standardized midrank scores) was used to determine $p$-value. DMFT Index for 14-17 years was: very low = 0-2; low = 3-5; moderate $=6-8$; high $=9+$. 
Chapter 3 Table 5

Odds Ratios and Adjusted Odds Ratios for Decayed Missing and Filled Teeth and Family Relationships, Fatalism toward Preventive Care, and Fear Factors from Generalized Estimating Equations for adolescents 14-17 years

Genetic Factors Contributing to Oral Health Disparities in Appalachia, 2002-2009

\begin{tabular}{|c|c|c|c|}
\hline & $\begin{array}{l}\text { Unadjusted OR } \\
\text { Single variable } \\
\text { [95\% CI] } \\
\text { p-value }\end{array}$ & $\begin{array}{l}\text { Adjusted OR } \\
\text { full model } \\
{[95 \% \mathrm{CI}]} \\
\text { p-value }\end{array}$ & $\begin{array}{l}\text { Adjusted OR } \\
\text { reduced model } \\
{[95 \% \mathrm{CI}]} \\
\text { p-value }\end{array}$ \\
\hline \multicolumn{4}{|l|}{ Family Relationships } \\
\hline Single parent vs. both parents, same home & $\begin{array}{l}0.94 \\
{[0.47,1.87]} \\
.8567\end{array}$ & $\begin{array}{l}0.59 \\
{[0.19,1.86]} \\
.3655\end{array}$ & $\begin{array}{l}0.88 \\
{[0.41,1.88]} \\
.7376\end{array}$ \\
\hline \multicolumn{4}{|l|}{ Niece/Nephew/Step-/Grandchild Other vs. } \\
\hline First biological child & $\begin{array}{l}1.26 \\
{[0.56,2.86]} \\
.5796\end{array}$ & $\begin{array}{l}1.93 \\
{[0.62,6.02]} \\
.2552\end{array}$ & $\begin{array}{l}1.13 \\
{[0.44,2.85]} \\
.8013\end{array}$ \\
\hline Second biological child vs. First biological child & $\begin{array}{l}1.52 \\
{[0.69,3.34]} \\
.2958\end{array}$ & $\begin{array}{l}2.27 \\
{[0.76,6.77]} \\
.1404\end{array}$ & $\begin{array}{l}1.60 \\
{[0.67,3.84]} \\
.2929\end{array}$ \\
\hline Fatalism Scale (high vs. low) & $\begin{array}{l}1.03 \\
{[0.55,1.92]} \\
.9214\end{array}$ & $\begin{array}{l}1.47 \\
{[0.57,3.74]} \\
.4238\end{array}$ & $\begin{array}{l}1.32 \\
{[0.67,2.74]} \\
.4563\end{array}$ \\
\hline Dental Fear Survey (high vs. low) & $\begin{array}{l}0.95 \\
{[0.49,1.83]} \\
.8812\end{array}$ & $\begin{array}{l}1.37 \\
{[0.55,3.42]} \\
.5042\end{array}$ & $\begin{array}{l}1.10 \\
{[0.51,2.35]} \\
.8160\end{array}$ \\
\hline Short Form Fear of Pain Questionnaire (high vs. low) & $\begin{array}{l}0.99 \\
{[0.45,2.19]} \\
.9794\end{array}$ & $\begin{array}{l}0.51 \\
{[0.17,1.54]} \\
.2342\end{array}$ & $\begin{array}{l}0.67 \\
{[0.25,1.77]} \\
.4219\end{array}$ \\
\hline
\end{tabular}

Note: Based on 191 children, ages 14-17 years, with an exchangeable working correlation structure.

DMFT Index for 14-17 years was: very low $=0-2 ;$ low $=3-5$; moderate $=6-8$; high $=\geq 9$; dichotomized to 0-5 and $\geq 6$.

OR-Odds Ratio; $\mathrm{Cl}$-confidence interval

Reduced model has variables of interest listed above and is adjusted for: gender (female vs. male); age (17 years;

16 years; 15 years vs. 14 years); and family education (less than/high school vs. more than high school).

Full Model additionally adjusted for: race/ethnicity (minority vs. White); income $(\$ 15,000$ to $\$ 50,000$; less than $\$ 15,000$ vs. $\$ 50,000$ and greater); site (WV vs. PA); and BMI (obese, overweight vs. normal weight). The model had 151 clusters, an exchangeable working correlation of -0.1863215164 , and a QIC of 183.1693.

Combining birth categories vs. first biological child- unadjusted OR: $0.72(0.38,1.35 ; p=.3044)$

Full model AOR: $0.59(0.25,1.38 ; p=.2216)$

Reduced AOR: $0.80(0.41,1.56 ; p=.5164)$ 
Chapter 3: Table 6

Odds Ratios and Adjusted Odds Ratios for Decayed Missing and Filled Teeth and Family Relationships, Fatalism, and Fear from Generalized Estimating Equations: Males 14-17 years

Genetic Factors Contributing to Oral Health Disparities in Appalachia, 2002-2009

\begin{tabular}{|c|c|c|c|}
\hline Variable & $\begin{array}{l}\text { Unadjusted OR } \\
\text { Single variable } \\
{[95 \% \mathrm{Cl}]} \\
\text { p-value }\end{array}$ & $\begin{array}{l}\text { Adjusted OR } \\
\text { full model } \\
{[95 \% \mathrm{Cl}]} \\
\text { p-value }\end{array}$ & $\begin{array}{l}\text { Adjusted OR } \\
\text { reduced model } \\
{[95 \% \mathrm{Cl}]} \\
\text { p-value }\end{array}$ \\
\hline Family Relationships & & & \\
\hline Single parent vs. both parents, same home & $\begin{array}{l}1.13 \\
{[0.40,3.14]} \\
.8088\end{array}$ & $\begin{array}{l}0.08 \\
{[0.01,0.42]} \\
.0249\end{array}$ & $\begin{array}{l}1.08 \\
{[0.22,3.56]} \\
.9046\end{array}$ \\
\hline Niece/Nephew/Step-/Grandchild Other vs. & & & \\
\hline First biological child & $\begin{array}{l}1.11 \\
{[0.30,7.50]} \\
.8814\end{array}$ & $\begin{array}{l}3.34 \\
{[0.06,183.43]} \\
.5549\end{array}$ & $\begin{array}{l}1.72 \\
{[0.38,7.70]} \\
.4805\end{array}$ \\
\hline Second biological child vs. First biological child & $\begin{array}{l}2.51 \\
{[0.84,7.50]} \\
.0991\end{array}$ & $\begin{array}{l}14.08 \\
{[0.70,282.74]} \\
.0841\end{array}$ & $\begin{array}{l}2.64 \\
{[0.81,8.59]} \\
.1080\end{array}$ \\
\hline Fatalism Scale (high vs. low) & $\begin{array}{l}1.07 \\
{[0.40,2.86]} \\
.8940\end{array}$ & $\begin{array}{l}0.19 \\
{[0.02,1.91]} \\
.1576\end{array}$ & $\begin{array}{l}1.06 \\
{[0.37,3.05]} \\
.9135\end{array}$ \\
\hline Dental Fear Survey (high vs. low) & $\begin{array}{l}0.73 \\
{[0.26,2.07]} \\
.5592\end{array}$ & $\begin{array}{l}1.25 \\
{[0.10,15.46]} \\
.8602\end{array}$ & $\begin{array}{l}0.80 \\
{[0.26,2.50]} \\
.7033\end{array}$ \\
\hline Short Form Fear of Pain Questionnaire (high vs. low & $\begin{array}{l}2.20 \\
{[0.68,7.14]} \\
.1877\end{array}$ & $\begin{array}{l}12.86 \\
{[1.71,96.59]} \\
.0130\end{array}$ & $\begin{array}{l}2.65 \\
{[0.56,12.49]} \\
.2180\end{array}$ \\
\hline
\end{tabular}

Note: Based on 89 children, ages 14-17 years, with an exchangeable working correlation structure.

OR-Odds Ratio; $\mathrm{Cl}$-confidence interval

DMFT Index for 14-17 years was: very low = 0-2; low = 3-5; moderate = 6-8; high = $\geq 9$; dichotomized to 0-5 and $\geq 6$.

Reduced model has variables of interest listed above and is adjusted for: age (17 years; 16 years; 15 years vs. 14 years); and family education (less than/high school vs. more than high school).

Full Model additionally adjusted for: race/ethnicity (minority vs. White); income $(\$ 15,000$ to $\$ 50,000 ;$ less than $\$ 15,000$ vs. $\$ 50,000$ and greater); site (WV vs. PA); and BMI (obese, overweight vs. normal weight). The model had 76 clusters, an exchangeable working correlation of -0.0448552408 , and a QIC fit of 78.1816.

Combining birth categories vs. first biological child- unadjusted OR: $0.57(0.22,1.86 ; p=.2418)$

Full model AOR: $0.22(0.04,1.25 ; p=.0873)$

Reduced AOR: 0.0 Hessian Matrix not positive; estimation error 
Chapter 3: Table 7

Odds Ratios and Adjusted Odds Ratios for Decayed Missing and Filled Teeth and Family Relationships, Fatalism, and Fear from Generalized Estimating Equations: Females 14-17 years

Genetic Factors Contributing to Oral Health Disparities in Appalachia, 2002-2009

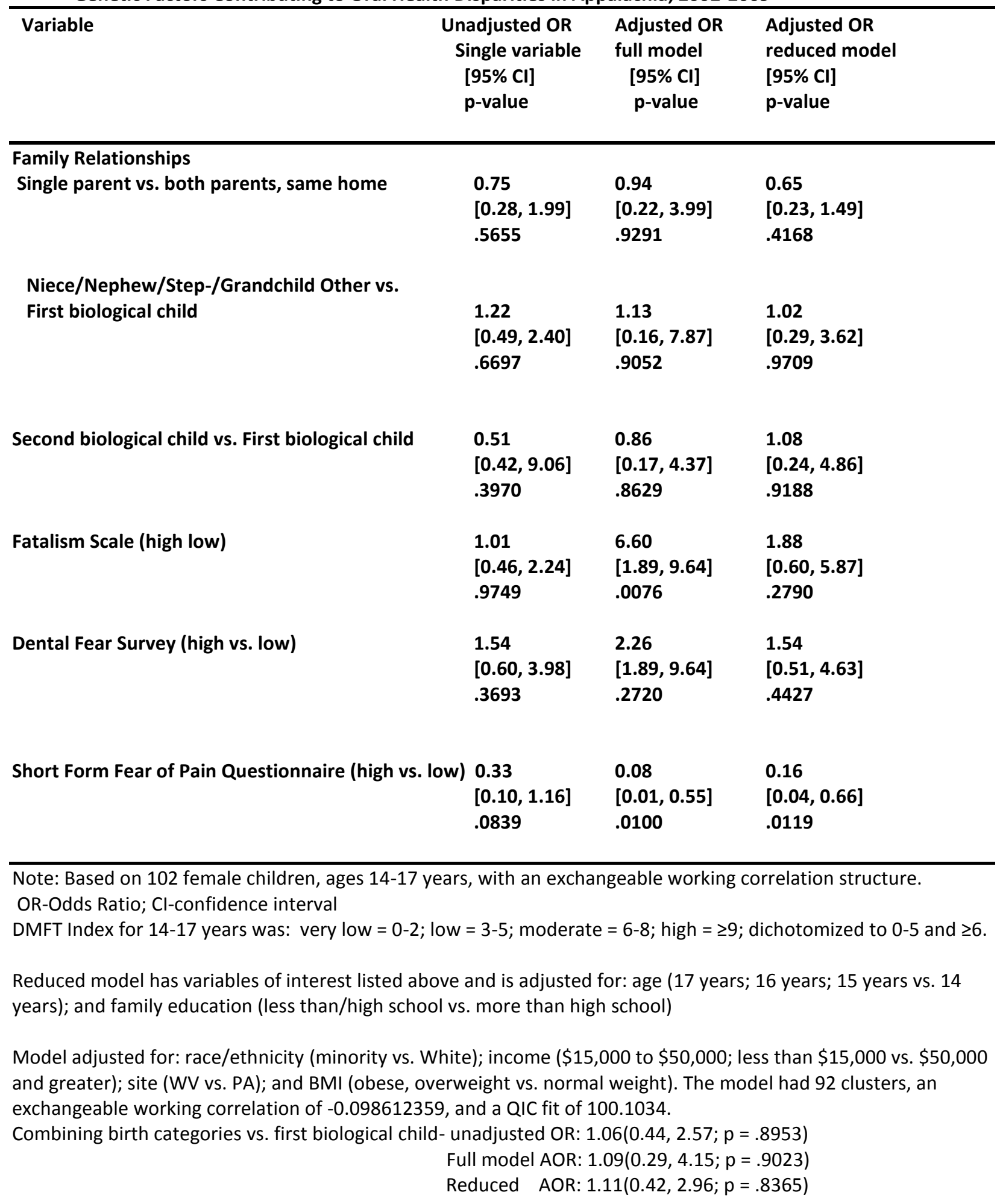


Chapter 4: Table $1 \quad$ Descriptive Characteristics Adults, 18 years and above

Genetic Factors Contributing to Oral Health Disparities in Appalachia, 2002-2009, N = 1125

\begin{tabular}{|c|c|c|}
\hline & Sample N & $(\%)$ \\
\hline \multicolumn{3}{|l|}{ Gender } \\
\hline Males & 410 & $(36.4 \%)$ \\
\hline Females & 715 & $(63.6 \%)$ \\
\hline \multicolumn{3}{|l|}{ Age } \\
\hline $18-24$ & 147 & $(14.2 \%)$ \\
\hline $25-44$ & 758 & (73.1\%) \\
\hline $45+$ & 132 & $(12.7 \%)$ \\
\hline Mean & 34.3 & $( \pm 9.3 \%)$ \\
\hline Missing 88 & & \\
\hline \multicolumn{3}{|l|}{ Race/Ethnicity } \\
\hline White & 992 & $(89.3 \%)$ \\
\hline Black & 99 & ( $8.9 \%)$ \\
\hline Other & 20 & $(1.8 \%)$ \\
\hline Missing 14 & & \\
\hline \multicolumn{3}{|l|}{ Marital Status } \\
\hline Never married & 151 & $(13.6 \%)$ \\
\hline Domestic Partner & 112 & $(10.1 \%)$ \\
\hline Married & 688 & $(61.1 \%)$ \\
\hline Separated & 41 & ( $3.7 \%)$ \\
\hline Divorced & 99 & ( $8.9 \%)$ \\
\hline Widow & 16 & $(1.4 \%)$ \\
\hline Missing 18 & & \\
\hline \multicolumn{3}{|l|}{ Site } \\
\hline Pennsylvania & 382 & $(34.0 \%)$ \\
\hline West Virginia & 743 & $(66.0 \%)$ \\
\hline \multicolumn{3}{|l|}{ Family Income } \\
\hline Less than $\$ 10,000$ & 174 & (16.9\%) \\
\hline$\$ 10,000-\$ 14,999$ & 163 & $(15.9 \%)$ \\
\hline$\$ 15,000-\$ 24,999$ & 143 & (13.9\%) \\
\hline$\$ 25,000-\$ 34,999$ & 129 & $(12.6 \%)$ \\
\hline$\$ 35,000-\$ 49,999$ & 164 & $(16.0 \%)$ \\
\hline$\$ 50,000-\$ 74,999$ & 133 & $(12.9 \%)$ \\
\hline$\$ 75,000-\$ 99,999$ & 55 & $(5.4 \%)$ \\
\hline$\$ 100,000-\$ 149,999$ & 33 & ( $3.2 \%)$ \\
\hline$\$ 150,000-\$ 199,999$ & 26 & $(2.5 \%)$ \\
\hline$\$ 200,000$ and above & 8 & $(0.8 \%)$ \\
\hline Missing 97 & & \\
\hline
\end{tabular}

Continued 
Chapter 4: Table $1 \quad$ Descriptive Characteristics Adults, 18 years and above

Genetic Factors Contributing to Oral Health Disparities in Appalachia, 2002-2009, N = 1125

\begin{tabular}{lrl}
\hline & Sample N & $(\%)$ \\
\hline Highest degree in family & & \\
Less than High School degree & 71 & $(6.4 \%)$ \\
High School & 429 & $(38.6 \%)$ \\
Technical School degree & 181 & $(16.3 \%)$ \\
Some College & 181 & $(16.3 \%)$ \\
$\quad$ Undergraduate degree & 144 & $(13.0 \%)$ \\
Graduate degree & 104 & $(9.4 \%)$ \\
$\quad$ Missing 15 & & \\
& & \\
Family Relationships to index person & & \\
Index & 692 & $(61.5 \%)$ \\
$\quad$ First spouse & 292 & $(26.0 \%)$ \\
Second spouse & 54 & $(4.8 \%)$ \\
Third spouse & 16 & $(1.4 \%)$ \\
Fourth spouse or above & 6 & $(0.5 \%)$ \\
Parent of index & 12 & $(1.1 \%)$ \\
First Child & 26 & $(2.3 \%)$ \\
Second Child & 10 & $(0.9 \%)$ \\
Third Child or above & 2 & $(0.2 \%)$ \\
Married-in & 2 & $(0.2 \%)$ \\
Other & 13 & $(1.2 \%)$ \\
& & \\
Body Mass Index & 30.0 & $( \pm 7.8)$ \\
Normal & & \\
Overweight & & \\
Obese & 283 & $(29.7 \%)$ \\
Mean & 268 & $(28.1 \%)$ \\
Missing 172 & 402 & $(42.2 \%)$ \\
& &
\end{tabular}

Continued 
Chapter 4: Table 1 Descriptive Characteristics Adults, 18 years and above

Genetic Factors Contributing to Oral Health Disparities in Appalachia, 2002-2009, N = 1125

\begin{tabular}{|c|c|c|}
\hline & Sample N & (\%) \\
\hline \multicolumn{3}{|l|}{ Total Decayed Missing Filled Teeth } \\
\hline 0 & 67 & $(6.0 \%)$ \\
\hline 1 & 48 & $(4.3 \%)$ \\
\hline 2 & 53 & ( $4.7 \%)$ \\
\hline 3 & 42 & ( $3.7 \%)$ \\
\hline 4 & 62 & ( $5.5 \%)$ \\
\hline 5 & 78 & ( $6.9 \%)$ \\
\hline 6 & 59 & ( $5.2 \%)$ \\
\hline 7 & 76 & ( $6.8 \%)$ \\
\hline 8 & 96 & ( $8.5 \%)$ \\
\hline 9 & 61 & ( $5.2 \%)$ \\
\hline 10 & 51 & ( 4.5\%) \\
\hline 11 & 64 & ( $5.7 \%)$ \\
\hline 12 & 62 & ( $5.5 \%)$ \\
\hline 13 & 44 & ( $3.9 \%)$ \\
\hline 14 & 49 & ( $4.4 \%)$ \\
\hline 15 & 31 & ( $2.8 \%)$ \\
\hline 16 & 25 & ( $2.2 \%)$ \\
\hline 17 & 25 & ( $2.2 \%)$ \\
\hline 18 & 19 & ( $1.7 \%)$ \\
\hline 19 & 22 & ( $2.0 \%)$ \\
\hline 20 & 15 & ( $1.3 \%)$ \\
\hline 21 & 21 & ( $1.9 \%)$ \\
\hline 22 & 16 & ( $1.4 \%)$ \\
\hline 23 & 5 & ( $0.4 \%)$ \\
\hline 24 & 10 & ( $0.9 \%)$ \\
\hline 25 & 4 & $(0.4 \%)$ \\
\hline 26 & 2 & ( $0.2 \%)$ \\
\hline 27 & 2 & $(0.2 \%)$ \\
\hline 28 & 16 & ( $1.4 \%)$ \\
\hline Mean & 9.3 & $( \pm 6.4 \%)$ \\
\hline \multicolumn{3}{|l|}{ Dental Fear Survey } \\
\hline Little/no fear & 552 & (49.1\%) \\
\hline Some/pretty much/very & 573 & (50.9\%) \\
\hline \multicolumn{3}{|c|}{ Short Form Fear of Pain Questionnaire } \\
\hline Little/no fear & 207 & $(18.4 \%)$ \\
\hline Some/pretty much/very & 918 & (81.6\%) \\
\hline \multicolumn{3}{|l|}{ Fatalism Scale } \\
\hline Low & 789 & (70.1\%) \\
\hline High & 336 & (29.9\%) \\
\hline
\end{tabular}


Chapter 4: Table 2

Decayed Missing and Filled Teeth, Adults, 18 years and above

Genetic Factors Contributing to Oral Health Disparities in Appalachia, 2002-2009, N = 1125

N (row \%)

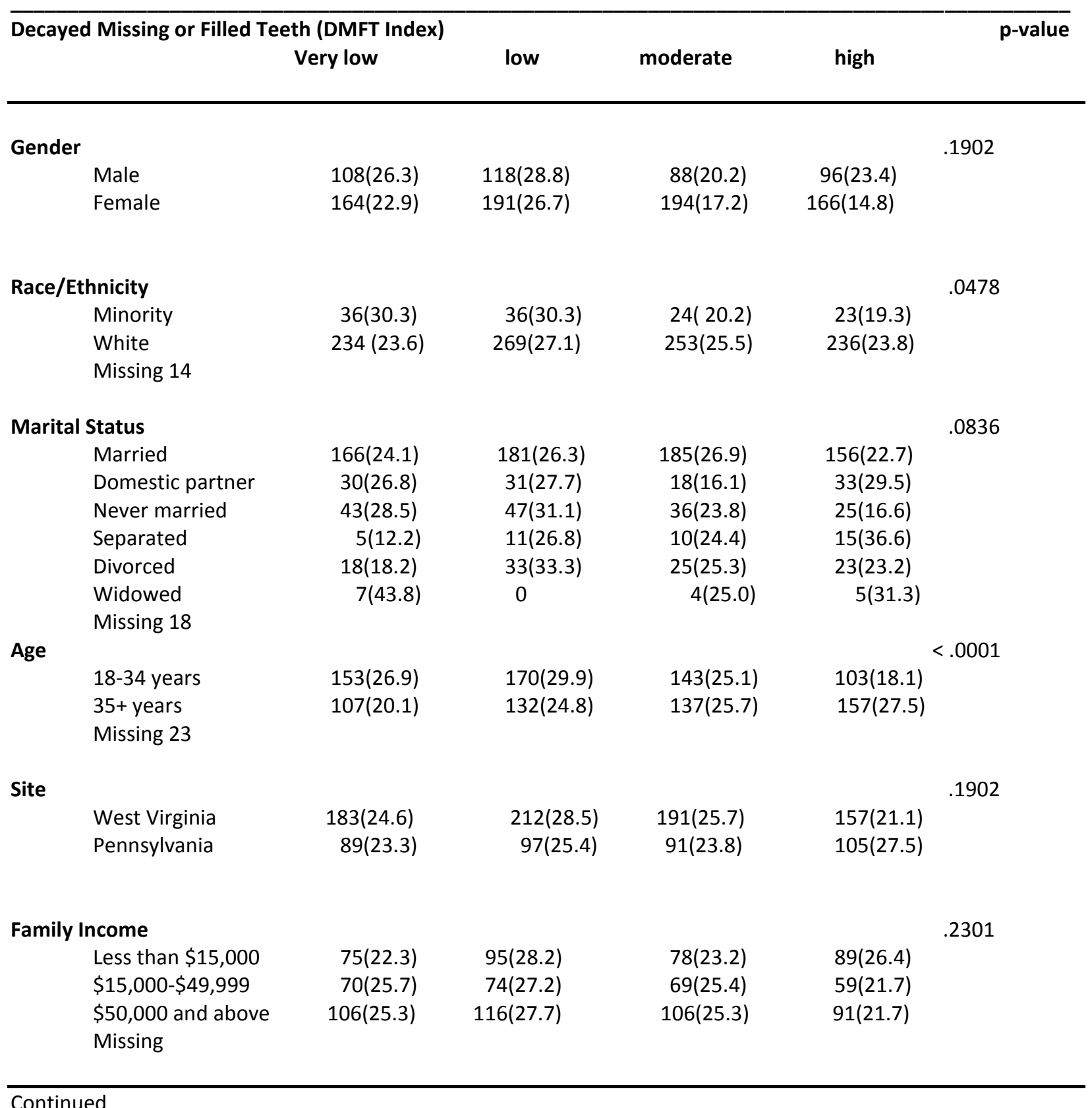

Continued 
Chapter 4: Table 2

Decayed Missing and Filled Teeth, Adults, 18 years and above

Genetic Factors Contributing to Oral Health Disparities in Appalachia, 2002-2009, N = 1125

N (row \%)

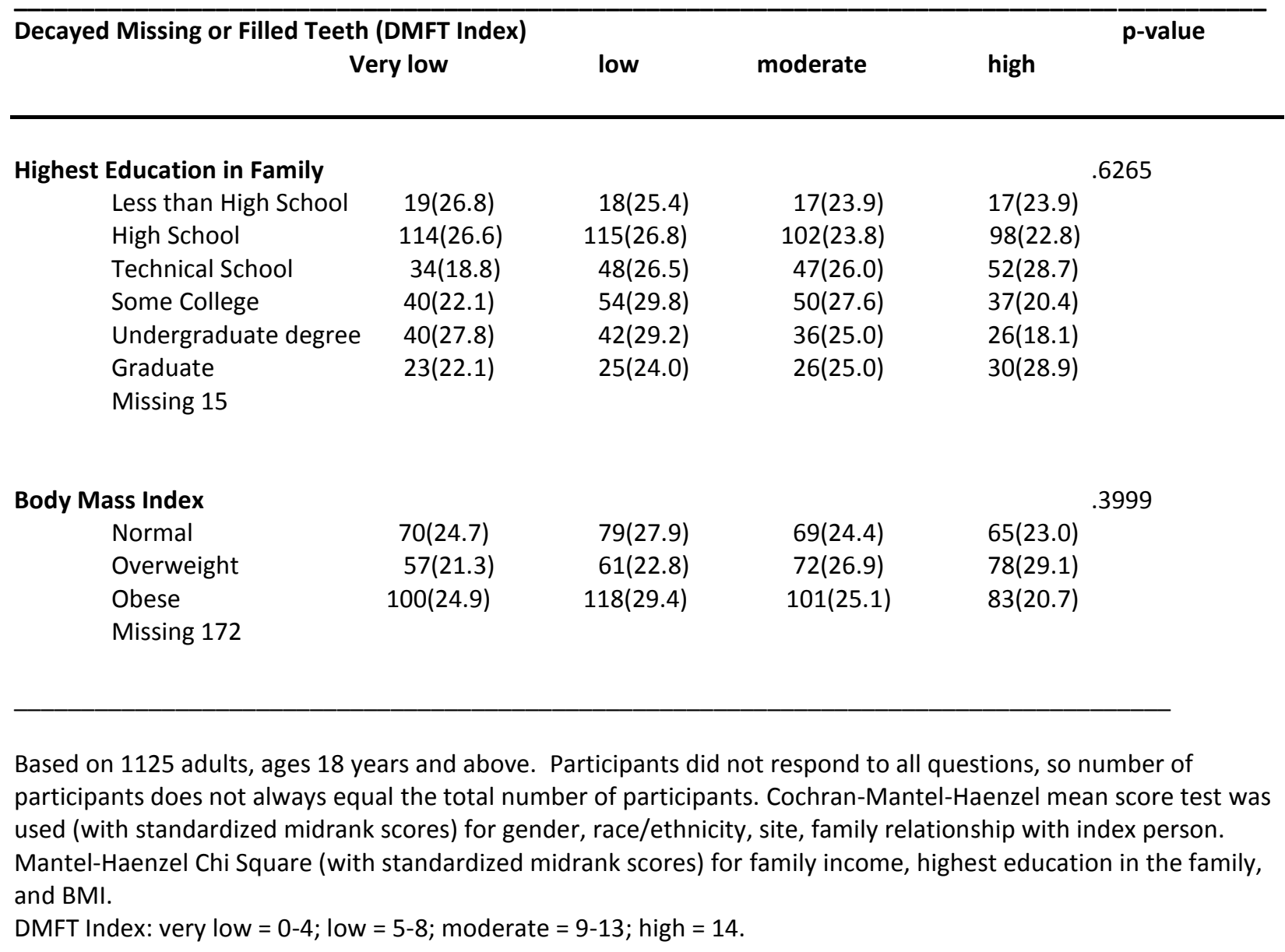


Chapter 4: Table 3

Fatalism and Decayed Missing and Filled Teeth, Adults, 18 years and above

Genetic Factors Contributing to Oral Health Disparities in Appalachia, 2002-2009, N = 1125

N (row \%)

\begin{tabular}{crrrr}
\hline $\begin{array}{c}\text { Decayed Missing or Filled Teeth } \\
\text { very low }\end{array}$ & low & moderate & high \\
\hline & & & & \\
Fatalism Scale & & & & \\
Low & $191(23.9)$ & $230(28.8)$ & $203(25.4)$ & $175(21.9)$ \\
High & $81(24.9)$ & $79(24.2)$ & $79(24.2)$ & $87(26.7)$ \\
& & & & \\
\hline
\end{tabular}

p-value

Based on 1125 adults, ages 18 years and above. Participants did not respond to all questions, so number of participants does not always equal the total number of participants. Mantel-Haenzel Chi Square Exact test was used (with standardized midrank scores).

DMFT Index: very low = 0-4; low = 5-8; moderate = 9-13; high = 14+. 
Chapter 4: Table 4

Fear and Decayed Missing and Filled Teeth, Adults, 18 years and above Genetic Factors Contributing to Oral Health Disparities in Appalachia, 2002-2009, N = 1125

N (row \%)

\begin{tabular}{|c|c|c|c|c|c|}
\hline \multicolumn{5}{|c|}{ Decayed Missing or Filled Teeth } & \multirow[t]{2}{*}{ p-value } \\
\hline & very low & low & moderate & high 5 & \\
\hline \multicolumn{6}{|l|}{ Dental Fear Survey } \\
\hline & & & & & $<.0001$ \\
\hline Little/no fear & $148(26.8)$ & $173(31.3)$ & $126(22.8)$ & 105 (19.0) & \\
\hline Some/pretty much/very & $124(21.6)$ & $136(23.7)$ & $156(27.3)$ & $157(27.4)$ & \\
\hline \multicolumn{6}{|c|}{ Short Form Fear of Pain Questionnaire } \\
\hline & & & & & .6240 \\
\hline Little/no fear & $49(23.7)$ & $60(29.0)$ & $56(27.1)$ & $42(20.3)$ & \\
\hline Some/pretty much/very & $223(24.3)$ & 249(27.1) & 226(24.6) & $220(24.0)$ & \\
\hline
\end{tabular}

Based on 1125 adults, ages 18 years and above. Mantel-Haenzel Chi Square Exact test was used (with standardized midrank scores).

DMFT Index: very low = 0-4; low = 5-8; moderate = 9-13; high = 14+. 


\section{Chapter 4: Table 5}

Odds Ratios and Adjusted Odds Ratios for Decayed Missing and Filled Teeth and Family Relationships, Fatalism, and Fear from Generalized Estimating Equations for adults, 18 years and above

Genetic Factors Contributing to Oral Health Disparities in Appalachia, 2002-2009

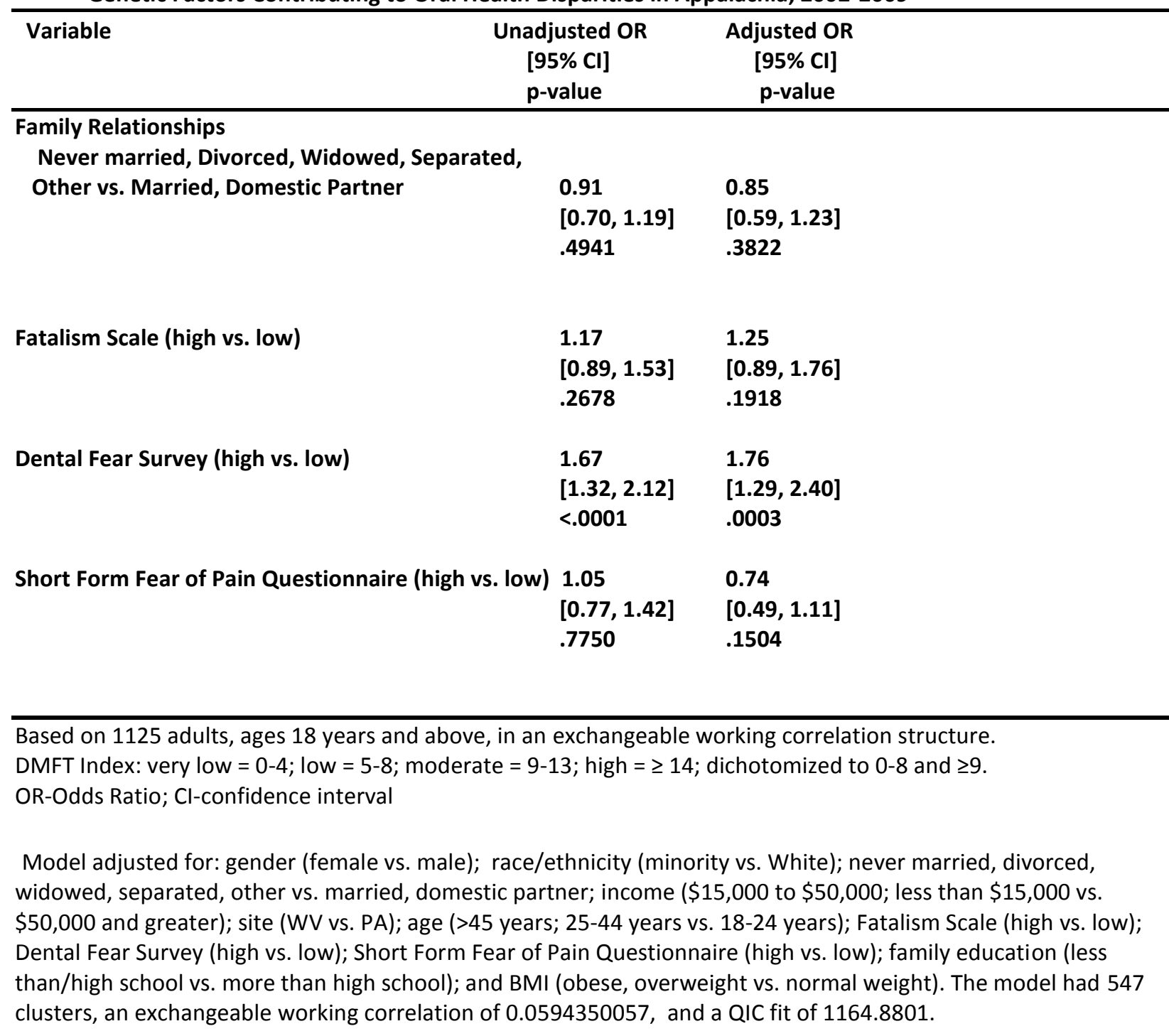




\section{Chapter 4: Table 6}

Odds Ratios and Adjusted Odds Ratios for Decayed Missing and Filled Teeth and Family Relationships, Fatalism, and Fear from Generalized Estimating Equations: Males $>18$ years

Genetic Factors Contributing to Oral Health Disparities in Appalachia, 2002-2009

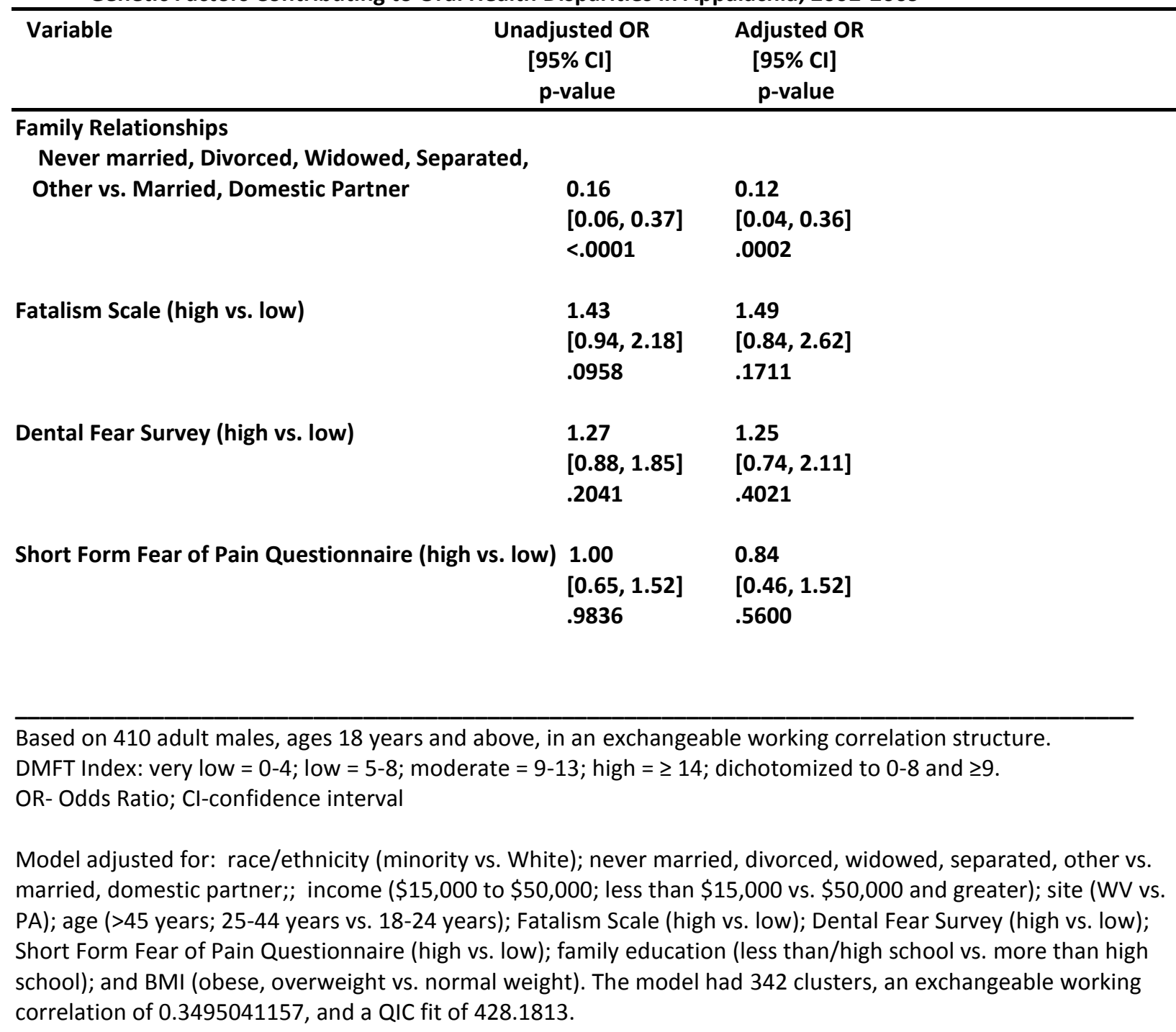




\section{Chapter 4: Table 6}

Odds Ratios and Adjusted Odds Ratios for Decayed Missing and Filled Teeth and Family Relationships, Fatalism, and Fear from Generalized Estimating Equations: Females $>18$ years

Genetic Factors Contributing to Oral Health Disparities in Appalachia, 2002-2009

\begin{tabular}{|c|c|c|}
\hline Variable & $\begin{array}{l}\text { djusted OR } \\
{[95 \% \mathrm{Cl}]} \\
\text { p-value }\end{array}$ & $\begin{array}{c}\text { Adjusted OR } \\
{[95 \% \mathrm{Cl}]} \\
\text { p-value }\end{array}$ \\
\hline \multicolumn{3}{|l|}{ Family Relationships } \\
\hline Other vs. Married, Domestic Partner & $\begin{array}{l}1.18 \\
{[0.87,1.59]} \\
.2833\end{array}$ & $\begin{array}{l}1.18 \\
{[0.75,1.84]} \\
.4742\end{array}$ \\
\hline Fatalism Scale (high vs. low) & $\begin{array}{l}1.06 \\
{[0.76,1.48]} \\
.7384\end{array}$ & $\begin{array}{l}1.17 \\
{[0.75,1.83]} \\
.4844\end{array}$ \\
\hline Dental Fear Survey (high vs. low) & $\begin{array}{l}1.88 \\
{[1.39,2.54]} \\
<.0001\end{array}$ & $\begin{array}{l}2.11 \\
{[1.41,3.14]} \\
.0003\end{array}$ \\
\hline Short Form Fear of Pain Questionnaire (high vs. low) & $\begin{array}{l}1.00 \\
{[0.65,1.53]} \\
.9965\end{array}$ & $\begin{array}{l}0.75 \\
{[0.42,1.32]} \\
.3120\end{array}$ \\
\hline \multicolumn{3}{|c|}{$\begin{array}{l}\text { Based on } 715 \text { adult females, ages } 18 \text { years and above, in an exchangeable working correlation structure. } \\
\text { DMFT Index: very low = 0-4; low = 5-8; moderate =9-13; high = } \geq 14 \text {; dichotomized to } 0-8 \text { and } \geq 9 \text {. } \\
\text { OR- Odds Ratio; Cl-confidence interval }\end{array}$} \\
\hline \multicolumn{3}{|c|}{$\begin{array}{l}\text { Model adjusted for: race/ethnicity (minority vs. White); never married, divorced, widowed, separated, other vs. } \\
\text { married, domestic partner; income ( } \$ 15,000 \text { to } \$ 50,000 ; \text { less than } \$ 15,000 \text { vs. } \$ 50,000 \text { and greater); site (WV vs. } \\
\text { PA); age (>45 years; } 25-44 \text { years vs. } 18-24 \text { years); Fatalism Scale (high vs. low); Dental Fear Survey (high vs. low); } \\
\text { Short Form Fear of Pain Questionnaire (high vs. low); family education (less than/high school vs. more than high } \\
\text { school); and BMI (obese, overweight vs. normal weight). The model had } 519 \text { clusters, an exchangeable working } \\
\text { correlation of }-0.113585918 \text {, and a QIC fit of } 731.8780 \text {. }\end{array}$} \\
\hline
\end{tabular}


Imputations

Children. COHRA study had 280 participants, 7 had missing DMFT data; 36 had $>20 \%$ fear or fatalism data missing. The final sample size was 237.

Fatalism: There were 24 people who had imputations; there were 28 mean imputations (.98\%).

Fear: There were 51 people who had imputations; there were 275 mean imputations (4.00\%)

Adolescents. COHRA study had 219 participants, 6 had missing DMFT data; 22 had $>20 \%$ fear or fatalism data missing. The final sample size was 191.

Fatalism: There were 6 people who had imputations; there were 8 mean imputations (.31\%).

Fear: There were 18 people who had imputations; there were 58 mean imputations (.91\%).

Adults. COHRA study had 1319 participants, 67 had missing DMFT data; 127 had >20\%l fear or fatalism data missing. The final sample size was 1125 .

Fatalism: There were 42 people who had imputations; there were 45 mean imputations (.33\%)

Fear: There were 95 people who had imputations; there were 260 mean imputations (.80\%).

Imputations

Pre-teens Adolescents Adults

Fatalism questions

$\begin{array}{llll}1 & 2 & 0 & 1 \\ 2 & 2 & 0 & 2 \\ 3 & 5 & 0 & 2 \\ 4 & 0 & 0 & 5 \\ 5 & 4 & 2 & 5 \\ 6 & 1 & 1 & 6 \\ 7 & 1 & 0 & 3 \\ 8 & 1 & 0 & 8 \\ 9 & 1 & 1 & 2 \\ 10 & 5 & 0 & 8 \\ 11 & 3 & 3 & 2 \\ 12 & 3 & 1 & 1\end{array}$


Imputations

\section{Pre-teens Adolescents Adults}

\section{Fear questions}

$\begin{array}{rrrr}1 & 11 & 2 & 5 \\ 2 & 16 & 3 & 8 \\ 3 & 12 & 2 & 8 \\ 4 & 14 & 3 & 13 \\ 5 & 26 & 3 & 15 \\ 6 & 17 & 2 & 8 \\ 7 & 18 & 2 & 11 \\ 8 & 2 & 2 & 5 \\ 9 & 3 & 1 & 8 \\ 10 & 5 & 0 & 6 \\ 11 & 3 & 0 & 9 \\ 12 & 2 & 2 & 7 \\ 13 & 3 & 1 & 11 \\ 14 & 12 & 3 & 10 \\ 15 & 14 & 5 & 11 \\ 16 & 18 & 3 & 9 \\ 17 & 17 & 3 & 9 \\ 18 & 19 & 3 & 17 \\ 19 & 3 & 0 & 10 \\ 20 & 9 & 1 & 5 \\ 21 & 5 & 1 & 10 \\ 22 & 12 & 1 & 5 \\ 23 & 2 & 0 & 6 \\ 24 & 6 & 2 & 6 \\ 25 & 2 & 3 & 10 \\ 26 & 5 & 3 & 10 \\ 27 & 2 & 2 & 10 \\ 28 & 11 & 3 & 10 \\ 29 & 6 & 2 & 8\end{array}$




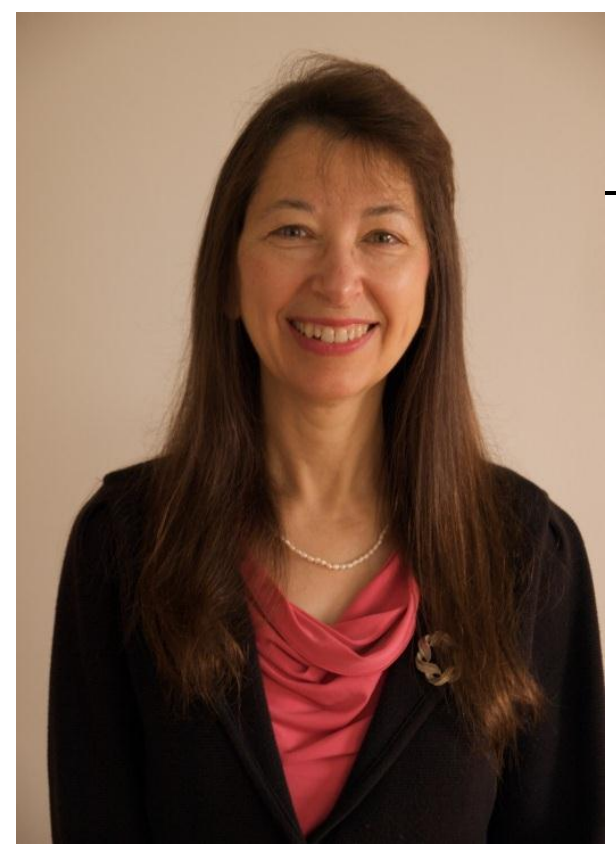

\section{R. CONSTANCE WIENER, MA, DMD, PhD}

304 Pisgah Road, Bruceton Mills, WV $26525 \quad 304-685-8209$

\section{EDUCATION}

PhD, Public Health Epidemiology 2010-2012 West Virginia University, Morgantown, WV

Advanced Certificate--1990-Robert Morris University, University Boulevard, Moon Township, PA 15108 (Cobol)

DMD-1982--University of Pittsburgh School of Dental Medicine

Block Drug Research Award-Sapphire/Ceramic crowns

MA Education, Psychology emphasis--1977-- Washington Jefferson College, Washington, PA

BA, Chemistry-1974--Washington Jefferson College, Washington, PA

(Phi Sigma Biology ; \& Chemistry Honorary)

DENTAL LICENSES WV, PA, NY (inactive), $\mathrm{OH}$ (inactive)

\section{EXPERIENCE}

Assistant Professor, Cariology research, Dental Practice and Rural

PO Box 9495, Morgantown, WV $26506-2012$ Health, WVU School of Dentistry, Robert C. Byrd Health Sciences,

Center for Oral Health Research in Appalachia, Department of Research, WVU, Morgantown, WV 26506-

Cariology Etiology Investigator (Pregnant mothers and their babies)

Health and Human Services/ Indian Health Service/Acting Chief Dental Officer, QNBMHF, PO Box 160 Belcourt, ND 58316 7/2009-7/2010-work with 6 other dentists, 2 hygienists, 4 EFDAs, and 2 DAs

Assistant Professor, Department of Dental Practice and Rural Health, WVU School of Dentistry, Robert C. Byrd Health Sciences Center, PO Box 9495, Morgantown, WV 26506 (2007-present)

2008-present (courtesy appointment -7/2009)

Academic Course Director--Community Dentistry 715; Introduction to Dental Auxiliary Utilization 725; Clinical Course Director--Clinical Dental Auxiliary Utilization 775; co-director--Removable Partial Dentures 726. I taught dental students

in pre-clinical courses-Dental Anatomy; Inlays/Onlays; Composite and Amalgam Restorations; and Removable Partial

Dentures. I taught dental students and dental hygiene students in clinical areas: Restorative; Hygiene; Diagnostic Services; Pediatric Dentistry; and DAU. I provided patient care in Pediatric Dentistry \& General Faculty Group

\section{Practices}

Wiener RC, Sambamoorthi U. Dental Fluorosis and Lumbar Spine Bone Mineral Density in Adults, ages 20-49 years: Results from the 2003-2004 National Health and Nutrition Examination Survey. Under second review. JDH.2012.

Wiener RC. The occurrence of phi in dento-facial beauty of fine art from antiquity through the Renaissance.

European Journal of Esthetic Dentistry. 2012 in press.

Wiener RC. Case Study: Tooth Jewelry and an Eight-Year-Old Child. Journal of Dental Hygiene. 2012 in press.

Wiener RC, Shankar A. Association between Serum Uric Acid Levels and Sleep Variables: Results from the

National

Health and Nutrition Survey 2005-2008. International Journal of Inflammation. 2012. doi:10.1155/2012/363054.

Wiener R, Wu B, Plassman B, Crout R, McNeil D, Wiener M, Kao E, Caplan D. Oral hygiene self-care of older adults in West Virginia: Effects of gender. Journal of Dental Hygiene. 2012;86:231-238.

Wiener RC, Wiener MA. Unmet Dental and Orthodontic Need of Children with Special Health Care Needs in West Virginia.

Rural and Remote Health. 2012;12 :2069. http://www.rrh.org.au.

Wiener RC, Crout RJ. Perceived Unmet Dental Needs--Children with Special Health Care Needs in States with Appalachian Counties. Commune Bonum. 2012;II;44-49.

Wiener RC, Zhang R, Shankar A. Elevated Serum C-Reactive Protein and Markers of Sleep Disordered Breathing. International Journal of Vascular Medicine. 2012;Article ID 914593. Doi 10.1155/2012/914593. 
Reviewer-Commune Bonum. January, 2012.

Wiener RC. Secondhand and Thirdhand Tobacco Smoke Exposure in Children Living in States Containing Appalachian

Counties: A Surveillance. JRTPH. 2011;10:111-118.

Wiener RC, Wiener Pla R. Evaluation of tobacco patient education material for tobacco prevention and cessation used in West Virginia University Dental Programs. JDH. 2011;Summer:204-210.

Wiener RC, Hendryx MS. Obesity and Diabetes Prevalence and Distribution in the U.S. by Rural-Urban Setting. Commune Bonum. 2011;1:23-29.

Wiener R,Wiener MA. Breastfeeding prevalence and distribution in the USA and Appalachia

by rural and urban setting. Rural and Remote Health. 2011:11;1713. Available from http://www.rrh.org.au.

Reviewer-Rural and Remote Health, May, 2011

Reviewer-JADA manuscript 261-10 (May, 2010)

Wu B, Goedereis E, Crout R, Plassman PL, DiNapoli E, McNeil DW, Wiener M A, Boone M, Wiener RC, Kao EC, Bai L.

Recruitment of Rural and Cognitively Impaired Older Adults for Dental Research. Special Care in Dentistry. 2010;30:193-199.

Wiener RC, Wiener MA. Xerostomia, SGH and clinical dry mouth: the internet and literacy. World Dental Online 2010:5/28 Available at www.worlddental-online.com/index.php?id=2724

Wiener RC, Wu Bei, Crout R, Wiener M, Plassman B, Kao E, McNeil D. Hyposalivation and xerostomia in dentate older adults. JADA. 2010;141:270-284.

Wiener RC, Crout RJ, Wiener MA. Toothpaste Use by Children Journal of Dental Hygiene. 2009:83 (Supplement)141-145.

Wiener RC, Crout RJ, Sandell J, Howard B, Ouassa L, Wearden S, Wiener M. Local Anesthetic Syringe Ergonomics and

Student Preferences. JDE. 2009;73:518-522.

2012 Mar 24-Abstract/presentation $41^{\text {st }}$ AADR, Tampa, Perceived Unmet Dental Needs

2011 Oct 30-Abstract/presentation APHA, DC, Fluoridation in Rural-Urban Settings in the United States

2011 Mar 16-Abstract/poster $40^{\text {th }}$ IADR, San Diego, Validity of Self-Reported tooth counts

2010 Mar 4-Abstract/poster 39 ${ }^{\text {th }}$ IADR, DC, Gender Differences in Oral Hygiene Practices--Older Adults

2010 Mar 4-Abstract/poster $39^{\text {th }}$ IADR, DC, Oral Hygiene and Self-Assessment of Oral Health

2010 Mar 4-Abstract/poster 39 ${ }^{\text {th }}$ IADR DC, Oral Health Disparities Among Older Adults

2009 April 1-Abstract/ poster 38th IADR meeting, Miami Abstract 117357 Xerostomia and SGH in WV Elderly (4th author)

2009 April 1-Abstract/ poster 38th IADR meeting, Miami Abstract 117426 Tooth Loss and Nutrition in Elderly (lead author)

2009 April 1--Abstract / poster 38th IADR meeting, Miami Recruitment of elders for dental research (5th author) 2009 April 1--Abstract /poster 38th IADR meeting, Miami 120565 Depression and Oral health in Older Adults (8th author)

2008 April-Abstract/poster $37^{\text {th }}$ IADR meeting, Dallas Comparison of OB/GYNs Oral Health Education Abstract PI Methamphetamine Information: Appalachian Physician Assistants' Needs Assessment, WVU research grant, 2007-present; PAEA for 11/1/2008 as Methamphetamine Information: Assessing Physician Assistants in KY and WV

Dental Officer, SRMHS 412 State Rt 37, Akwesasne, NY 13655 2004-2007

I provided patient care and patient education at a public health/Native American site.

Collaborated with various departments in the facility (medical, pharmacy, mental health, Partridge House Drug Rehabilitation) to develop Public Health Programs for the Mohawk population. Equipped facility with new Gendix digital panoramic-cephalometric unit; A-dec computer ready cabinetry; Instrument Management System; Dell computers in the operatories. I worked with USET_-United Southern and Eastern Tribes to increase the target GPRA (Government Performance Review Act) standards for the 2010 Healthy Person Project-we had $10 \%$ of all sealants in the Nashville Service Area. Member of cadre of reviewers for incoming malpractice cases ( $A d$ hoc)

Primary author-2007 Sportsguards and Children's Oral Health Grant from Nashville Region

Secondary author-2006 Early Childhood Caries Grant from the Indian Health Services Member of the cadre of nationwide reviewers for Indian Health Services' Health Promotion/

Disease Prevention Grant program (2005-2006) Wrote weekly Oral Health column for Indian Time Newspaper Radiology Officer at St. Regis Mohawk Health Services-Dental Infection Control Officer at SRMHS-Dental

Dental Practice of Wiener and Wiener-1982-2004 private practice

1994-2004 1425 Burgettstown Plaza, Burgettstown, PA 15021

Provided patient care and patient education and infection control programs; managed accounts.

1988-1994 R. D. 2 Avella, PA

1983-1988 412 W. Main Street, Ligonier, PA 
Science Department Chairperson and Chemistry teacher 1976-1977

Avella High School, Avella, PA 15312 Taught students chemistry/physical sciences; managed the department

\section{Life Sciences Instructor 1975-1976}

Washington Hospital School of Nursing, Washington, PA

Taught nursing students biochemistry, anatomy, physiology; developed innovative, self-paced interactive curriculum; organized labs; designed evaluation procedures.

Contributing Author to 4 series: Life Science Modules, Sam Mentzer, et al. Washington Hospital Press, 1976.

\section{ASSOCIATIONS}

Dental Anthropology Association-2010-present

North Dakota Dental Association-2009-present

American Dental Association-ADA 8/1982-present

West Virginia Dental Association-WVDA-5/2007-present

Monongahela Valley Dental Association-5/2007-present

American Dental Education Association-ADEA 5/2007-present

International Association for Dental Research--!ADR 5/2007-present

West Virginia Section--American Association for Dental Research-WV AADR 5/2007-present

St. Lucy's Guild to the Blind-6/1990-present

Friends of Decker Creek member-3/2008-present

Soil Conservation District member

New York State Dental Association--NYDA (6/2004-2007)

American Public Health Association-2011

American Mensa, Vandalia Mensa

Et cognoscetis veritatem et veritas liberabit vos John 8:32 